\title{
Aportacións sobre a tipoloxía e composición florística dos bosques mesófilos de quercíneas do occidente da Cornixa Cantábrica (NW Ibérico)
}

Recibido: 6 maio 2010 / Aceptado: 31 agosto 2010

(C) IBADER- Universidade de Santiago de Compostela 2010

\begin{abstract}
Resumo Realízase unha revisión da tipoloxía fitosociolóxica das formacións arboradas dominadas por especies do xénero Quercus existentes no extremo setentrional de Galicia e o NW de Asturias a partir da revisión da información existente e da aportada nunha mostraxe de 183 novas localidades. Aínda que se mantén a inclusión dos bosques maioritarios deste territorio na asociación Blechno spicant-Quercetum roboris, reinterprétase o número e xerarquía das unidades de rango inferior (subasociacións, variantes, facies, fases) neles identificadas. Ademáis, dase a coñecer a existencia de carballais termófilos galaico-portugueses (as. Rusco aculeati-Quercetum roboris) en diversas localidades da área de estudo situadas entre a desembocadura do Río Eume (A Coruña) e O Valadouro (Lugo), así como a de reboleiras con carballo (as. Lonicero periclymeni-Quercetum pyrenaicae) nas cunca media e alta do río Eo, diversos tributarios pola esquerda do Río Navia e no tramo medio do Río Narcea. Por último, considérase necesario aportar máis datos para clarificar a entidade sintaxonómica dos carballais existentes ao longo das cuncas altas dos ríos Miño, Mandeo e Tambre. A reinterpretación proposta eleva de un a tres (catro?) a variedade de asociacións de bosques de quercíneas mesófilas existentes na área de estudio, o que supón un considerable incremento da diversidade fitocenótica arbórea recoñecida nesta unidade bioxeográfica.
\end{abstract}

Palabras chave carballais · reboleiras · fitosocioloxía reinterpretación · Galicia · Asturias · NW España

\section{Manuel Antonio Rodríguez Guitián}

Departamento de Produción Vexetal. Escola Politécnica Superior de Lugo. USC. Campus Universitario s/n, 27002-Lugo.

E-mail: manuelantonio.rodriguez@usc.es.

\begin{abstract}
A reasessment of the typology of mesophilous oak-forests in the western part of the Cantabrian Cornise is made taking into account published data and 183 new floristic relevès. A new hyerarquical model with only two subassociations and many variants, facies an phases is proposed for the most widespread oak-forests in the study area belonging to the association Blechno spicantQuercetum roboris. In addition, galaico-portuguese thermophillous oak-forests of the association Rusco aculeati-Quercetum roboris were identified in the strech from Eume stuary (A Coruña province) to $O$ Valadouro valley (Lugo province), mainly on sunny slopes, and pyrenean oakdominated forests of the association Lonicero periclymeniQuercetum pyrenaicae were recognised along middle and high watersheds of the rivers Eo, Navia and Narcea. The phytosociological status of the oak forests present in the headwaters of Miño, Mandeo and Tambre rivers still remains uncertain since they lack at all of the characteristic hygrophylous and thermophilous plants of above mentioned associations. These results raise from one to three (four?) the number of mesophillous oak-forests associations recognised in the study area which constitutes a remarkable increasing of its arboreal vegetation diversity.
\end{abstract}

Key words pedunculate-oak woodlands - pyrenean-oak woodlands · phytosociology · reassessment · Galicia . Asturias · NW Spain

\section{Introducción e obxectivos}

Os bosques dominados por especies caducifolias e marcescentes do xénero Quercus L. teñen unha ampla distribución ao longo dos territorios temperados noribéricos e son un elemento fundamental da paisaxe nas áreas con unha influencia antrópica menos severa. A pesar de elo, o coñecemento detallado da variabilidade florística e do ambiente ecolóxico no que crecen estes bosques dista moito de ser homoxéneo dentro da área xeográfica comentada. Así, mentras se dispón de abundante información para a parte centro-oriental da Cornixa Cantábrica (cf. Braun-Blanquet 1967, Navarro 1974, Álvarez 
Rodríguez 1976, Loidi Arregui 1983, Lastra Menéndez 1989, Herrera Gallástegui 1995, Loidi Arregui et al. 1997), ésta limítase a pouco máis de 80 inventarios florísticos publicados en pouco máis de media ducia de traballos na parte occidental. Ademáis, a información florística aportada é difícil de valorar, xa que foi obtida seguindo metodoloxías diversas e facendo uso de superficies de inventario altamente heteroxéneas, que oscilan entre os 60 e os 500 $\mathrm{m}^{2}$ (cf. Tüxen \& Oberdorfer 1958, Braun-Blanquet 1967, Bellot 1968, Losa Quintana 1973, Díaz González 1975, Castroviejo Bolivar 1988, Izco et al. 1990, Mayor \& Fernández 2007).

Da análise das referencias máis recentes sobre esta temática desprendese unha gran uniformidade nos carballais acidófilos presentes no extremo occidental cantábrico, pois segundo Izco et al. (1990) todos eles se incluirían na asociación Blechno spicant-Quercetum roboris, dentro da que se contemplan catro subasociacións (táboa 1). Non obstante, Losa Quintana (1973) interpretou, a partir das súas observacións na cunca baixa do Río Eume, que cara ao seu límite occidental, estes bosques tenden a posicionarse nas ladeiras avesías mentras que nos tesos e vertentes soalleiras se verían reemplazados por carballais de carácter máis heliófilo, pertencentes á asociación termomesotemperada galaico-portuguesa Rusco aculeatiQuercetum roboris, de caracter máis helio-xérófilo. Sen embargo, Izco et al. (1990) non aportan conclusións clarificadoras a este respecto.

Máis aló dos límites establecidos para a área bioxeográfica comentada, os bosques de quercíneas mesófilas existentes pertenecerían a outras comunidades arboradas. Nos territorios costeiros e interiores a baixa altitude situados ao $\mathrm{S}$ da desembocadura do Río Eume e ate o pedemonte da Dorsal Galega, os bosques de Quercus presentarían un carácter netamente termófilo e se incluirían na asociación Rusco aculeati-Quercetum roboris (Izco 1987, RivasMartínez 1987), dentro da que se teñen diferenciado dúas subasociacións: violetosum rivinianae (típica) e quercetosum suberis (Amigo et al. 1998). Pola súa parte, ao longo da cabeceira do Río Miño, os carballais da BlechnoQuercetum roboris contactarían cos galaico-portugueses supratemperados da Myrtillo-Quercetum roboris (Izco 1987, Rivas-Martínez 1987), mentras que na cunca media e baixa do Río Navia o farían coas reboleiras con carballo da asociación Lonicero periclymeni-Quercetum pyrenaicae (Rivas-Martínez et al. 2002). Estes últimos bosques serían sustituídos nas áreas montañosas das cuncas asturianas dos ríos Aviouga, Íbias e Narcea polos carballais albares e reboleiras das asociacións Luzulo henriquesii-Quercetum petraeae, Linario trornithophorae-Quercetum petraeae e Linario triornithophorae-Quercetum pyrenaicae (cf. RivasMartínez 1987, Rivas-Martínez et al. 2002)(táboa 1). Por último, na mitade centro-occidental da área de estudio, os faiais acidófilos da asociación Saxifrago spathularidisFagetum sylvaticae a miudo establecen contacto inferior na secuencia catenal altitudinal cos carballais aquí estudiados podendo, en condicións favorables para a faia, formar rodais inmersos dentro deles (Rodríguez Guitián et al.
2003). Os conxuntos de especies características e diferenciais propostos para discriminar todos estes tipos de bosques detállanse na táboa 1.

Aínda que nun traballo anterior (Rodríguez Guitián 2005) xa se realizou unha descrición somera das principais características dos bosques existentes no Subsector Cantábrico occidental, a evidencia de que a variedade de formacións arboradas dominadas por especies mesófilas do xénero Quercus dentro deste territorio bioxeográfico é maior do que ate o momento se viña admitindo levounos a plantexar unha revisión da súa tipoloxía co obxectivo de afondar no coñecemento da variabilidade territorial que este conxunto de bosques presenta no ámbito xeográfico comentado.

\section{Área de estudio}

Á área de traballo comprende básicamente os territorios cántabro-atlánticos que se extenden entre as desembocaduras dos ríos Nalón (Asturias) e Eume (A Coruña) que, desde o punto de vista bioxeográfico se inclúen íntegramente dentro do Subsector Cantábrico occidental na denominación de unidades bioxeográficas proposta por Rodríguez Guitián \& Ramil-Rego (2008) coincidente, a grandes rasgos, co Subsector GalaicoAsturiano definido por Rivas-Martínez (1987) e os distritos Galaico Septentrional, Asturiano Septentrional e Lucense na terminoloxía de Vázquez \& Díaz González (2005)(figura 1).

As principais características climáticas deste territorio (elevada nubosidade e baixa estacionalidade da precipitación, cun aporte estival relativamente elevado e baixos índices de continentalidade) debense á súa proximidade ás aguas mariñas cantábricas e atlánticas e ao efecto barreira que realizan as abondosas cadeas montañosas distribuidas ao largo da área sinalada, aínda que estas tendencias atenúanse lixeiramente, polo seu maior alonxamento do litoral, cara á parte alta da cunca do Río Eo (Lugo-Asturias) e os tramos medios dos ríos Navia e Narcea (Felicísimo Pérez 1990, IGN 1991). A aplicación da clasificación bioclimática de Rivas-Martínez (2007) á área de estudio amosa que se trata de territorios con ausencia de seca estival (macrobioclima temperado típico) e cun bioclima maioritario de tipo hiperoceánico (Rodríguez Guitián \& Ramil-Rego 2007). Os termotipos representados son o termotemperado (0-150 m), mesotemperado inferior (150-450 m), mesotemperado superior $(450-700 \mathrm{~m})$ e o supratemperado inferior $(>700 \mathrm{~m})$, mentres que os ombrotipos identificados oscilan entre os tipos subhúmedo superior e o ultrahiperhúmedo. Os tipos litolóxicos dominantes son de carácter silíceo (rochas metamórficas ácidas, granitos, sedimentos detríticos cenozoicos) entre os que, puntualmente, afloran delgados estratos de rochas calías (IGME 1982, 1984; ITGE 1991). O marcado predominio de sustratos pobres en nutrientes condiciona o carácter fortemente ácido dos solos, que soamente se ve rebaixado nos escasos enclaves con afloramentos de rochas carbonatadas (calías, dolomías) e ultrabásicas (serpentinitas) ou en posicións favorables para a acumulación das bases e restos vexetais (partes baixas de 


\begin{tabular}{|c|c|}
\hline Sintaxóns (abreviatura) & Taxóns característicos e diferenciais $\left(^{*}\right)$ \\
\hline \multicolumn{2}{|l|}{ Blechno spicant-Quercetum roboris } \\
\hline subas. dryopteridetosum aemulae $(\boldsymbol{B}-\mathbf{Q} \boldsymbol{d})$ & $\begin{array}{l}\text { Quercus robur, Castanea sativa, Athyrium filix-femina, Betula } \\
\text { pubescens, Dryopteris aemula, D. dilatata, Osmunda regalis, } \\
\text { Polygonatum verticillatum, Sorbus aucuparia }\end{array}$ \\
\hline subas. lauretosum nobilis (B-QI) & $\begin{array}{l}\text { Quercus robur, Castanea sativa, Athyrium filix-femina, Betula } \\
\text { pubescens, Dryopteris aemula, D. dilatata, Osmunda regalis, } \\
\text { Polygonatum verticillatum, Arbutus unedo*, Laurus nobilis*, Rubia } \\
\text { peregrina*, Ruscus aculeatus }{ }^{*}, \text { Smilax aspera* }\end{array}$ \\
\hline subas. pulmonarietosum longifoliae (B-Qp) & $\begin{array}{l}\text { Quercus robur, Castanea sativa, Sorbus aucuparia, Athyrium filix- } \\
\text { femina, Betula pubescens, Dryopteris aemula, D. dilatata, Osmunda } \\
\text { regalis, Polygonatum verticillatum, Fraxinus excelsior*, Mercurialis } \\
\text { perennis }{ }^{*} \text {, Milium effussum, Primula acaulis }{ }^{*} \text {, Pulmonaria longifolia*, } \\
\text { Sanicula europaea*, Ulmus glabra* }\end{array}$ \\
\hline subas. fagetosum sylvaticae (B-Qf) & $\begin{array}{l}\text { Quercus robur, Castanea sativa, Athyrium filix-femina, Betula } \\
\text { pubescens, Dryopteris aemula, D. dilatata, Osmunda regalis, } \\
\text { Polygonatum verticillatum, Sorbus aucuparia, Fagus sylvatica* }\end{array}$ \\
\hline subas. hieracietosum umbellatae & $\begin{array}{l}\text { Quercus robur, Castanea sativa, Athyrium filix-femina, Betula } \\
\text { pubescens, Dryopteris aemula, D. dilatata, Osmunda regalis, } \\
\text { Polygonatum verticillatum, Sorbus aucuparia, Viola riviniana, } \\
\text { Potentilla erecta, Hieracium umbellatum }\end{array}$ \\
\hline
\end{tabular}

Rusco aculeati-Quercetum roboris

subas. violetosum rivinianae $(\boldsymbol{R}-\mathbf{Q v})$

Quercus robur, Quercus pyrenaica, Castanea sativa, Laurus nobilis, Ilex aquifolium, Ruscus aculeatus, Hedera hibernica, Lonicera periclymenum, Teucrium scorodonia, Holcus mollis, Physospermum cornubiense, Viola rivinana, Asplenium onopteris

Quercus robur, Quercus pyrenaica, Castanea sativa, Laurus nobilis, Ilex aquifolium, Ruscus aculeatus, Hedera hibernica, Lonicera periclymenum, Teucrium scorodonia, Holcus mollis, Physospermum

subas. quercetosum suberis $(\boldsymbol{R}-\mathbf{Q q})$ cornubiense, Viola rivinana, Asplenium onopteris, Arbutus unedo*, Quercus suber*, Rubia peregrina*, Osyris alba*, Daphne gnidium*, Carex distachya*

Quercus robur, Vaccinium myrtillus, Galium rotundifolium ${ }^{*}$, Hieracium

Myrtillo-Quercetum roboris $(M-Q)$ bourgae ${ }^{*}$, Laserpitium thalictrifolium*, Picris longifolia*, Rubus lusitanicus*, Eryngium juressianum*,

\begin{tabular}{c}
\hline $\begin{array}{c}\text { Luzulo henriquesii-Quercetum petraeae }(\mathbf{L h}-\mathbf{Q}) \\
\text { subas. quercetosum petraeae }(\mathbf{L} \boldsymbol{h}-\mathbf{Q q})\end{array}$ \\
subas. fagetosum sylvaticae (Lh-Qf)
\end{tabular}

Lonicero periclymeni-Quercetum pyrenaicae $(L-Q)$ Saxifrago spathularidis-Fagetum sylvaticae

subas. fagetosum sylvaticae (S-Ff)

subas. sorbetosum aucupariae (S-Fs)
Quercus petraea, Quercus x rosacea, Avenella flexuosa, Luzula henriquesii, Saxifraga spathularis, Vaccinium myrtillus

Quercus petraea, Quercus x rosacea, Avenella flexuosa, Luzula henriquesii, Saxifraga spathularis, Vaccinium myrtillus, Fagus sylvatica*

Quercus pyrenaica, Quercus robur, Arbutus unedo*, Cytisus striatus*, Daboecia cantabrica*, Luzula lactea*, Ulex gallii*

Fagus sylvatica, Quercus robur, Castanea sativa, Blechnum spicant, Saxifraga spathularis, Polystichum setiferum, Avenella flexuosa, Ruscus aculeatus, Laurus nobilis, Tamus communis

Fagus sylvatica, Quercus robur, Blechnum spicant, Saxifraga spathularis, Avenella flexuosa, Sorbus aucuparia*

Táboa 1.- Taxóns discriminantes (característicos e diferenciais *) propostos por distintos autores para diversos tipos de bosques presentes no extremo NW ibérico (adaptado de Pinto da Silva et al. 1950; Tüxen \& Oberdorfer 1958; Izco et al. 1990, Díaz González \& Fernández Prieto 1994a; Amigo et al. 1998, Pulgar 1999, Rodríguez Guitián et al. 2003 e Rodríguez Guitián 2006). Na discusión dos resultados utilízanse os acrónimos de comunidades que figuran entre paréntesis

ladeira, valgadas, recháns) procedentes das partes elevadas das vertentes no resto dos casos (Álvarez \& DíazFierros 1995, Macías Vázquez \& Calvo de Anta 1992, 2001).

\section{Metodoloxía}

Tomando como referencia a información dispoñible, realizouse unha selección de inventarios publicados de bosques obxecto deste estudo considerando exclusivamente aqueles nos que a suma da cobertura acadada polas especies do xénero Quercus presentes fose igual ou superior ao $50 \%$ da superficie inventariada, descartando, ademáis, aqueles outros que se tiveran recollido en áreas de inventariación de reducida superficie $\left(<100 \mathrm{~m}^{2}\right)$ ou presentaran un número de especies excesivamente baixo $(<10)$. Tamén foron descartadas as mostras de bosques nos que os Quercus e Fagus sylvatica, sendo as especies arbóreas dominantes, acadan valores de cobertura semellantes. A distribución xeográfica das localidades seleccionadas serviu de base para a realización de novas tomas de datos nas áreas carentes de información seguindo a metodoloxía fitosociolóxica sigmatista (Braun- 
Blanquet 1979). A procedencia e localización precisa dos inventarios utilizados amósase no Anexo I que figura ao final deste traballo.

Como criterio xeral, na nomenclatura botánica seguíronse as propostas de Flora ibérica (Castroviejo 1986-2007) para os grupos publicados nesta obra e os de Flora Europea (Tutin et al. 1964-1980) no resto. Non obstante, debido aos avances experimentados na taxonomía vexetal ao longo das últimas décadas e a disparidade de criterios empregados polos autores das diversas referencias bibliográficas empregadas, realizáronse diversas adaptacións nomenclaturais que atinxiron aos xéneros Hedera (en todos os casos as citas de $H$. helix foron consideradas como $H$. hibernica seguindo a Sahuquillo et al. 2001), Polypodium (todas as presenzas foron asimiladas con Polypodium vulgare), Asphodelus e Rubus (nestes últimos casos a determinación realizóuse a nivel de xénero, Asphodelus sp. e Rubus sp., respectivamente).

Coa información florística recopilada elaborouse unha base de datos á que se lle engadíu información relativa á situación xeográfica das localidades inventariadas (coordenadas UTM), aspectos topográficos (altitude, pendente, orientación, posición topográfica), atributos estruturais (altura dominante e cobertura por estratos), litoloxía e caracterización bioclimática. Este último conxunto de datos calculóuse para cada unha das localidades inventariadas utilizando os gradientes establecidos por Rodríguez Guitián (2004) mediante regresión lineal entre a altitude e os valores dos índices lc (índice de continentalidade), Itc (índice de termicidade compensado) e lo (índices ombrotérmicos) propostos por Rivas-Martínez (2007) determinados a partir dos datos proporcionados por unha rede de 113 estacións meteorolóxicas distribuídas ao longo da área de estudio e territorios limítrofes.

No plano fitosociolóxico, as discusións realízanse tendo en conta as referencias bibliográficas previas sobre estes e outros tipos de bosques cos que poden gardar algunha relación, xa sexa de tipo catenal a unha escala local ou ben dentro do contexto bioxeográfico no que se enmarcan. Para axilizar a lectura e comprensión do apartado de resultados e discusión, faise alusión ás comunidades vexetais mencionadas por medio dos acrónimos que se presentan na táboa 1.

\section{Resultados e discusión}

Antes de abordar a discusión sobre a interpretación fitosociolóxica dos bosques estudiados parécenos importante facer algunhas consideracións acerca da presenza neles de varios taxóns arbóreos que teñen sido utilizados por diversos autores para diferenciar determinadas comunidades fundamentados na súa

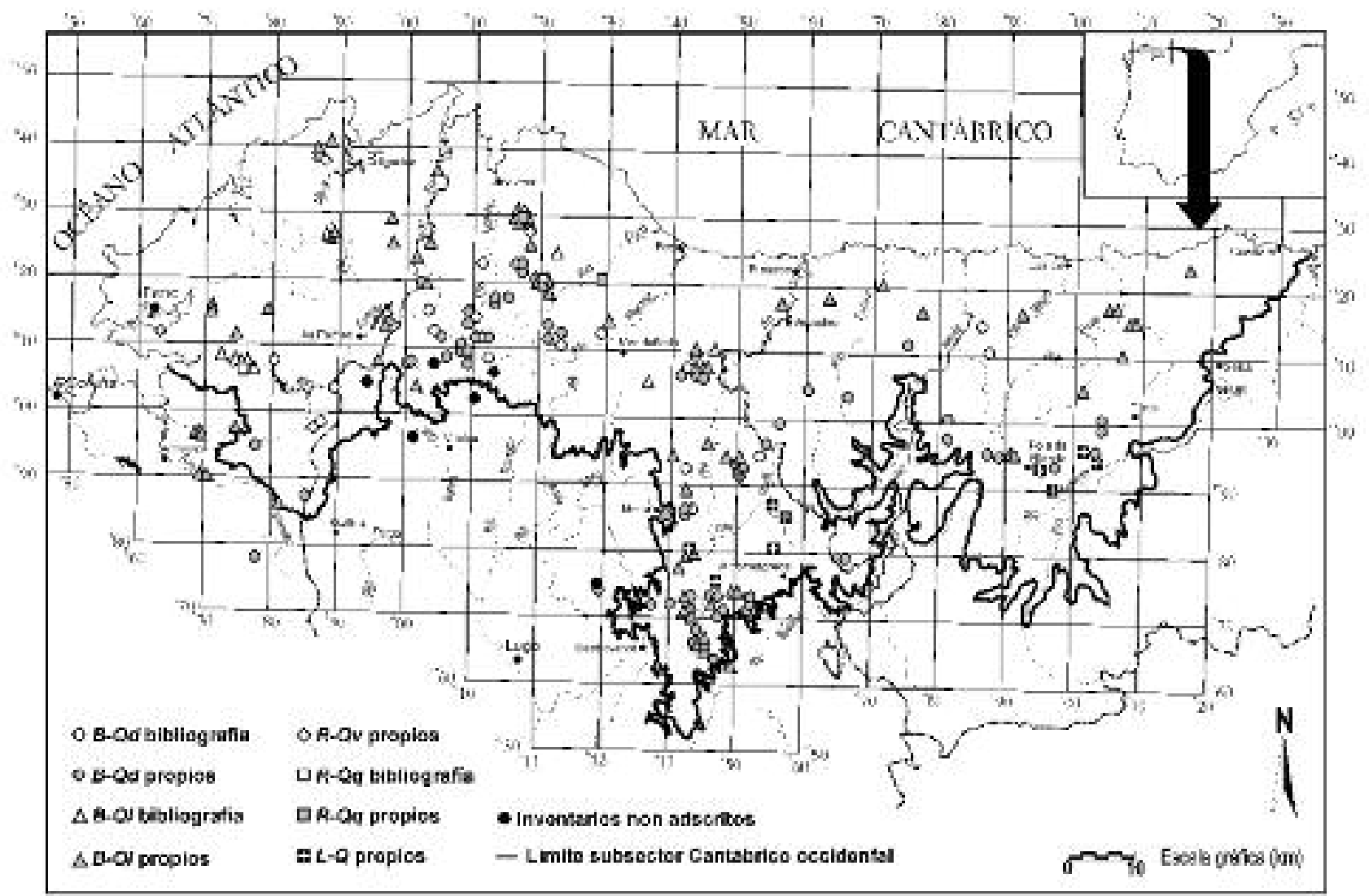

Figura 1.- Delimitación da área de estudo (Subsector Cantábrico occidental) e localización dos inventarios de bosques analizados. Para a interpretación dos acrónimos, ver a táboa 1 
distribución corolóxica. É o caso dos carballais cántabroatlánticos que se diferenciarían dos orocantábricos pola presenza exclusiva nos primeiros de Quercus robur, mentras que Quercus petraea e o seu híbrido co anterior (Quercus x rosacea) serían privativos dos segundos (RivasMartínez et al. 1984a, Díaz González \& Fernandez Prieto 1994a, 1994b; Fernández Prieto \& Díaz González 1998). Sen embargo, este criterio é claramente discordante co coñecemento desde antigo de poboacións de Quercus petraea dentro do territorio aquí tratado (Losa Quintana 1973, Rigueiro Rodríguez \& Silva-Pando 1984, Amaral Franco 1990, Vila \& Díaz-Maroto 2002). A distribución confirmada por nós de Quercus petraea e $Q$. x rosacea (figura 2) é bastante máis extensa da admitida ate o momento e abrangue unha área que se estende de xeito prácticamente ininterrompido polos macizos montañosos que van desde a Serra da Capelada (A Coruña) ata os límites orientais do Subsector Cantábrico occidental coas unidades Ovetense e Laciano-Narceense (Asturias), existindo citas desta especie en localidades máis meridionais situadas na cunca baixa do Río Eume (Losa Quintana 1973, Rigueiro Rodríguez 1991).

A coexistencia de $Q$. robur, Q. petraea e Quercus x rosacea na área cantábrica occidental (figuras 2 e 3 ) é concordante co observado no resto da Cornixa Cantábrica (subsectores Santanderino-Vizcaíno e Euskaldún Oriental), donde os tres taxóns poden formar parte de bosques da asociación
Hyperico pulchri-Quercetum roboris, na que se inclúen carballais hiperoceánicos de carácter acidófilo e distribución termo e mesotemperada (cf. Rivas-Martínez et al. 1984a; Rivas-Martínez et al. 1991, Loidi Arregui et al. 1997). Á vista desta información e da aportada na figura 4, na que se amosa o reparto altitudinal de diversas especies arbóreas presentes nas carballeiras estudiadas, a suposta fidelidade de Quercus petraea e $Q$. x rosacea polos territorios montañosos da Cordillera Cantábrica no seu extremo occidental de distribución, parécenos máis que dubidosa, ademáis de incoherente co que acontece nos territorios cantábricos orientais. Por outro lado, aínda que nalgúns dos carballais estudiados poda darse un claro dominio de Quercus petraea ou $Q$. x rosacea, estas situacións non deben de confundirse cos carballais albares orocantábricos (táboa 2, columnas 4 e 5), pois nestes están ausentes, entre outras, especies como Q. robur, Castanea sativa, Dryopteris aemula, Athyrium filix-femina, Ruscus aculeatus, etc.

Ademáis da presenza dos taxóns do xénero Quercus comentados, nalgúns dos bosques inventariados está presente o rebolo, Q. pyrenaica (figura 2). A cobertura acadada por esta especie varía desde menos do $1 \%$ ata o claro dominio no estrato superior ( $>50 \%$ de cobertura). Como no caso dos Quercus anteriormente comentados, diversasreferencias constatan a presenza no oriente cantábrico de $Q$. pyrenaica dentro das carballeiras da asociación Hyperico pulchri-Quercetum roboris,

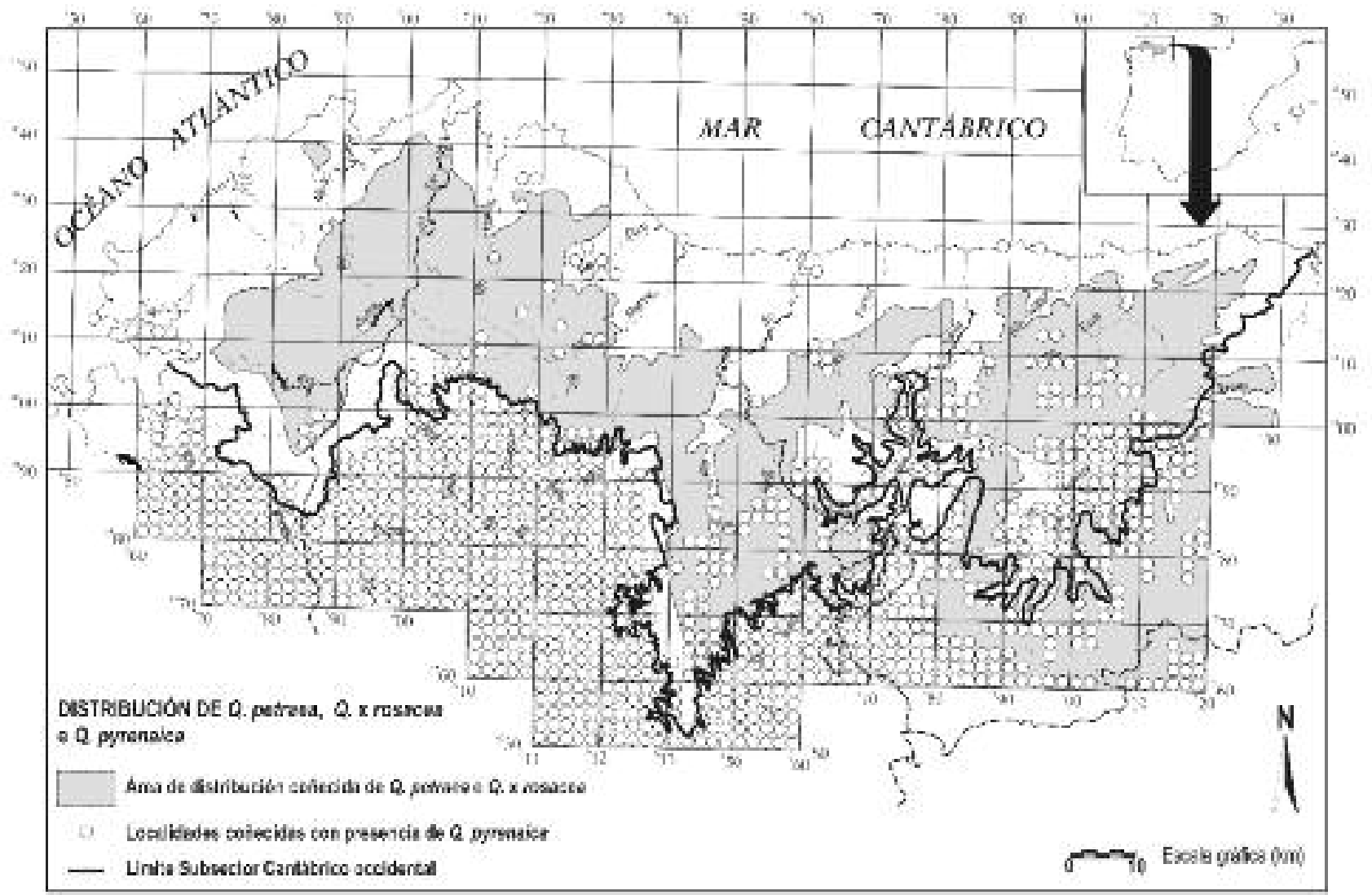

Figura 2.- Distribución coñecida de Q. petraea, Q. x rosacea e Q. pyrenaica na área de estudio (datos propios) 
principalmente alí donde este tipo de bosques entra en contacto coas reboleiras meridionais da asociación Melampyro pratensis-Quercetum pyrenaicae (táboa 2, columnas $3 b$ e $3 d$ ). Tanto neses territorios como nos veciños ovetenses, a aparición do rebolo dentro da área teórica de óptimo para $Q$. robur interprétase como indicadora dunha menor oceaneidade ou unha maior insolación ou xericidade con respecto ós territorios circundantes (Guinea 1949, 1953; Dupont 1974, Díaz González \& Fernández Prieto 1994a, 1994b; Fernández Prieto \& Díaz González 1998; Loidi Arregui et al. 1997).

Por último, queremos sinalar algunhas cuestións acerca da aparición de Fagus sylvatica nalgúns dos bosques estudiados. Esta árbore ten na actualidade unha distribución relativamente contínua desde a raia cos subsectores Ovetense e Altonarceense-Ancarés ata o val do Río Navia, facéndose escasa entre a cunca deste río e a do Eo (cf. Rodríguez Guitián et al. 2001), estando totalmente ausente na metade oeste da área de estudio (figura 5). Sen embargo, fontes documentais (García de Longoria 1798, Guitián Rivera 1995, 1996) e traballos paleobotánicos baseados en análises polínicas (cf. Taboada-Castro et al. 1996, Ramil-Rego \& Aira 1992, 1998; Ramil-Rego et al. 2000) establecen a súa existencia ata épocas recentes en áreas máis occidentais e cercanas ao mar. Esto permite afirmar que esta árbore debeu formar parte, ata períodos históricos ou protohistóricos ( $<2.500$ anos), de distintos tipos de bosques en amplas áreas do interior galego e, máis puntualmente, do norte de Portugal, así como nos diversos tipos de bosques presentes no territorio aquí tratado. Como pode observarse na figura 4, esta especie está presente en case todos os intervalos altitudinais considerados, desde prácticamente o nivel do mar até máis de $800 \mathrm{~m}$, cubrindo unha ampla gama de ombroclimas.

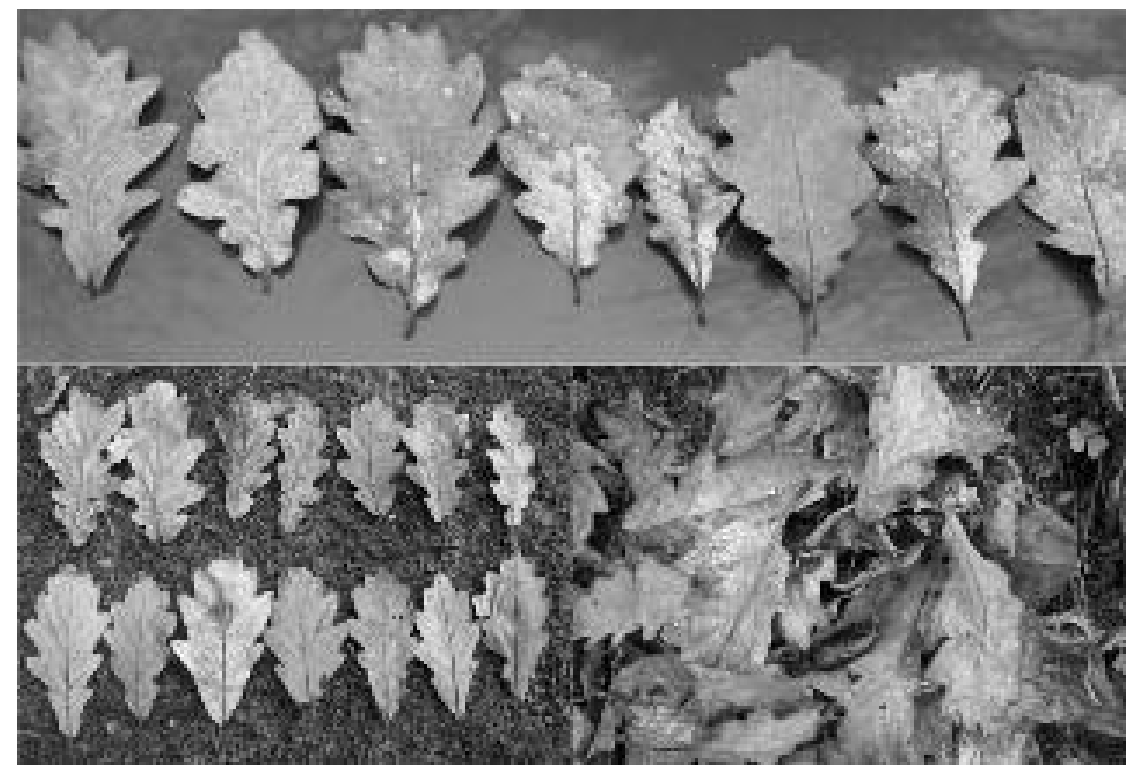

Distribución altitudinal de cliversos taxóns arbóreos

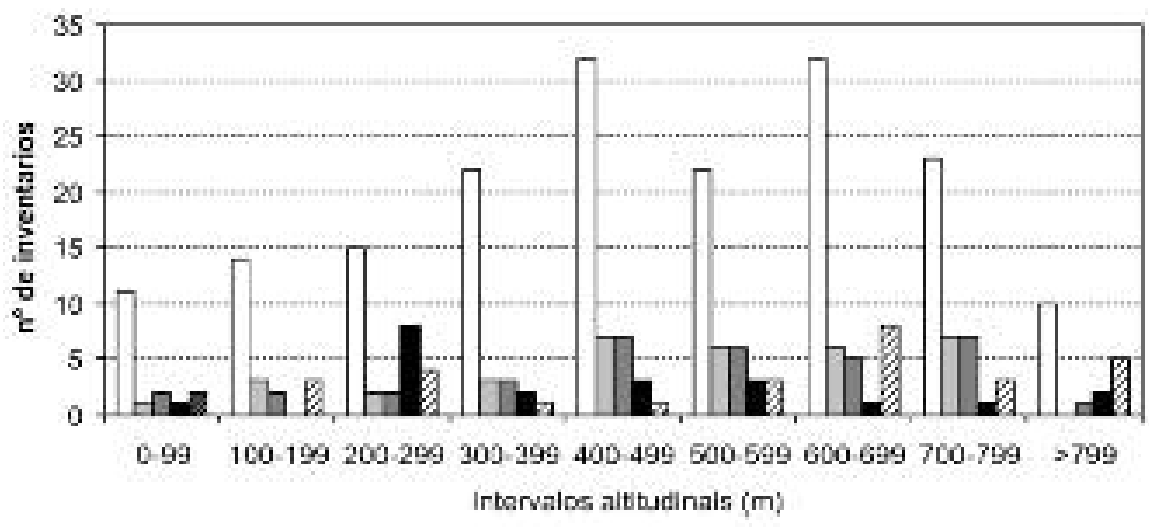

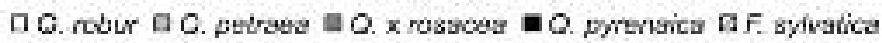

Figura 3.- Variabilidade morfolóxica foliar dos Quercus caducifolios presentes nalgúns dos bosques estudiados. Arriba, mostras recollidas no "Carballal de San Xulián" (Grandas de Salime, Asturias); no estremo esquerdo, fenotipos correspondentes a Quercus robur, no estremo dereito, Quercus petraea; no medio, formas transicionais frecuentes nos individuos hibridóxenos entre as dúas anteriores. Abaixo esquerda: mostras procedentes da Fraga de Reigadas (A Pontenova-A Fonsagrada, Lugo); neste caso a variación vai desde a esquina superior esquerda (fenotipos de Quercus robur) á inferior dereita (fenotipos de $Q$. petraea). Abaixo dereita: follas mesturadas de Quercus petraea e Q. x rosacea fotografiadas na Fraga dos Casás (Cerdido, A Coruña)

Figura 4.- Distribución altitudinal de Fagus sylvatica e diversos taxóns do xénero Quercus presentes nos bosques estudados 
Columna Núm. inv.

Altitud (Dm)

Alt. máx. (Dm)

Alt. min. (Dm)

$\mathrm{N}^{\circ}$ de taxóns

Altura $E_{1}(m)$

Cob. $E_{1}(>1,5 \mathrm{~m})(\%)$

Cob. $E_{2}(<1,5 \mathrm{~m})(\%)$

Taxóns característicos

Teucrium scorodonia

Lonicera periclymenum

Ilex aquifolium

Stellaria holostea

Holcus mollis

Polypodium vulgare

Betula pubescens

Euphorbia amygdaloides

Viola riviniana

Corylus avellana

Melampyrum pratense

Quercus robur

Quercus pyrenaica

Hypericum pulchrum

Taxus baccata

Ranunculus tuberosus

Ajuga reptans

Castanea sativa

Lathyrus linifolius

Pulmonaria longifolia

Blechnum spicant

Euphorbia dulcis

Avenella flexuosa

Vaccinium myrtillus

Acer pseudoplatanus

Sorbus aucuparia

Anemone nemorosa

Luzula henriquesii

Oxalis acetosella

Dryopteris dilatata

Quercus petraea

Quercus x rosacea

Fagus sylvatica

Polystichum setiferum

Solidago virgaurea

Arenaria montana

Hedera helix

Fraxinus excelsior

Hypericum androsaemum

Helleborus occidentalis

Crepis lampsanoides

Dryopteris filix-mas

Saxifraga spathularis

Physospermum cornubiense

Hedera hibernica

Hyacinthoides non-scripta

Dryopteris affinis

Primula acaulis

Aquilegia vulgaris

Polygonatum odoratum

Melittis melissophyllum

Polygonatum verticillatum

Mercurialis perennis

Euphorbia hyberna

Athyrium filix-femina

Lastrea limbosperma

Dryopteris aemula

Osmunda regalis

Erica mackaiana

Viola reichenbachiana

Sanicula europaea

Scrophularia alpestris

Ulmus glabra

Ceratocapnos claviculata

Prunus avium

Tamus communis

Asplenium onopteris

Táboa 2.- Táboa florística sintética de diversos tipos de bosques cántabro-euskaldúns, galaico-asturianos e galaico-portugueses (exclúense as compañeiras presentes en menos de 8 columnas)

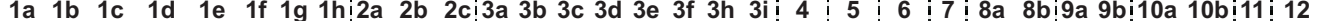
97 --

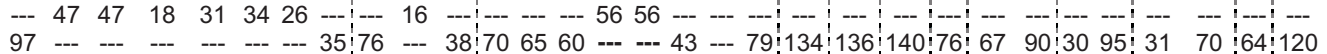

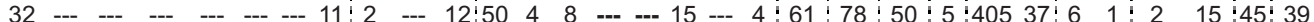

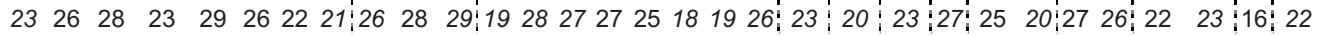

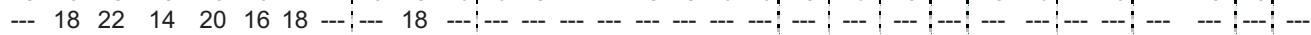

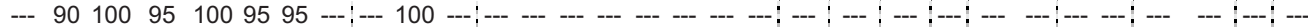

--- 7595100909595 ---

\section{iacións e unidades superiores}

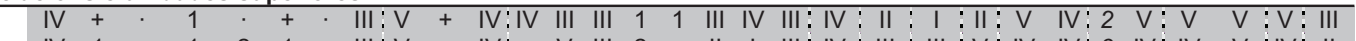

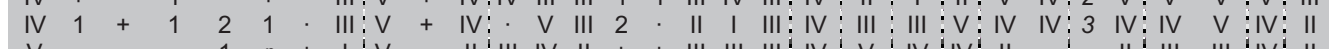

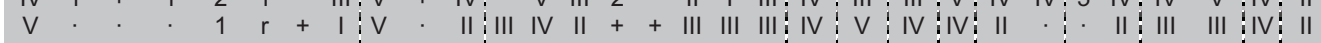

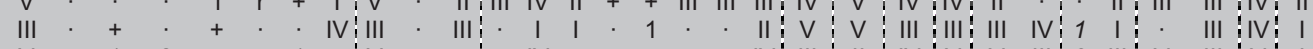

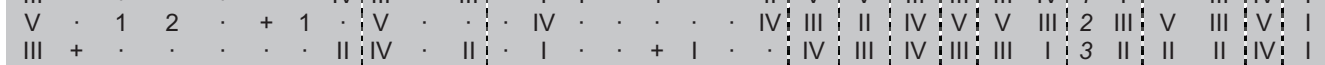

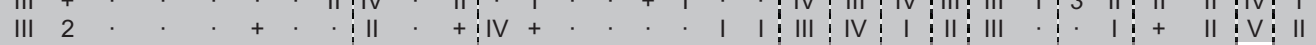
III I . III II II III . + IV I II I

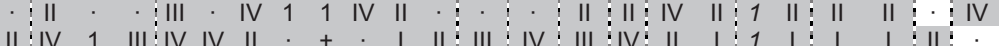
II I $1+$ I IV II 21 . I III IV II . I + II 1 I . II . I

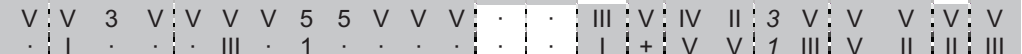
I I I III . III IV + 1 IV III III + . I I I II I I 2 II I. I I I I

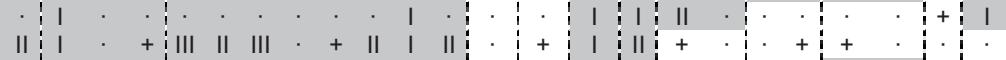

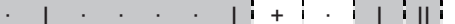

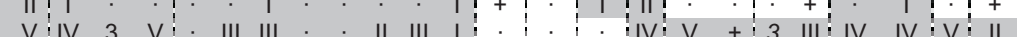

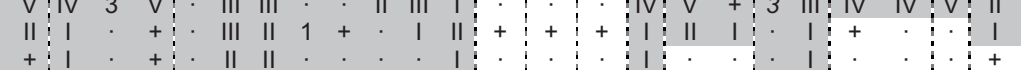

+ V IV 1 III V V IV . + III III III II III V V . + . I . II . II

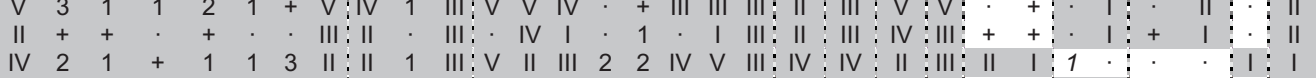

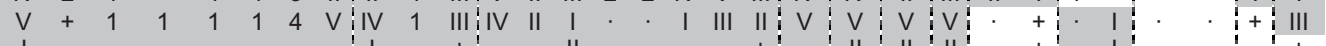

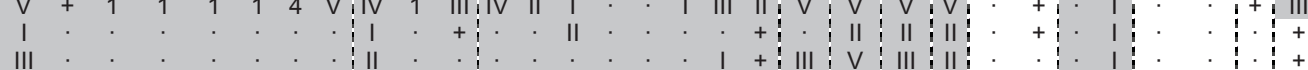

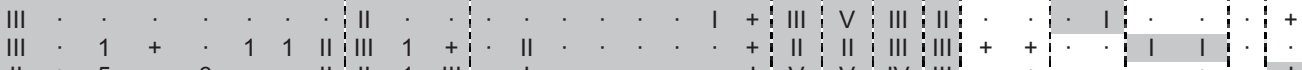

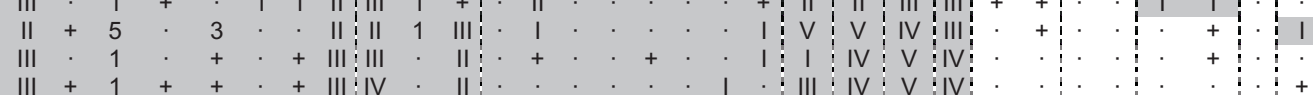

$\mathrm{III}+1++\begin{aligned} & \mathrm{II} \\ & \mathrm{I}\end{aligned}$

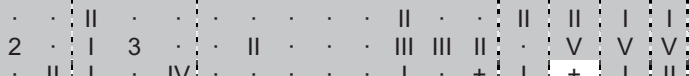

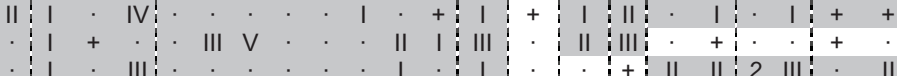

IV . III V V V $1+$ III IV $V$ I

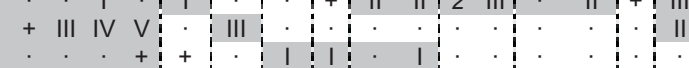

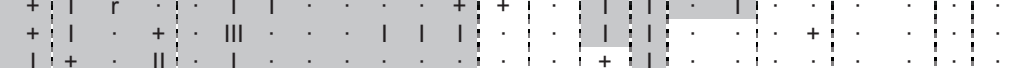

$1:+$

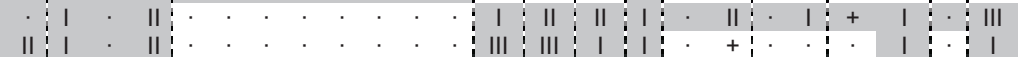


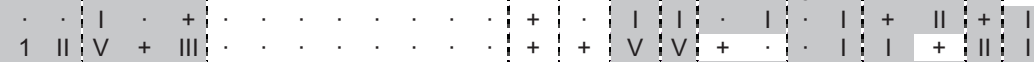

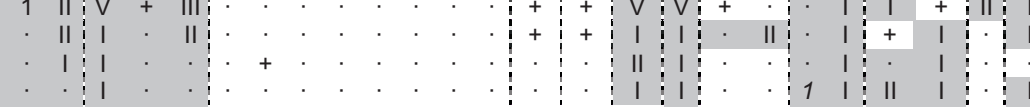

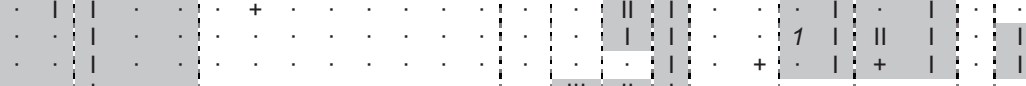
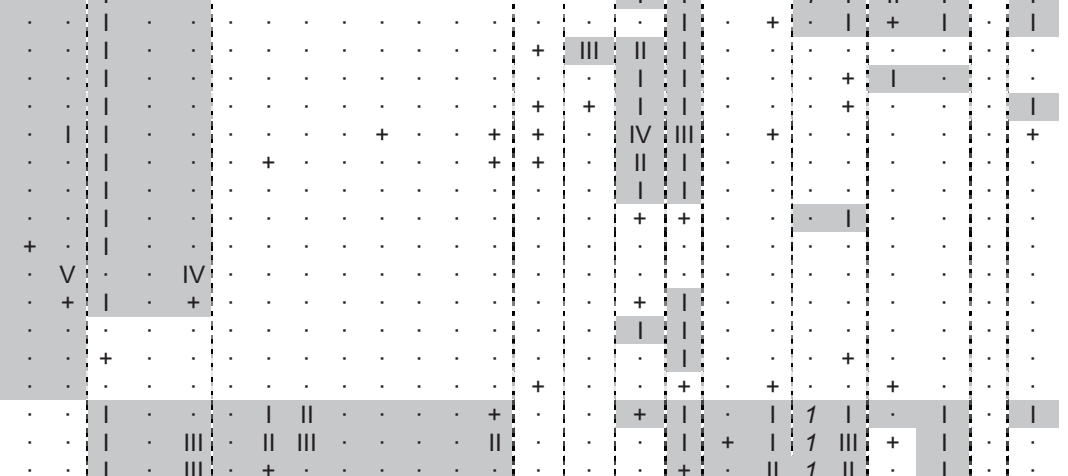
Columna

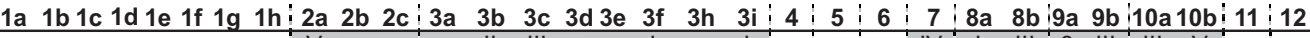

Ruscus aculeatus

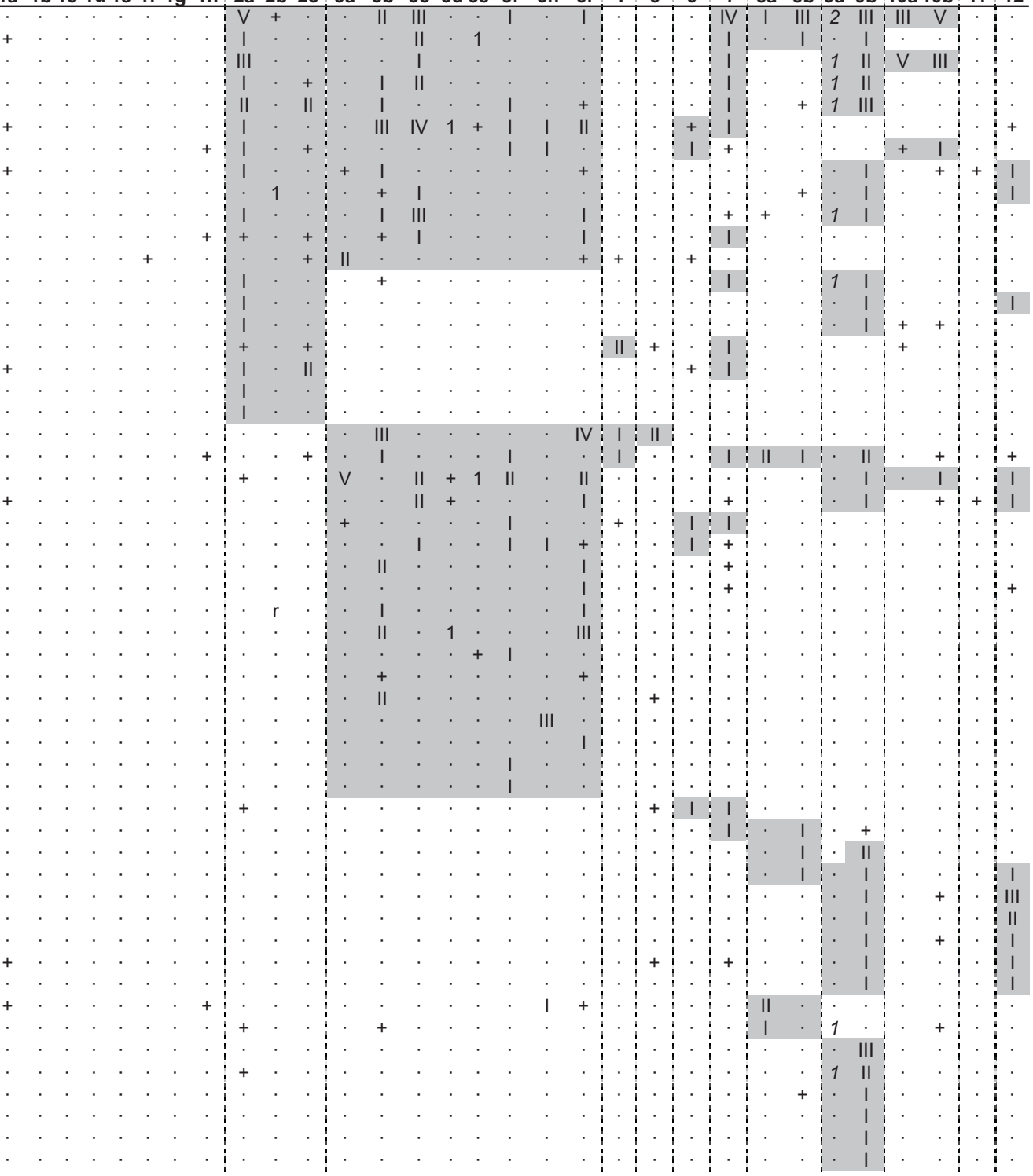

Hieracium umbellatum

Laurus nobilis

Rubia peregrina

Arbutus unedo

Stachys officinalis

Lysimachia nemorum

Salix atrocinerea

Hieracium sabaudum

Potentilla sterilis

Vicia sepium

Sorbus aria

Smilax aspera

Ajuga meonantha

Davallia canariensis

Hieracium murorum

Carex sylvatica

Woodwardia radicans

Cystopteris fragilis

Viola gr. sylvestris

Luzula forsteri

Veronica officinalis

Conopodium majus

Saxifraga hirsuta

Daphne laureola

Cornus sanguinea

Sorbus torminalis

Quercus ilex

Prunus spinosa

Festuca heterophylla

Acer campestre

Sorbus intermedia

Ulex cantabricus

Populus tremula

Phyllitis scolopendrium

Veronica montana

Milium effusum

Helleborus foetidus

Genista falcata

Galium rotundifolium

Anemone trifolia subsp. albida

Laserpitium thalictrifolium

Aquilegia dichroa

Lilium martagon

Hieracium bourgaei

Carex caryophyllea

Quercus x andegavensis

Quercus suber

Daphne gnidium

Carex distachya

Cistus psilosepalus

Cistus salviifolius

Osyris alba

\section{Compañeiras}

Pteridium aquilinum

Rubus sp.

Daboecia cantabrica

Frangula alnus

Agrostis capillaris

Potentilla erecta

Erica arborea

Crataegus monogyna

Pseudarrhenatherum longifolium

Pyrus cordata

Digitalis purpurea

Anthoxanthum odoratum

Ulex gallii

Asphodelus sp.

Brachypodium sylvaticum

Carex pilulifera

Brachypodium rupestre

Calluna vulgaris

Erica cinerea

Erica vagans

Omphalodes nitida

Ulex europaeus

Cirsium filipendulum

Lithodora prostrata

Agrostis curtisii

Cruciata glabra

Cytisus scoparius

Táboa 2 cont.- Táboa florística sintética de diversos tipos de bosques cántabro-euskaldúns, galaico-asturianos e galaico-portugueses (exclúense as compañeiras presentes en menos de 8 columnas) 
Táboa 2 cont.- Táboa florística sintética de diversos tipos de bosques cántabro-euskaldúns, galaico-asturianos e galaico-portugueses (exclúense as compañeiras presentes en menos de 8 columnas)

Taxóns de baixa presenza característicos de alianza, orde e clase: en 1a: Conopodium pyrenaeum: +; en 1h: Conopodium pyrenaeum: +; en 2c: Melica uniflora: +; Moehringia trinervia: +; Poa nemoralis: +; en 4: Salix caprea: +; en 5: Melica uniflora: +; en 6: Lamiastrum galeobdolon: +; en 7: Allium ursinum: +; Cardamine impatiens: +; Conopodium pyrenaeum: +; Galium odoratum: +; Scilla lilio-hyacinthus: +; en 9b: Melica uniflora: +; en 12: Melica uniflora: +; Poa nemoralis: +.

Procedencia da información recopilada :

1: Blechno spicant-Quercetum roboris subas. dryopteridetosum aemulae

1a: columna sintética a partir das tábs. $8 \mathrm{a}, 8 \mathrm{~b}$ e $8 \mathrm{c}$ deste traballo.

1b: Monte Roblidiello, baixada a La Presanca (Piloña, Asturias; 30T 310/4792).

1c: Entre La Presanca e a Mallada Degoes, monte El Muñizón (Piloña, Asturias; 30T 311/4792).

1d: Puentenansa (Rionansa, Cantabria; 30T 385/4790).

1e: Val do Arroyo de Montea (Ruente, Cantabria; 30T 394/4791).

1f: Entre Fresneda e El Tojo (Los Tojos, Cantabria; 30T 395/4780).

1g: Parque Natural Saja-Besaya, Bárcena Luenga (Ruente, Cantabria; 30T 402/4787).

1h: columna sintética a partir de Martínez García et al. (1974): táb. pax. 72-73: invs. 2 e 5 e Navarro (1974): táb. XXI: invs. 1-7 e 11.

\section{2: Blechno spicant-Quercetum roboris subas. lauretosum nobilis}

2a: columna sintética a partir das tábs. 9a e $9 \mathrm{~b}$ deste traballo.

2b: Puentenansa (Rionansa, Cantabria; 30T 385/4790).

2c: columna sintética a partir de Martínez García et al. (1974): táb. pax. 72-73: invs. 1,3,4 e 6, e Navarro (1974): táb. XXI: invs. 8-10.

\section{3: Hyperico pulchri-Quercetum roboris}

3a: Onanindía Olalde (1986): táboa 5: 8 invs.

3b: Herrera Gallástegui (1995): táb. 80: 18 invs.

3c: Braun-Blanquet (1967): táb. 29: inv. 1,2,4,5,21 e 23).

3d: Jaunsaras (Ulzama, Navarra), Rivas-Martínez et al. (1991): táb. 22: inv. 4.

3e: Arraiz (Navarra), Báscones (1978): táb. 19: inv. 3.

3f: Rivas-Martínez et al. (1984b): táb. 1: 6 inv.

3h: Catalán (1987): táb. 2: 34 invs.

3i: Loidi et al. (1997): táb. 9: 16 invs.

\section{4: Luzulo henriquesii-Quercetum petraeae subas. quercetosum petraeae}

columna sintética a partir de Fernández Prieto \& Vázquez (1987): táb. 1: invs. 1-11; e Silva-Pando (1990): táb. 9: inv. 6.

\section{5: Luzulo henriquesii-Quercetum petraeae subas. fagetosum sylvaticae}

columna sintética a partir de Fernández Prieto \& Vázquez (1987): táb. 1: invs. 19-22; Rodríguez Guitián et al. (2000): táb. 1: inv. 4-7; e Silva-Pando (1990): táb. 13: inv. 3.

6: Saxifrago spathularidis-Fagetum sylvaticae subas. fagetosum sylvaticae columna sintética a partir de Rodríguez Guitián (2006): táb. 2: 16 inv.; Rodríguez Guitián et al. (2003): táb. VII: inv. 54; e Rodríguez Guitián et al. (2003): táb. VIII: invs. 17, 20, 24, 35, 36, 39, 40, 43, 45 e 47-60.

7: Saxifrago spathularidis-Fagetum sylvaticae subas. sorbetosum aucupariae columna sintética a partir de Rodríguez Guitián (2006): táb. 1: 29 inv., Rodríguez Guitián et al. (2003): táb. VII: invs. 1-15, 18, 19, 2123, 25-28, 29-31, 33, 37, 38, 41, 44 e 46, e Rodríguez Guitián et al. (2003): táb. VIII: invs. 16, 28, 32, 34 e 42.

\section{8: Lonicero periclymeni-Quercetum pyrenaicae}

8a: columna sintética a partir dos inventarios da táb. 10 deste traballo.

8b: columna sintética a partir dos inventarios de Silva-Pando (1990): táb. 11: 1, 4, 8, 10-17 e inventario páx. 293, Rodríguez Guitián et al. (2000): táb. 5: 3 invs., e Rivas Martínez et al. (2002): inv. páx. 142.

9: Rusco aculeati-Quercetum roboris subas. violetosum rivinianae

9a: columna sintética a partir dos inventarios da táb. 10 deste traballo.

9b: columna sintética a partir de Dantas Barreto (1958): cadro XXIV: inv. 37; Casaseca (1959): táb. Páx. 348bis: invs. 1, 3, 5 e 6; Bellot Rodríguez (1968): cadro 17: invs. 7 e 8; Amigo \& Romero (1994): táb. 6: inv. 1, 10-12, 14-17; Amigo et al. (1998): táb. 2: inv. 1-8, 11, 12 e 14; e Pulgar Sañudo(1999): táb. 2: inv. 18. 
10: Rusco aculeati-Quercetum roboris subas. quercetosum suberis

10a: columna sintética a partir dos inventarios da táb. 10 deste traballo

10b: columna sintética a partir de Pinto da Silva et al. (1950): cadro I: inv. 508; Rivas Goday (1950): táb. páx. 451-453: 3 invs. e táb. páx. 355-356: 3 invs.; Dantas Barreto (1958): cadro XXIV: invs. 5, 31, 32 e 36; Bellot Rodríguez (1968): cadro 18 : inv. 11 e cadro 23: invs. 1-15, 17 e 20; Losa Quintana (1973): táb. 1: invs. 3 e 6; Amigo \& Romero (1994): táb. 6: inv. 2-5, 7-9, 13, 18 e 19; Amigo et al. (1998): táb. 2: invs. 9,10,13 e 15 e táb. 3: 19 invs.; Pulgar Sañudo (1999): táb. 2: invs. 1-13 e 15-17 e táb. 3: inv. 2.

11: carballais chairegos (sen adscripción fitosociolóxica)

columna sintética a partir dos inventarios da táb. 10 deste traballo.

\section{2: Myrtillo-Quercetum roboris.}

columna sintética a partir dos inventarios de Pinto da Silva et al. (1950): cadro I: invs. 504, 505 e 522; Dantas Barreto (1958): cadro XXVI: invs. 2-4, 6, 10-15, 17, 19, 20, 22-26, 29, 38-43; Bellot Rodríguez (1968): cadro 16: invs. 1-6, 9,10,12 e15 e cadro 18: invs. 2,12 e 14; Dalda González (1972): cadro 11: 5 invs.; Amigo \& Romero (1994): táb. 6: inv. 6; Izco et al. (1994): táb. VIII: invs. 1 e 4; Amigo et al. (1998): táb. 2: inv. 16; Pulgar Sañudo (1999): táb. 2: invs. 14, 19 e 20; táb. 3: invs. 1 e 3-5.

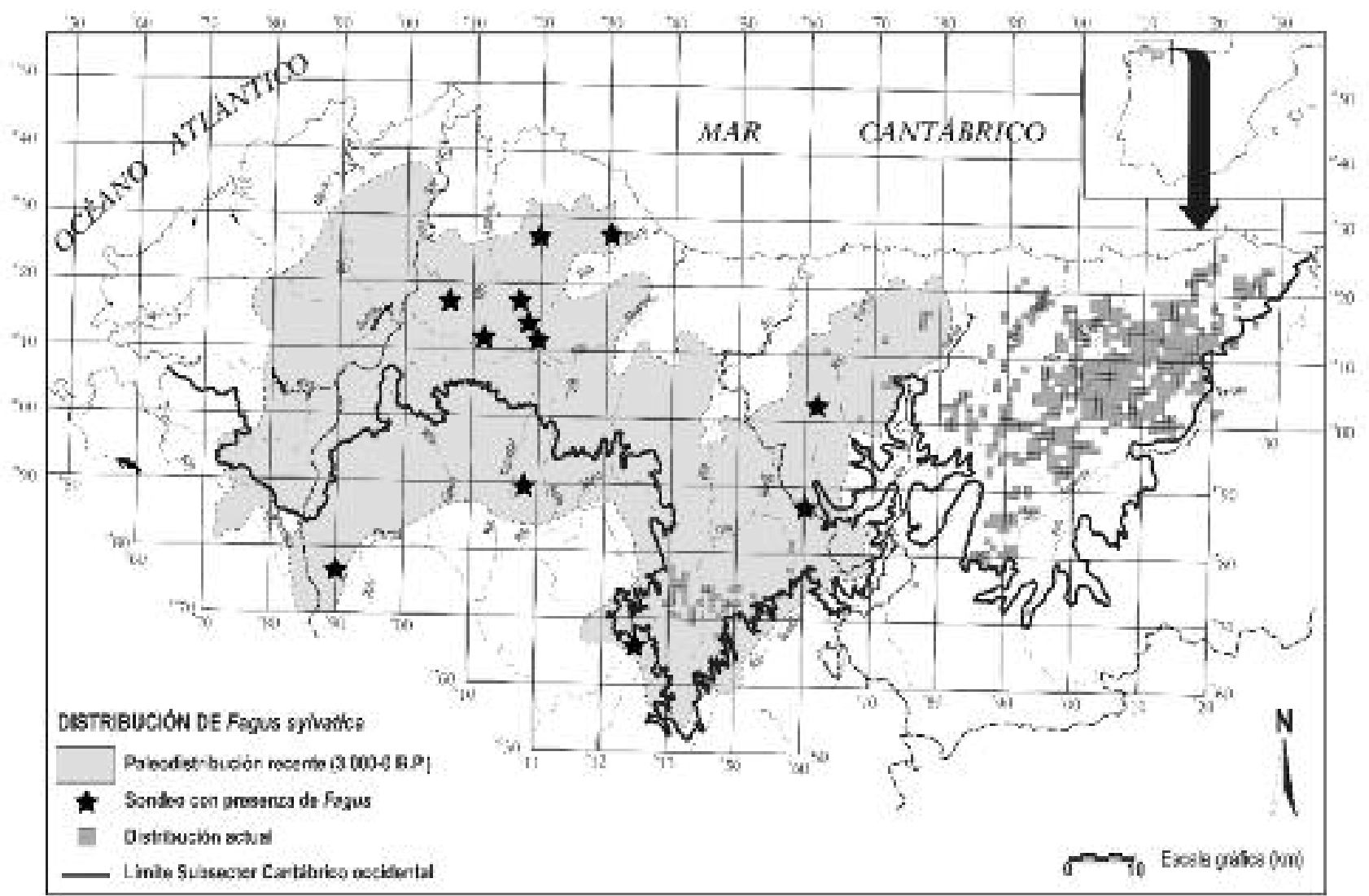

Figura 5.- Distribución actual de Fagus sylvatica no extremo noroccidental ibérico e áreas de extinción recente $(<3.000$ anos). Modificado de Rodríguez-Guitián et al. (2001)

A faia é unha árbore presente igualmente nas áreas costeiras centro-orientais cantábricas, dentro dos bosques da asociación cántabro-euskalduna Hyperico pulchriQuercetum roboris (cf. Rivas-Martínez et al. 1984a, 1984b; Aseginolaza Iparaguirre et al. 1996, Loidi Arregui et al. 1997), descrita orixinalmente coma un carballal acidófilo dominado por Q. robur (táboa 2). Nestes casos Fagus sylvatica aparecería en situacións de ecotono cos faiais acidófilos cántabro-euskaldúns (Saxifrago hirsutaeFagetum sylvatica) ou en áreas baixas cando localmente se acada unha pluviometría suficientemente elevada. Por outro lado, coñécese a existencia de faiais a altitudes considerablemente baixas (100-500 $\mathrm{m}$ ) ao longo da mitade oriental da área de estudio (Rodríguez Guitián et al. 2003) que teñen continuidade nos territorios litorais e sublitorais ovetenses e cántabro-euskaldúns (Loidi Arregui 1983, Loidi Arregui et al. 1997, Rodríguez Guitián 2006). Estas razóns nos parecen suficientes para plantexar que a faia debe ser considerada como una especie máis integrante do cortexo florístico dos carballais aquí estudiados, cando menos alí onde existan condicións climáticas axeitadas para o seu desenvolvemento, debéndose a súa ausencia actual na mitade occidental do subsector cantábrico occidental á actividade deforestadora antrópica e non a factores ambientais. 
Interpretación fitosociolóxica segundo os
antecedentes existentes

En primeira instancia, realizóuse a interpretación fitocenótica das mostras de bosques estudados tendo en conta os criterios florísticos propostos por Izco et al. (1990) e Rivas-Martínez et al. (2002), obténdose o adscrición dos inventarios en función das combinación de especies diferenciais presentes que se amosa na táboa 3. Como se pode apreciar, o conxunto de inventarios con maior representación (94 mostras, 42,9\%) responden á combinación florística descrita para a asociación $B-Q$, comunidade vexetal na que, até este momento, se veñen incluindo á totalidade de carballais presentes no territorio estudiado. A pesares delo, case a mitade dos inventarios (102 mostras, $46,5 \%$ do total) non cumplen estritamente os criterios florísticos de diferenciación empregados por presentar combinacións florísticas nas que se mesturan especies diferenciais de dúas ou tres asociacións, mentras que ningunha das mostras presenta as especies que no seu día foron propostas para discriminar os carballais da asociación Myrtillo-Quercetum roboris (M-Q). Por último, un conxunto de 23 mostras (10,5\% do total) carece de todas as especies diferenciais propostas polos diferentes autores.

\begin{tabular}{lcc}
\hline Combinacións de especies diferenciais & $\mathbf{N}^{\circ}$ inv. & $\mathbf{\%}$ \\
\hline Exclusivamente $B-Q$ & 94 & 42,9 \\
Exclusivamente $R-Q$ & 4 & 1,8 \\
Exclusivamente $L-Q$ & 28 & 12,8 \\
Exclusivamente $M-Q$ & 0 & 0,0 \\
$B-Q+R-Q$ & 15 & 6,8 \\
$B-Q+L-Q$ & 46 & 21,0 \\
$R-Q+L-Q$ & 3 & 1,4 \\
$B-Q+R-Q+L-Q$ & 6 & 2,7 \\
Sen especies diferenciais & 23 & 10,5 \\
\hline Total & $\mathbf{2 1 9}$ & $\mathbf{1 0 0}$ \\
\hline
\end{tabular}

Táboa 3.- Resultado da asignación sintaxonómica a nivel de asociación das mostras estudiadas tendo en conta os grupos de especies diferenciais da táboa 1

A coexistencia de taxóns diferenciais de unidades sintaxonómicas diferentes no mesmo inventario tamén se observa cando se fai unha análise semellante para as subasociacións descritas dentro da asociación $B-Q$ (táboa 4 ), pois case o $50 \%$ dos inventarios que se poderían incluir nesta comunidade amosan a coexistencia de plantas diferenciais de dúas ou tres subasociacións. Estes resultados reflexan unha certa situación de desorde dentro do esquema fitosociolóxico actualmente vixente no que atinxe aos bosques estudiados, podéndose resumir as causas dos desaxustes observados nas seguintes:

- a descrición de comunidades e a elección de grupos de taxóns diferenciais baseadas nun número baixo de inventarios.

- a existencia de deficiencias no coñecemento da coroloxía de numerosos taxóns, o que acarrea discrepancias entre as diagnoses orixinais das comunidades e o coñecemento derivado de novas observacións.

- a descrición de comunidades baseada na presenza de especies de baixo valor diagnóstico en ambientes nemorais, como taxóns heliófilos cuxo óptimo se atopa en matogueiras frecuentes no entorno dos bosques estudiados.

- a ausencia de datos sobre comunidades próximas coas que se necesita establecer diferencias florísticas e, como consecuencia, o recurso á comparación con sintaxóns descritos en áreas xeográficas lonxanas, que responden a características bioclimáticas e bioxeográficas ben distintas.

- o emprego de criterios non homoxéneos na escolla do rango sintaxonómico a aplicar para as comunidades definidas.

Quizás as eivas que conlevan unha maior problemática na aplicación da metodoloxía fitosociolóxica de entre as sinaladas sexan as duas primeiras, en especial cando aparecen de xeito combinado. A descrición de unidades básicas (asociacións) a partir dun número reducido de mostras (inventarios florísticos) é unha práctica que adoita inducir á definición de comunidades vexetais pouco consistentes, tanto no relativo ás súas especies características e diferenciais, como no relativo á súa ecoloxía ou distribución xeográfica, na liña do comentado por Izco (1994). Desgrazadamente, esta situación non se restrinxe ao ámbito de estudo, senón que afecta, en maior ou menor medida, á totalidade de áreas xeográficas nas que se ten aplicado este método de análise da vexetación a escala mundial. Para tratar de paliar esta situación, o Código Internacional de Nomenclatura Fitosociolóxica (Weber et al. 2000) recomenda que a descrición e tipificación das unidades básicas se realice en base a un número mínimo de 10 localidades de inventario, repartidas ao longo dun área xeográfica suficientemente extensa como para que se recolla a variabilidade existente na comunidade e se poda recoñecer unha combinación mínimamente constante de especies características ligadas a unhas certas condicións ambientais ou territorio bioxeográfico. No caso que nos ocupa, o número mínimo recomendado parece claramente insuficiente se se ten en conta a amplitude xeográfica do territorio, que ronda os $7.000 \mathrm{~km}^{2}$.

A ausencia de criterios coherentes e fundamentados á hora de propoñer o estatus sintaxonómico das diversas combinacións florísticas descritas provoca, no caso aquí tratado, dificultades de asignación de inventarios a comunidades debido á coexistencia en moitas das mostras de especies diferenciais que foron propostas con carácter excluinte. Este problema obsérvase tanto a nivel de asociación como de subasociacións, pero é especialmente frecuente con relación aos subsintaxóns tipificados dentro da asociación Blechno spicant-Quercetum roboris. En gran medida, esta situación teríase evitado se, en lugar de otorgar un mesmo estatus a algunhas das combinacións florísticas descritas (subasociacións dryopteridetosum aemulae, lauretosum nobilis, pulmonarietosum longifoliae), éstas foran xerarquizadas tendo en cota a amplitude xeográfica e ecolóxica dos factores ambientais causantes das indicadas combinacións florísticas diferenciadas. Así, parece obvio que o grao de termicidade dun territorio debería ter unha consideración de rango xerárquico superior como causa de modificación da composición 
florística dunha comunidade (diferenciación entre a subas. dryopteridetosum e a lauretosum no caso que nos ocupa) que as modificacións locais debidas á un incremento no contido en bases do solo dentro dun ambiente xeral de pobreza en nutrientes (subas. pulmonarietosum longifoliae). Ademáis, é necesario ter en conta que as causas ecolóxicas que xustifican as variacións florísticas representadas polas subasociacións comentadas non son excluíntes, pois se deben a factores independentes. Esto explica que na práctica, e aténdonos exclusivamente a os factores termométricos e nutricionais, constátase a existencia de bosques cuxa composición florística pode corresponder a catro situacións resultado da combinación dos devanditos factores: bosques termófilos e oligotrofos, bosques termófilos e mesotrofos, bosques non termófilos e oligotrofos e bosques non termófilos e mesotrofos.

\begin{tabular}{lcc}
\hline Combinacións de especies diferenciais & $\mathbf{N}^{\circ}$ inv. & \% \\
\hline subas. dryopteridetosum aemulae & 25 & 15,5 \\
subas. hieracietosum umbellatae & 38 & 23,6 \\
subas. lauretosum nobilis & 16 & 9,9 \\
subas. pulmonarietosum longifoliae & 3 & 1,9 \\
subas. fagetosum sylvaticae & 2 & 1,2 \\
subas. hieracietosum + lauretosum & 35 & 21,7 \\
subas. hieracietosum + pulmonarietosum & 1 & 0,6 \\
subas. hieracietosum + fagetosum & 9 & 5,6 \\
subas. lauretosum + pulmonarietosum & 3 & 1,89 \\
subas. lauretosum + fagetosum & 7 & 4,3 \\
subas. hieracietosum + lauretosum + pulmonarietosum & 14 & 8,7 \\
subas. hieracietosum + lauretosum + fagetosum & 6 & 3,7 \\
subas. hieracietosum + pulmonarietosum + fagetosum & 2 & 1,2 \\
\hline Total & $\mathbf{1 6 1}$ & $\mathbf{1 0 0}$ \\
\hline
\end{tabular}

Táboa 4.- Resultado da asignación sintaxonómica a nivel de subasociación das mostras estudiadas que conteñen especies diferenciais da asociación Blechno spicantQuercetum roboris segundo os criterios de Izco et al. (1990) e Díaz González \& Fernández Prieto (1994)
O exemplo de comunidade de máis dificil encaixe nalgunha das descritas é o da subasociación fagetosum sylvaticae dos carballais $B-Q$, descrita por Díaz \& Fernández Prieto (1994a). Dito subsintaxón tería como única especie diferencial a Fagus sylvatica, cuxa aparición nos bosques estudiados daríase en "territorios colinos superiores (mesotemperados superiores) ou montanos (supratemperados)" cun bioclima "alomenos hiperhúmido" ao tratarse dunha especie presuntamente "de montaña". Sobre esta atribución autoecolóxica para a faia lembramos o comentado nun apartado anterior sobre a súa distribución altitudinal e bioclimática na área de estudio e convidamos ao lector á consulta dos nosos anteriores traballos sobre os faiais litorais e sublitorais da Cornixa Cantábrica (Rodríguez Guitián et al 2003, Rodríguez Guitián 2006). Ademáis de ser incongruente o razoamento que leva a utilizar a Fagus sylvatica como especie diferencial desta comunidade, o inventario no que se fundamenta a súa descrición contén diversas especies pouco tolerantes ao frío entre as que se atopa Laurus nobilis, escollida previamente por lzco et al. (1990) xunto con outras especies termófilas, como diferenciais da subasociaón lauretosum nobilis. Nesta situación, ¿cal é o criterio prevalente á hora de adscribir un inventario como este a algunha das dúas subasociacións comentadas?

Sen sairmos da mentada asociación $B-Q$, o caso da subasociación hieracietosum umbellatae destas carballeiras, de distribución exclusivamente ovetense (cf. Tüxen \& Oberdorfer 1958, Rivas-Martínez 1987, Díaz González \& Fernández Prieto 1994a), ofrece igualmente unha gran inconsistencia en canto ao seu fundamento florístico. Os seus autores sinalan como especies diferenciais fronte á subasociación típica (dryopteridetosum aemulae) taxóns como Viola riviniana, Potentilla erecta, Hieracium umbellatum e Betula pubescens. Sen embargo, esta suposta segregación florístico-xeográfica choca coa presenza, en maior ou menor medida, de ditas especies nas carballeiras galaico-asturianas analizadas, ademáis de que se trata de taxóns que poden estar ausentes dentro dos carballais ovetenses, como se acredita observando as táboas florísticas publicadas, entre outros autores, por Martínez García et al. (1974) e Navarro (1974)(táboa 2). Por elo estimamos que esta subasociación carece de sustento en base á información actualmente dispoñible.

Outro problema diferente o plantexa a escasa representatividade que, ao noso xuizo, ten a escueta táboa de tres mostras que inclúe o inventario tipo da subasociación pulmonarietosum longifoliae destes carballais, definida como unha comunidade situada en "posiciones de vaguada o de fondo de valle de mayor trofía y frescura de suelo" (Izco et al. 1990). Aquí atopámonos coa paradoxa de que o seu inventario tipo corresponde fisionómicamente a un abeledo, pois Corylus avellana domina claramente o estrato superior (índice 5.4), mentras que o carballo (Quercus robur) ten unha presencia anecdótica (índice r). Esta estructura distante da dun carballal tamén se aprecia noutro dos inventarios da táboa na que se fundamenta a diagnose desta comunidade, mentras que o terceiro parece axustarse máis ao aspecto que podería esperarse para un bosque da área de estudo que medre nas condicións anteriormente mencionadas.

Dificultades de interpretación doutra índole son as derivadas da utilización de plantas cuxo óptimo ecolóxico non se atopa en formacións arboradas como especies discriminantes de tipos diferentes de bosques. Neste caso, o seu valor fitosociolóxico é cuestionable, sobre todo cando se trata de especies de ampla distribución territorial. Esto ocurre cos bosques descritos por Rivas-Martínez et al. (2002) baixo a denominación de Lonicero periclymeniQuercetum pyrenaicae, que se diferenciarían doutros tipos de reboleiras e carballais pola presencia neles dun conxunto florístico constituído, entre outras especies, por plantas típicas de matogueiras (Cytisus striatus, Daboecia 
cantabrica, Luzula lactea, Ulex gallii) e microbosques esclerófilos (Arbutus unedo). Moitos destes taxóns teñen, desde a nosa perspectiva, un escaso valor diagnóstico no extremo noroccidental ibérico aos efectos que se lles atribúe, pois se trata de especies que atopan o seu óptimo ecolóxico en formacións arbustivas máis ou menos influenciadas por actividades humanas (lumes periódicos, pastoreo, etc.) e unha distribución xeográfica que sobrarda amplamente a establecida para as comunidades arboradas ás que se pretenden ligar. Problemas semellantes poderían achacarse aos conxuntos de especies diferenciais propostos polos autores mencionados para separar estes bosques dos carballais galaico-asturianos (Galium scabrum, Luzula lactea, Quercus pyrenaica) e galaicoportugueses (Asplenium adiantum-nigrum, Avenella flexuosa, Melampyrum pratense, Saxifraga spathularis, Vaccinium myrtillus)(cf. Izco et al. 1990, Amigo et al. 1998).

En último lugar, a escaseza de datos sobre as representacións boscosas que establecen contacto coas carballeiras estudiadas cara o limite meridional da parte occidental da área de estudio (Subsector OurensanoLugués), ata o de agora asignadas á asociación MyrtilloQuercetum roboris (cf. Rivas-Martínez 1987, Izco 1987, Izco et al. 1994, Amigo et al. 1998), dificulta a valoración axeitada das posibles diferencias que poidan existir entre elas. A maioría dos inventarios dispoñibles en territorio galego desta comunidade proceden das montañas limítrofes entre Ourense e o norte de Portugual (serras de Peneda e Xurés-Gerês), moi alonxadas xeográficamente e con condicións climáticas bastante diferentes das da área de estudio, polo que, a priori, poderían presentar diferencias florísticas máis ou menos patentes cos carballais existentes na Terra Chá luguesa. Segundo os autores orixinais deste sintaxón (Pinto da Silva et al. 1950), Vaccinium myrtillus, Rubus lusitanicus, Galium rotundifolium, Laserpitium thalictrifolium, Eryngium juressianum e Picris Iongifolia permitirían diferenciar este tipo de carballeiras de distribución supratemperada das termo-mesotemperadas dos pertencentes á asociación Rusco-Quercetum roboris, criterio que manteñen a grandes rasgos diversos autores posteriores (Dantas Barreto 1958, Izco et al. 1990, SilvaPando 1991a, 1991b, 1991c; Pulgar Sañudo 1999). A estas especies poderíase engadir, seguido a lzco et al. (1990), Anemone trifolia subsp. albida, herba nemoral cuxo límite setentrional coñecido sitúase na metade sur da Dorsal Galega. Aínda admitindo este conxunto de especies diferenciais, a composición florística dos escasos inventarios que se posúen de áreas lucenses próximas ao territorio aquí estudiado (cf. Izco et al. 1994) non permite a súa identificación clara coas carballeiras supratemperadas galaico-portuguesas da asociación Myrtillo-Quercetum roboris, manténdose, polo de agora, a incógnita sobre a súa identidade fitosociolóxica.

\section{Necesidade dunha nova interpretación}

Todo o comentado ata o momento pon en evidencia a necesidade de revisar os criterios sobre os que se ven fundamentando a interpretación fitosociolóxica dos bosques dominados por quercíneas dentro da área de estudio. Esta reinterpretación debe ter en consideración que os principais factores ambientais que condicionan a composición florística dos carballais estudiados, e que establecen a principal diferencia co resto de bosques de quercíneas do seu entorno, son o forte carácter oceánico do clima e a existencia nos territorios litorais galaico-asturianos dunha humidade ambiental elevada durante a época estival causada pola condensación recurrente de masas nubosas orixinadas no Mar Cantábrico. Estas especiais condicións bioclimáticas reducen considerablemente as taxas de ETP e a demanda hídrica dos vexetais (Carballeira et al. 1983, Martínez Cortizas \& Castillo Rodríguez 1996) á vez que permiten que os solos se manteñan frescos e cun contido elevado de agua durante o verán, favorecendo a presenza de certas especies nemorais de carácter higroesciófilo, entre as que destaca un extenso grupo de pteridofitas (cf. Allorge \& Allorge 1941, Viane et al., 1987, Amigo \& Norman 1993, 1995; Boudrie 1998, Quintanilla \& Amigo 1999a, 1999b; Quintanilla et al. 2002). Así, ademáis das especies de fentos propostas por Izco et al. (1990) como diferenciais da asociación Blechno-Quercetum roboris (Athyrium filixfemina, Dryopteris aemula, D. dilatata, Osmunda regalis) poderíanse utilizar para distinguir estes bosques doutros tipos de carballais de carácter máis xérico ou menos oceánico, especies como Dryopteris filix-mas, Lastrea limbosperma, Davallia canariensis, Cystopteris fragilis, Hymenophyllum tunbrigense ou Woodwardia radicans. Asemade, poden empregarse cun carácter discriminante semellante algúns taxóns leñosos frecuentes nos claros forestais e matogueiras que se intercalan entre os bosques dos territorios cantábricos occidentais, como Erica mackaiana e Cytisus commutatus, ausentes por completo dos sectores Galaico-Portugués, Galaico interior e Altonarceense-Ancarés.

Por outro lado, a proximidade ao mar de gran parte do territorio bioxeográfico considerado exerce un efecto modulador das temperaturas ao longo do ano favorecendo a presenza dun importante número de especies termófilas nos bosques estudiados (Rubia peregrina, Smilax aspera, Ruscus aculeatus, Laurus nobilis, Arbutus unedo, Asplenium onopteris, Tamus communis). Sen embargo, estes taxóns xa non aparecen, salvo en enclaves especialmente protexidos, nos carballais de territorios bioxeográficos máis meridionais (subsectores Chairego, Ancarés e Narceense), sometidos a un clima de menor termicidade e maior continentalidade. Por elo, esta vinculación bioclimático-florística pode ser utilizada ventaxosamente para discriminar tipos de bosques fisionómicamente parecidos dunhas e outras áreas. Non obstante, este valor diferencial pérdese cando se enfrontan os carballais termófilos galaico-asturianos e os galaicoportugueses da asociación Rusco aculeati-Quercetum roboris. Neste caso, como se pode comprobar analizando a composición florística global da Rusco-Quercetum aportada por Amigo et al. (1998)(táboa 2), a diferenciación entre estes dous tipos de bosques ven dada pola presenza/ausencia do grupo de especies higro-esciófilas anteriormente comentadas, cuxos biotopos axeitados desaparecen progresivamente en sentido N-S ao longo do 
Golfo Ártabro, cando o ambiente atmosférico estival perde a influencia das néboas e os dias de orballo característicos do $\mathrm{N}$ das provincias de A Coruña e Lugo.

Tendo en conta o anteriormente exposto, os bosques dominados por quercíneas máis amplamente difundidos nos territorios cantábricos occidentais aquí tratados (Blechno spicant-Quercetum roboris) terían como características florísticas diferenciais respecto dos carballais acidófilos galaico-portugueses (Rusco-Quercetum e MyrtilloQuercetum) e as reboleiras naviano-ancarenses mesotermófilas (Lonicero periclymeni-Quercetum pyrenaicae) as seguintes:

- dominio fisionómico, e a miudo coexistencia en proporcións variables, de diversos taxóns caducifolios do xénero Quercus (Quercus robur, Quercus petraea, Quercus x rosacea); en xeral, Q. pyrenaica está ausente nestes bosques aínda que, en situacións especialmente favorables, pode chegar a ser abundante.

- presenza de especies higroesciófilas, entre as que destacan especialmente diversos pteridófitos (Athyrium filix-femina, Blechnum spicant, Cystopteris fragilis, Dryopteris aemula, D. dilatata, Hymenophyllum tunbrigense, Lastrea limbosperma, Osmunda regalis) e taxóns nemorais como Saxifraga spathularis, Luzula henriquesii ou Polygonatum verticillatum.

- presenza ocasional de certos arbustos (Erica mackaiana, Cytisus commutatus), frecuentes nas comunidades de sustitución destes bosques, exclusivos dos territorios galaico-asturianos.

A partir deste punto, a interpretación fitosociolóxica das combinacións florísticas existentes realizóuse tendo en conta a dimensión ecolóxica dos factores causales das combinaciónos florísticas, na liña do plantexado por Gehu (1998) resultando a correlación entre categorías sintaxonómicas de rango inferior ao de asociación (subasociación, variante, facies, fase) e factores ambientais/aspectos dinámicos que se amosan na táboa 5 . Esta proposta difire da planteada por Izco (2004), para quen unha subasociación vexetal pode estar sustentada, a xuizo do investigador, en causas edáficas, topográficas ou ombroclimáticas, con independencia de que o factor causal da diferenciación florística da comunidade en cuestión se manifeste nun ámbito micro, meso ou macroxeográfico. Niste senso, e como xa comentamos, cremos que o criterio que se empregue no establecemento da secuencia xerárquica a utilizar non debe ser arbitrario, senón que debe gardar relación coa importancia que os factores ambientais teñen na modificación florística local das comunidades.
Ademáis, dado que os factores que explican a variabilidade florística das comunidades vexetais acadan unhas intensidades e posibilidades de combinación que se poden delimitar con bastante precisión dentro dun ámbito bioxeográfico concreto, a aplicación do esquema de subunidades xerárquicas que se estableza para unha asociación vexetal determinada debería de ser extrapolable ao resto de comunidades homólogas coas cales comparte similar rango dentro do esquema de unidades sintaxonómicas manexado.

En consecuencia, para o grupo de bosques aquí tratado estableceuse un primeiro nivel de discriminación entre carballais con forte influencia oceánica ("carballais hiperoceánicos"), ricos en especies higro-esciófilas, e outros sometidas a condicións bioclimáticas non favorables para a presenza de ditas especies, xa fose debido a un incremento da continentalidade ou a un descenso apreciable da humidade ambiental durante a época estival. Dentro de cada un destes tipos de bosques poderíanse diferenciar categorías en función da presencia ou ausencia de especies termófilas nos que, á súa vez, cabería distinguir, en función do contido en nutrintes do solo sobre o que se asentan, bosques oligotrofos doutros de tendencia mesotrofa, distinguibles dos primeiros pola presencia de especies neutro-basófilas.

Como resultado da aplicación destes criterios, quedarían segregados en primeiro lugar os carballais incluíbles na asociación $B-Q$ do resto. Dentro destes bosques de carácter máis marcadamente oceánico propoñemos o mantemento de dúas das catro subasociacións que ata o de agora se viñan admitindo dentro desta asociación: a típica (dryopteridetosum aemulae), carente de especies termófilas, e a de distribución principalmente termomesotemperada inferior (lauretosum nobilis), recoñecible pola presenza de taxóns termófilos, como Asplenium onopteris, Arbutus unedo, Laurus nobilis, Rubia peregrina, Ruscus aculeatus ou Smilax aspera. Dentro destes subsintaxóns considérase oportuno diferenciar dúas variantes, típica (oligotrofa) e con tendencia á mesotrofía. Á súa vez, dentro de cada unha destas variantes, cabería diferenciar sendas facies: típica e heliófila, esta última caracterizada pola presencia de Quercus pyrenaica. Admitido este esquema, non terían cabida as subasociacións pulmonarietosum longifoliae, pois as situacións de maior trofia edáfica interprétanse como variantes, e fagetosum sylvaticae, xa que como se discutíu nun apartado anterior, a presenza da faia nos bosques estudiados non parece estar ligada a aspectos bioclimáticos, polo que propoñemos á revocación de ámbalas dúas unidades sintaxonómicas.

\begin{tabular}{lll}
\hline Factor causal & Rango fitosociolóxico & Exemplo \\
\hline Elemento mesoclimático (termotipo) & subasociación & subas. termófila/subas. mesófila \\
Riqueza en nutrientes do solo & variante & variante oligotrofa/variante mesotrofa \\
Aspectos microtopográficos & facies & facies heliófila/facies umbrófila \\
Causas dinámicas/grao de antropización & fase & fase típica/fase de Castanea sativa \\
\hline
\end{tabular}

Táboa 5.- Correspondencia entre factores responsables da variación florística dunha asociación vexetal e o rango fitosociolóxico aplicado neste traballo 
Canto aos bosques que carecen de especies higróesciófilas (29 inventarios), podería plantexarse a posibilidade de que se tratara de mostras que por alguha causa particular (pastoreo ou lumes pretéritos, localización en estacións edafo-topográficas especialmente desfavorables para as especies higroesciófilas, representación de estadíos forestais xuvenís ou deficientemente estruturados) presentaran unha composición florística alonxada do que se pode considerar máis frecuente dentro dos carballais máis amplamente extendidos no territorio considerado (asociación BlechnoQuercetum). A interpretación proposta para estes casos tivo en conta, ademáis da súa composición florística, as tipoloxías e combinacións de comunidades relacionadas dinámicamente cos distintos tipos de carballais descritos na área de estudio e territorios limítrofes que se amosan na táboa 6. Segundo esto, o estudo detallado das comunidades non arboradas que se atopan nas inmediacións dos bosques carentes de especies higroesciófilas analizados revela que en todo-los casos están ausentes comunidades ligadas exclusivamente aos carballais da Blechno-Quercetum, como as xesteiras da Ulici europaei-Cytisetum commutati, as matogueiras baixas da Gentiano pneumonanthe-Ericetum mackaianae e as uceiras da Avenello flexuosae-Ericetum arboreae.

Seguindo esta argumentación semella razoable incluir os bosques carentes de higro-esciófitos pero que teñen taxóns termófilos dentro da asociación Rusco aculeati-Quercetum roboris, de distribución moi puntual no territorio e, polo que se desprende da orientación dos lugares nos que foron obtidas as mostras desta comunidade, fortemente vinculada a ladeiras pedregosas de elevada inclinación e con orientación marcadamente soalleira, na liña do xa expresado por Losa Quintana (1973). A diferenciación destes bosques con respecto aos naviegos da LoniceroQuercetum pyrenaicae descritos por Rivas-Martínez et al. (2002) parece residir, á vista da escasa información ata o momento dispoñible sobre estes últimos, na ausencia neles de taxóns termófilos presentes na Rusco-Quercetum, como
Daphne gnidium, Rubia peregrina, Smilax aspera ou Laurus nobilis (táboa 2). Non obstante, estimamos necesario profundizar na colleita de información florística neste último tipo de bosques para ratificar esta hipótese.

A ubicación sintaxonómica definitiva dos carballais existentes ao longo de parte das cabeceiras da área meridional aquí tratada, entre a comarca de Betanzos e o estremo oriental da Terra Chá, que carecen simultáneamente de especies higroesciófilas e termófilas así como das comunidades leñosas de sutitución ligadas aos carballais da Blechno-Quercetum anteriormente mencionadas, e das que se estudiaron cinco mostras situadas en diversos lugares da cabeceira do Río Miño, queda pendente ate a realización de novos traballos. A súa composición florística fai que, polo momento, sexan difíciles de diferenciar dalgúns existentes no tramo medio do Río Eo que interpretamos como pertencentes á asociación Lonicero-Quercetum pyrenaicae; en cambio, creemos que se debe rexeitar a súa asimilación cos aspectos menos térmicos da asociación Rusco aculeati-Quercetum roboris, debido á total ausencia neles de especies termófilas, e tampouco nos parece axeitado incluilos na asociación Myrtillo-Quercetum roboris, tal e como se veu facendo ata o de agora (cf. Rivas-Martínez 1987), pois carecen de moitas das especies que aparecen nos inventarios publicados desta comunidade (táboa 2).

Tal e como se discutíu en apartados anteriores, a reinterpretación que aquí se propón debe aplicarse á totalidade dos territorios Galaico-Asturianos, área dentro da que estes bosques cumplen, en liñas xerais, as condicións florísticas anteriormente enunciadas (táboa 2). Como resumo da proposta reinterpretativa presentada, amósase na táboa 7 unha clave de discriminación florística das comunidades arbóreas identificadas neste traballo dentro do territorio estudiado, que coidamos pode ser de utilidade para ubicar sintaxonómicamente as diferentes combinacións florísticas que se poden encontrar no campo destas fitocenoses.

\begin{tabular}{|c|c|c|c|c|c|}
\hline \multirow{2}{*}{ Tipos de etapas seriais } & \multicolumn{5}{|c|}{ Tipo de bosque } \\
\hline & $B-Q$ & $R-Q v$ & $R-Q q$ & $L-Q$ & SA \\
\hline \multicolumn{6}{|l|}{ Orlas arbustivas altas } \\
\hline Frangulo alni-Pyretum cordatae & - & - & • & ? & $?$ \\
\hline Frangulo alni-Arbutetum unedonis & - & - - - & $?$ & - & $\ldots$ \\
\hline \multicolumn{6}{|l|}{ Uceiras } \\
\hline Avenello flexuosae-Ericetum arboreae & - & - . - & - - - & - . & - . - \\
\hline Pterosparto cantabrici-Ericetum aragonensis & $\ldots$ & $\ldots$ & $-\ldots$ & - & $?$ \\
\hline \multicolumn{6}{|l|}{ Queirogais } \\
\hline Gentiano pneumonanthe-Ericetum mackaianae & - & - - - & - - - & - - - & - - - \\
\hline Cirsio filipenduli-Ericetum ciliaris & - - - & - & - & - - - & $?$ \\
\hline Ulici europaei-Ericetum cinereae & ? & - & - & $?$ & - \\
\hline \multicolumn{6}{|l|}{ Xesteiras } \\
\hline Ulici europaei-Cytisetum commutati & - & - - - & - - - & - - - & - - \\
\hline Cytisetum striati subas. cytisetosum striati & - & - & - & - - - & $\bullet$ \\
\hline Cytisetum striati subas. cytisetosum multiflori & - - - & - - - & - - - & - & - - \\
\hline Cytiso scoparii-Genistetum polygaliphyllae subas. cytisetosum multiflori & $\ldots$ & $\ldots$ &.- & - & $\ldots$ \\
\hline
\end{tabular}

•: comunidade vinculada co tipo de bosque correspondente; - - -: comunidade non vinculada co tipo de bosque correspondente; ?: datos insuficientes. Acrónimos dos tipos de bosque como na táboa 1, salvo SA: "bosques sen adscrición fitosociolóxica".

Táboa 6.- Relación entre os tipos de bosques estudiados e os principais tipos de comunidades vexetais leñosas integrantes das súas respectivas series de vexetación. Elaborado a partir de Izco et al. (1990), Díaz Gonzaléz \& Fernández Prieto (1994,1996), Izco (1996) y Amigo et al. (1998). 
Caracterización ambiental e florística das comunidades de bosque recoñecidas

A continuación se describe a distribución xeográfica, o ambiente ecolóxico, a composición florística e estrutura dos tipos de bosques mesófilos dominados por especies caducifolias e marcescentes do xénero Quercus recoñecidos na área de estudio.

a) Carballais acidófilos galaico-asturianos hiperoceánicos típicos (Blechno spicant-Quercetum roboris subas. dryopteridetosum aemulae, $B-Q d$ ).

As características ambientais e florísticas deste grupo de carballais amósanse nas figuras $6 a$ e $6 \mathrm{~b}$ e nas táboas 8 e 9 . Trátase de bosques distribuídos maioritariamente por territorios de bioclima oceánico e hiperoceánico retirados da beira do mar e por altitudes superiores aos $400 \mathrm{~m}$ (figura $6 a)$. En coincidencia con este reparto, desenvolvense principalmente dentro dos termotipos mesotemperado superior e supratemperado e baixo ombrotipos húmedo superior e hiperhúmido inferior. No plano fisiográfico, adoitan situarse en ladeiras de inclinanción elevada (terreos escarpados ou moi escarpados na clasificación da FAO) e con exposición variable, aínda que concentrada nas orientacións de compoñente $\mathrm{N}$ (figura 6a). A escaseza de bosques en situacións topográficas achairadas e situadas en vertentes soalleiras non debe interpretarse como sinónima de ambientes pouco aptos para este tipo de bosques, senón como consecuencia da deforestación preferente destas posicións para o seu aproveitamento agro-gandeiro.

Os materiais de partida máis representados neste grupo de bosques son a "alternancia de rochas metamórficas silíceas", "cuarcitas" e "lousas", estando tamén presentes sobre rochas graníticas, neises "ollo de sapo", rochas básicas e sedimentos cenozoicos (figura 6b). Sobre estes materiais litolóxicos desenvólvense principalmente solos cun marcado carácter coluvial e escaso grao de diferenciación (regosoles), se ben en partes baixas de ladeira e pequenos recháns nas vertentes poden atoparse cambisoles e, principalmente nas proximidades de cumes montañosos, solos incipientes (leptosoles).

Desde o punto de vista fisionómico, a talla deste conxunto de bosques oscila entre os 8 e os $27 \mathrm{~m}$, situándose a media nos $16,3 \mathrm{~m}$. A cobertura do estrato superior tende a ser elevada (media do 94,8 \%), aínda que en ocasións descende ata o 60\% (táboa 7). As especies arbóreas máis constantes nestes bosques son Quercus robur e llex aquifolium, sendo algo menos frecuentes Corylus avellana, Betula pubescens e Sorbus aucuparia. De aparición máis esporádica son Castanea sativa, Quercus x rosacea, Fagus sylvatica, Quercus petraea, Quercus pyrenaica, Taxus baccata, Prunus avium, Ulmus glabra e Fraxinus excelsior. Por baixo das especies anteriores adoitan aparecer Erica arborea, Pyrus cordata e Frangula alnus, sendo moi escaso o espiñeiro (Crataegus monogyna). No nivel inferior, moito máis variable en cobertura que o anterior (20-100 \%), acádase un promedio elevado de recubrimento do chan $(81,4 \%)$ debido á presencia de numerosas especies de carácter nemoral como Vaccinium myrtillus, Anemone nemorosa, Dryopteris dilatata, $D$. affinis, D. aemula, Avenella flexuosa, Stellaria holostea, Oxalis acetosella, Saxifraga spathularis, Teucrium scorodonia, Physospermum cornubiense, Polypodium vulgare, Polygonatum verticillatum, Holcus mollis, Hedera hibernica e Lonicera periclymenum, así como algunhas outras incluibles no apartado de compañeiras (Rubus sp., Pteridium aquilinum e, en menor medida, Asphodelus sp., Daboecia cantabrica ou Omphalodes nitida).

O número de taxóns presentes neste tipo de carballeiras oscila entre 11 e 41 , sendo o valor medio de 23 (táboa 7). Con respecto ao grupo de especies compañeiras, acada por termo medio algo menos do $30 \%$ do total de taxóns presentes, se ben este valor pode variar grandemente, entre o 14 e o $53 \%$. Polo xeral, as especies introducidas non acadan unha significación salientable nestes carballais (máximo de unha especie por inventario), téndose censado nas mostras estudiadas soamente tres especies (Helichrysum foetidum, Pinus pinaster e Prunus laurocerasus).

No plano fitosociolóxico, distinguimos neste tipo de carballais dúas variantes: típica e mesotrofa. Esta última diferenciase pola presenza de especies con preferencias por solos máis ricos en nutrientes, características de bosques da orde Fagetalia sylvaticae, como Acer pseudoplatanus, Carex sylvatica, Conopodium majus, Fraxinus excelsior, Helleborus occidentalis, Hypericum androsaemum, Mercurialis perennis, Polystichum setiferum, Primula acaulis, Prunus avium, Pulmonaria Iongifolia, Ranunculus tuberosus, Sanicula europaea, Scrophularia alpestris ou Ulmus glabra. Nas áreas de topografía máis abrupta, esta variante marca a transición cara aos bosques mixtos de encostas escarpadas e barrancos que dun xeito moi fraccionado se distribúen nos enclaves máis fragosos das masas arboradas autóctonas ao longo da área de estudo (Rodríguez Guitián 2005).

En situacións de maior insolación e, polo xeral sobre solos máis areosos ou menos profundos, tanto nunha como noutra variante, pódese recoñecer unha facies heliófila na que o rebolo (Quercus pyrenaica), e as veces o su híbrido con Quercus robur (Quercus x andegavensis), adoitan incorporarse ao dosel destes bosques.

b) Carballais acidófilos galaico-asturianos hiperoceánicos termófilos (Blechno spicant-Quercetum roboris subas. lauretosum nobilis, $B-Q /)$.

As características ambientais e florísticas deste grupo de carballais amósanse nas figuras $6 a$ e $6 \mathrm{~b}$ e nas táboas 8 e 10. Os carballais galaico-asturianos termófilos presentan, en gran medida, unha distribución complementaria dos da subasociación típica, e dicir, con preferencia pola banda litoral e áreas interiores situadas a baixa altitude (figura 1). Non obstante, dado que as condicións de termicidade gañan cotas progresivamente superiores coa distancia ao mar, este tipo de carballais ten unha distribución altitudinal máis ampla que os primeiros, oscilando entre os $0-350 / 400$ $\mathrm{m}$ no sector litoral ata os $700-750 \mathrm{~m}$ en certas áreas interiores das cuncas do ríos Eo, Navia e Narcea. 
Distribucibn altitudinal

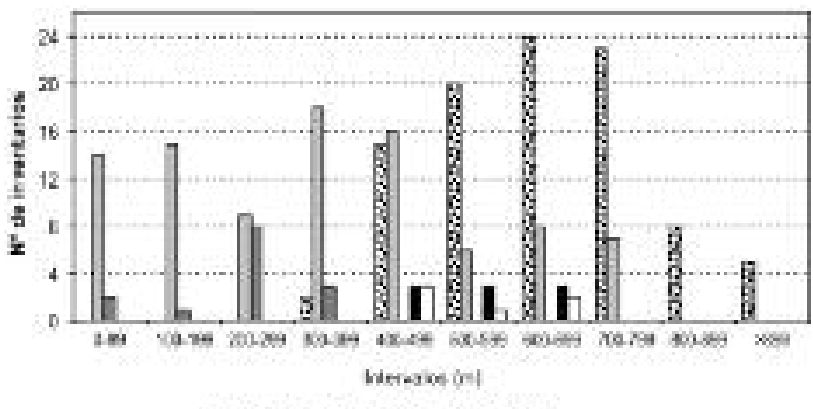

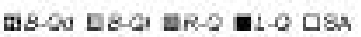

Exposicion das bocalidodes (

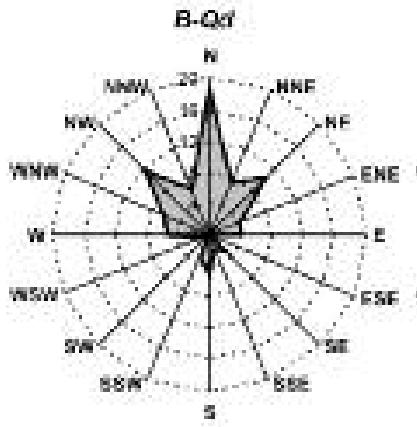

H: $11.6 \%$

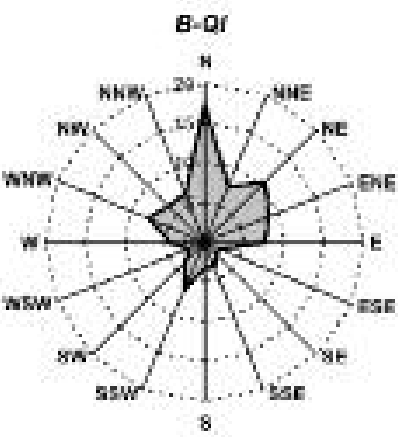

H: a.ds

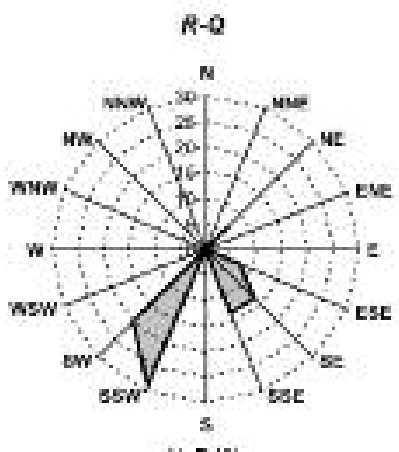

H: $7,1 \%$

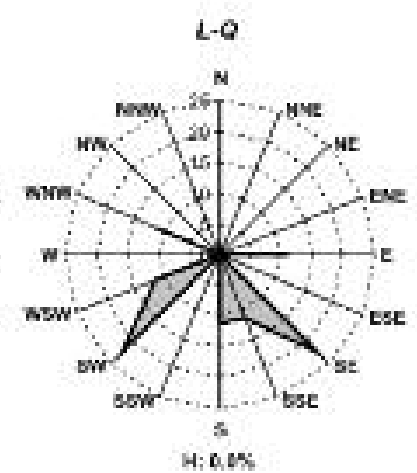

SA

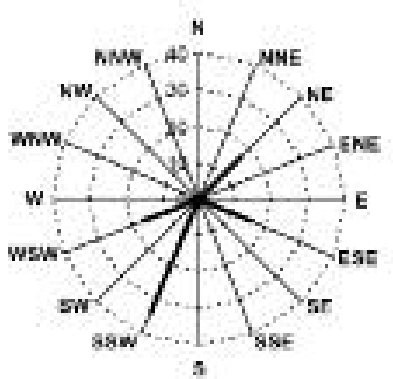

H. $16 \% \%$
Pendente (\%)

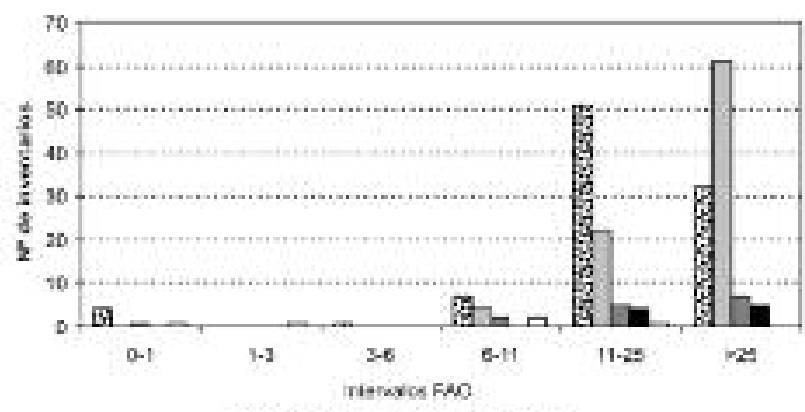

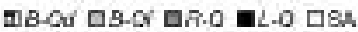

Blaclima

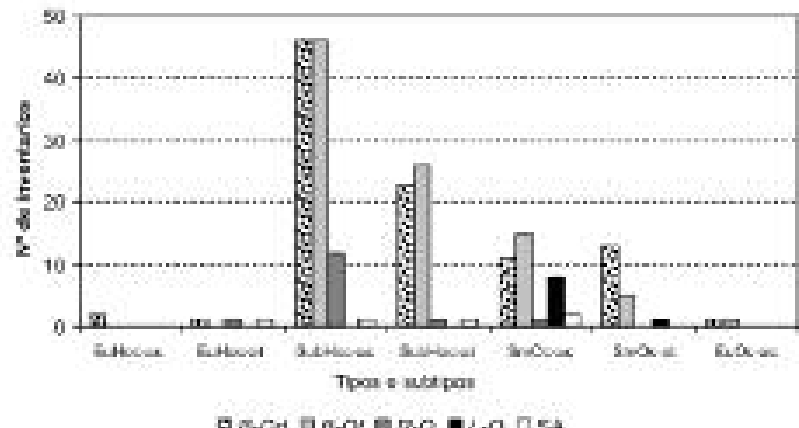

Temnotipos

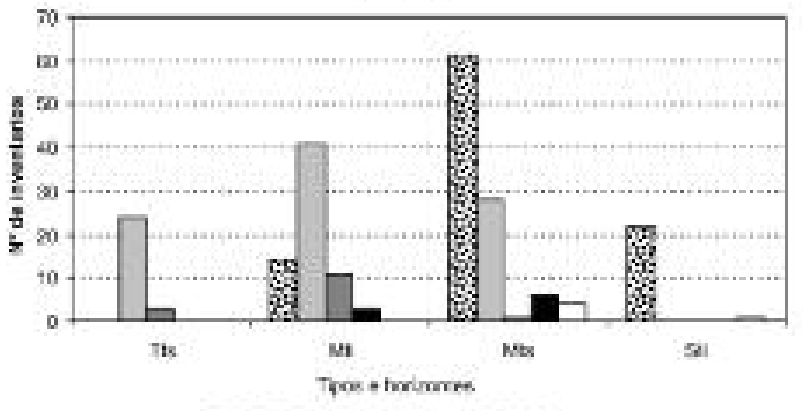

aB-Ou UBA ER-Q aLO LBA

Ombrotipea

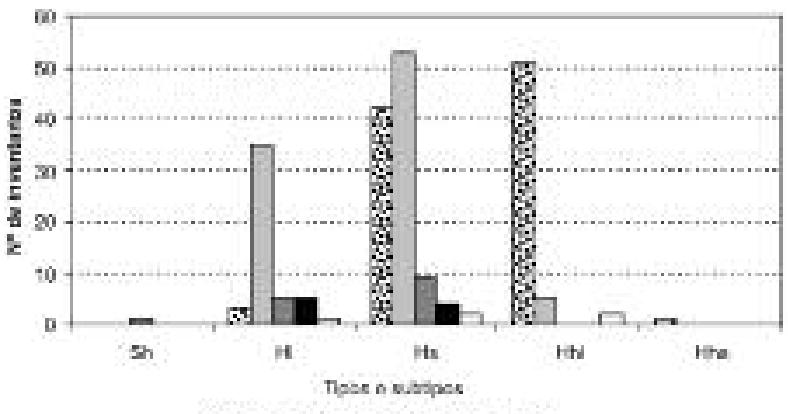

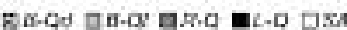

Figura 6a.- Distribución altitudinal, exposicións, intervalos de pendente e caracterización bioclimática dos tipos de bosque descritos neste traballo. Acrónimos das comunidades como na táboa 1, salvo SA: "bosques sen adscrición fitosociolóxica". Bioclimas: EuHoc-ac: euhiperoceánico acentuado; EuHoc-at: euhiperoceánico atenuado; SubHoc-ac: subhiperoceánico acentuado; SubHoc-at: subhiperoceánico atenuado; SmOc-ac: semioceánico acentuado; SmOc-at: semioceánico atenuado; EuOc-ac: euoceánico acentuado. Termotipos: Tts: termotemperado superior; Msi: mesotemperado inferior; Mts: mesotemperado superior; Sti: supratemperado inferior. Ombrotipos: Sh: subhúmido superior; Hi: húmido inferior; Hs: húmido superior; Hhi: hiperhúmidoinferior; Hhs: hiperhúmido superior 


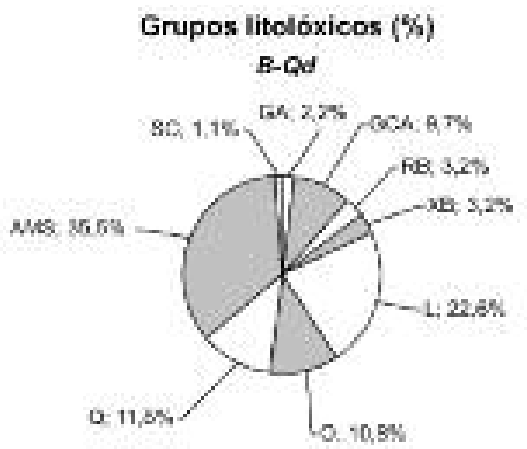

$B-C$

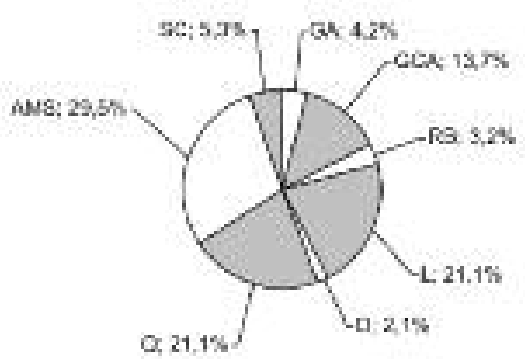

R.Q

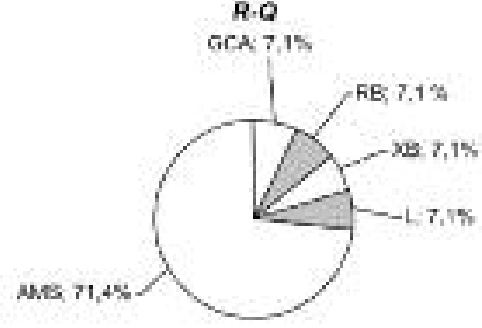

$1-a$

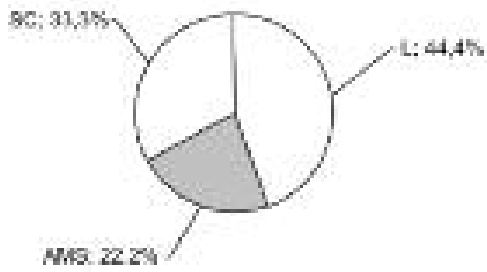

SA

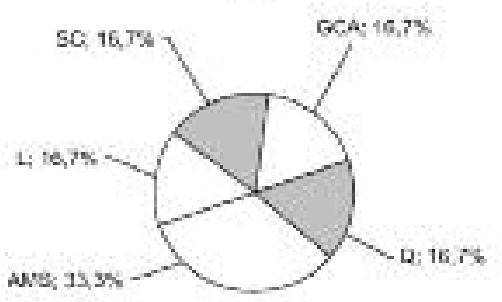

Posición topografica (\%) Q-Qd

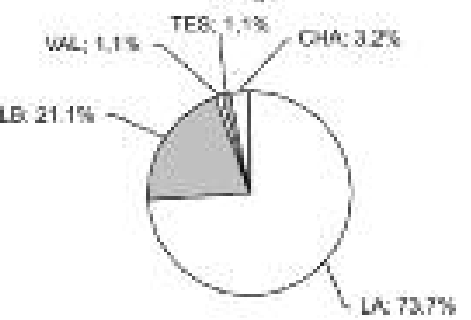

B.O

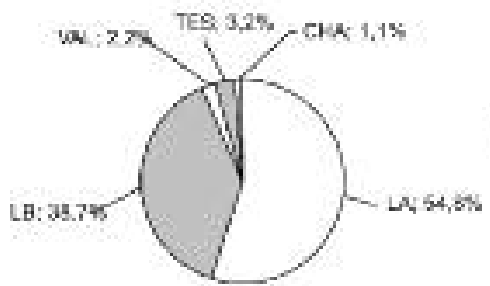

R-O

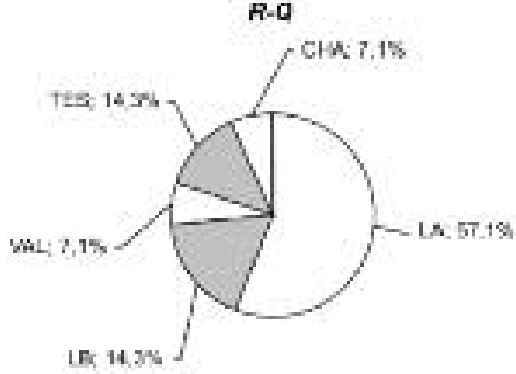

L- 0

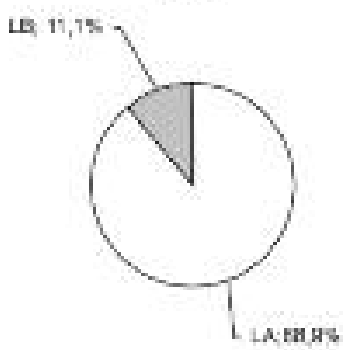

SA

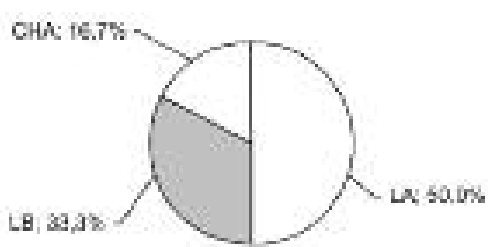

Tipo de solo (\%)

B. Qd

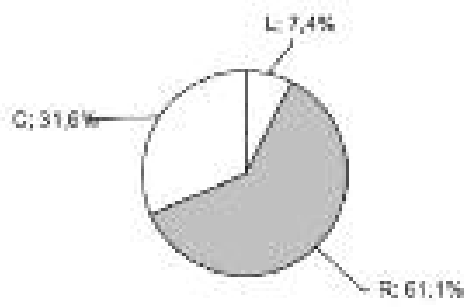

B-Q
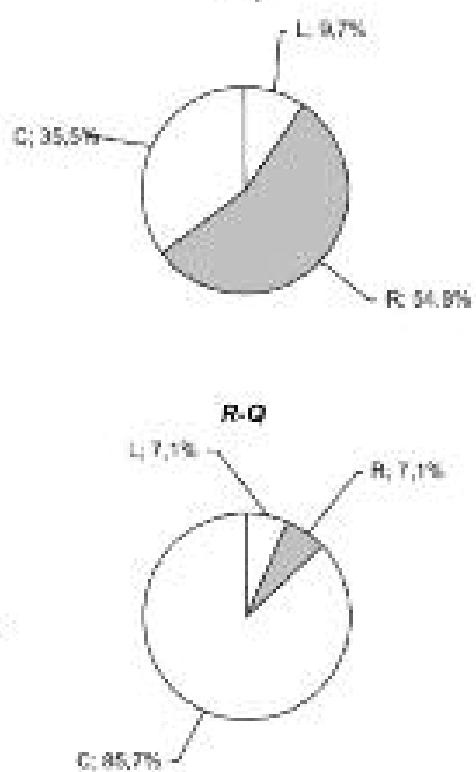

L-Q

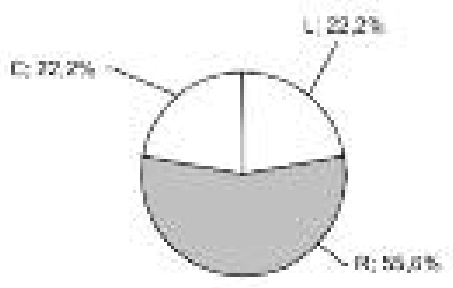

5A

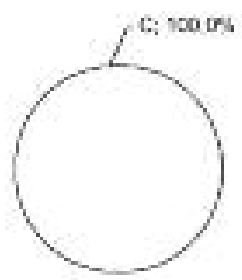

Figura 6b.- Grupos litolóxicos, posición topográfica e tipos de solos desenvolvidos baixo os tipos de bosque descritos neste traballo. Acrónimos das comunidades como na táboa 1, salvo SA: "bosques sen adscrición fitosociolóxica". Litoloxía: AMS: alternancia de rochas silíceas metamorfizadas; GA: granitoides alcalinos; GCA: granitoides alcalinos; SC: sedimentos cuaternarios; L: lousas; Q: cuarcitas; XB: xistos básicos; RB: rochas metamórficas básicas; O: xistos acedos tipo "ollo de sapo". Posición topográfica: LA: parte alta de ladeira; LB: parte baixa de ladeira; VAL: valgada; TES: teso; CHA: chaira. Tipo de solo: L: leptosol, R: regosol; C: cambisol 
Este grupo de carballais distribúese maioritariamente por territorios de bioclima hiperoceánico dentro dos termotipos termotemperado superior a mesotemperado superior e baixo ombrotipos predominantemente húmidos (figura 6a). A diferenza dos carballais da subasociación típica, case o $40 \%$ dos termófilos atópase en situacións fisiográficas de ladeira baixa e valgada (figura 6b). Tamén se observa unha maior representación sobre terreos de moi forte inclinación (arredor do $70 \%$ dos inventarios sitúanse en pendentes superiores a $25^{\circ}$ ). De tódo-los xeitos, é necesario lembrar que este reparto está moi condicionado coa distribución actual dos bosques na área de estudio e non se debe interpretar como indicativo do seu "óptimo" ecolóxico. As orientacións, aínda que moi variables, tamén amosan un certo incremento nas de compoñente $\mathrm{N}$.

Os solos sobre os que se asentan estes bosques manteñen o forte carácter coluvial comentado para os da subasociación típica, predominando os regosoles sobre os cambisoles e leptosoles. Están desenvolvidos nunha maior proporción sobre "alternancia de rochas silíceas metamórfizadas", observándose unha menor representación das rochas de tipo granítico e lousas (figura $6 b)$.

Estructuralmente falando, aquí se reúnen bosques dunha talla igualmente variable $(10-28 \mathrm{~m})$ pero, polo xeral, lixeiramente superior á dos típicos (17,1 $\mathrm{m}$ de promedio). Tamén os valores de cobertura mínima (70\%) e media $(96,4 \%)$ no estrato superior son maiores que os rexistrados no caso daqueles. A maior termicidade que se observa nas áreas nas que aparecen este tipo de bosques propicia un importante incremento no número de especies arbóreas presentes. Aínda que as especies máis constantes nestes bosques seguen a ser Quercus robur e Ilex aquifolium, neles gañan en importancia Castanea sativa, Corylus avellana, Crataegus monogyna, Quercus petraea e Quercus $x$ rosacea, mentras que non son raros Laurus nobilis e Arbutus unedo, que están ausentes dos carballais típicos; por contra, Betula pubescens, Sorbus aucuparia e Fagus sylvatica tenden a ser máis raros, mentras que seguen a presentar aparicións moi puntuais Taxus baccata, Prunus avium, Ulmus glabra e Fraxinus excerlsior. Como aspecto curioso neste apartado, merece mención a presenza de Fraxinus angustifolia e Fraxinus oxycarpa nalgúns destes carballais situados en partes baixadas de ladeiras da cunca media do Río Mandeo. Posiblemente, a incorporación local destas especies aos carballais se deba ao seu contacto cos bosques riparios desta zona (asociación Senecioni bayonnensis-Alnetum glutinosae), formacións nas que estes freixos son frecuentes (Amigo et al. 1987).

Pyrus cordata e Frangula alnus, coa frecuente incorporación de Crataegus monogyna, seguen a ser as principais especies que conforman o nivel arbóreo inferior ao do dosel, mentras que Erica arborea presenta unha apreciable reducción na súa frecuencia de aparición. O nivel inferior presenta un valor mínimo de recubrimento superior ao caso dos carballais típicos (10\%), se ben a media é algo inferior á destes $(77,4 \%)$. Neste estrato apréciase unha reducción da frecuencia de aparición de certas especies nemorais, como Vaccinium myrtillus, Blechnum spicant, Avenella flexousa ou Polygonatum odoratum, se ben outras a incrementan (Aquilegia vulgaris, Athyrium filix-femina, Hypericum androsemum, Luzula henriquesii, Potentilla sterilis, Viola riviniana). Dentro do grupo de compañeiras, descenden algo as silvas (Rubus sp.) e aumentan lixeiramente algunas herbas típicas de bordes forestais (Linaria trionithophora, Omphalodes nitida, Polygonatum odoratum) así como algúns higrófitos (Angelica sylvestris, Ajuga pyramidalis, Cardamine flexousa, Senecio nemorensis).

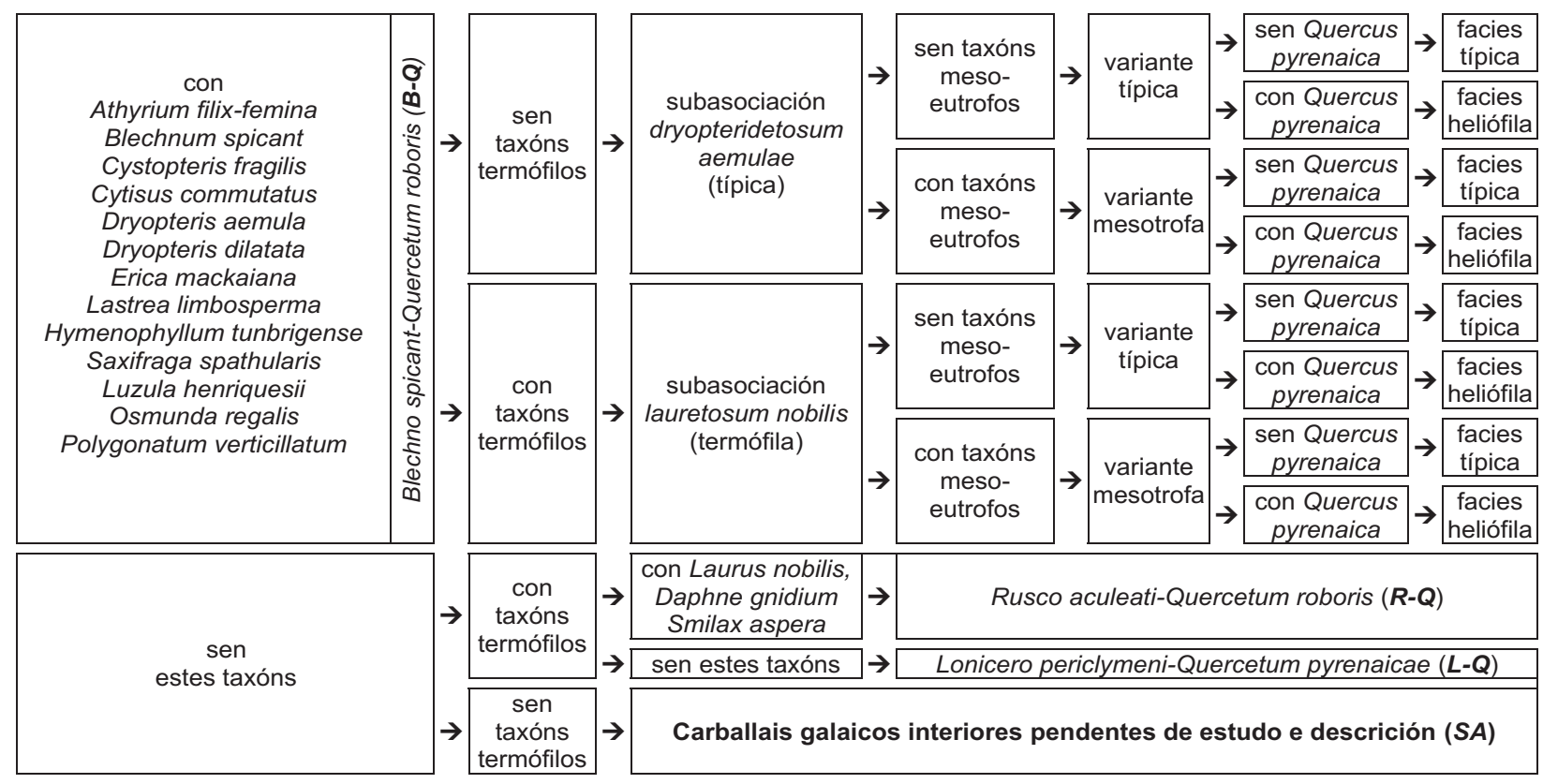

Táboa 7.- Clave florística para os bosques dominados por quercíneas presentes na área de estudo (Subsector Cantábrico occidental). Acrónimos das comunidades como na táboa 1, salvo SA: "bosques sen adscrición fitosociolóxica" 


\begin{tabular}{|c|c|c|c|c|c|c|}
\hline \multirow[b]{2}{*}{ Atributo } & \multirow[b]{2}{*}{ Valor } & \multicolumn{5}{|c|}{ Tipo de bosque } \\
\hline & & $B-Q d(97)$ & $B-Q I(93)$ & $R-Q(14)$ & $L-Q(9)$ & SA (6) \\
\hline \multirow{3}{*}{ Alt. $E_{1}(m)$} & $\max$ & 27,0 & 28,0 & 18,0 & 20,0 & 25,0 \\
\hline & med & 16,3 & 17,1 & 12,4 & 15,6 & 19,7 \\
\hline & $\min$ & 8,0 & 10,0 & 10,0 & 10,0 & 16,0 \\
\hline \multirow{3}{*}{ Cob. $E_{1}(>4,0 \mathrm{~m})(\%)$} & $\max$ & 100,0 & 100,0 & 100,0 & 100,0 & 100,0 \\
\hline & med & 94,8 & 96,4 & 84,6 & 92,8 & 92,5 \\
\hline & $\min$ & 60,0 & 70,0 & 70,0 & 90,0 & 80,0 \\
\hline \multirow{3}{*}{ Cob. $E_{2}(1,5-4,0 \mathrm{~m})(\%)$} & $\max$ & 70,0 & 70,0 & 60,0 & 40,0 & 70,0 \\
\hline & med & 24,1 & 28,7 & 24,5 & 20,7 & 40,0 \\
\hline & $\min$ & 5,0 & 10,0 & 5,0 & 5,0 & 10,0 \\
\hline \multirow{3}{*}{ Cob. $E_{3}(<1,5 \mathrm{~m})(\%)$} & $\max$ & 100,0 & 100,0 & 100,0 & 90,0 & 100,0 \\
\hline & med & 81,4 & 77,4 & 77,1 & 73,9 & 93,3 \\
\hline & $\min$ & 20,0 & 10,0 & 50,0 & 50,0 & 80,0 \\
\hline \multirow{3}{*}{$N^{\circ}$ taxóns } & $\max$ & 41 & 44 & 36 & 31 & 21 \\
\hline & med & 23 & 28 & 23 & 25 & 16 \\
\hline & $\min$ & 11 & 15 & 18 & 20 & 10 \\
\hline \multirow{3}{*}{ \% compañeiras } & $\max$ & 53 & 47 & 60 & 58 & 48 \\
\hline & med & 29 & 27 & 48 & 49 & 34 \\
\hline & $\min$ & 14 & 10 & 26 & 36 & 20 \\
\hline \multirow{3}{*}{$N^{\circ}$ neófitos } & $\max$ & 1 & 1 & 1 & 1 & 1 \\
\hline & med & 0 & 0 & 0 & 0 & 0 \\
\hline & $\min$ & 0 & 0 & 0 & 0 & 0 \\
\hline
\end{tabular}

Táboa 8.- Caracterización estrutural (valores de altura dominante e cobertura por estratos) e valoración florística dos bosques estudiados. Acrónimos das comunidades como na táboa 1 , salvo SA: "bosques sen adscrición fitosociolóxica". Entre paréntese indícase o número de mostras de cada tipo de bosque
Esta subasociación diferenciase da típica pola presenza dun longo conxunto de especies de carácter termófilo (Arbutus unedo, Asplenium onopteris, Clematis vitalba, Daphne gnidium, Davallia canariensis, Laurus nobilis, Rubia peregrina, Ruscus aculeatus, Smilax aspera e Tamus communis), moitas das cales se comparten coa asociación Rusco aculeati-Quercetum roboris, de distribución maioritaria polas áreas termotemperadas e mesotemperadas inferiores dos territorios galaicoportugueses.

As riquezas específicas media e máxima destes bosques (29 e 44 taxóns respectivamente) son superiores ás da subasociación típica e tamén o é o número de compañeiras que adoitan aparecer en cada inventario; non obstante, a proporción destas fronte ao total tende a ser inferior (táboa 7). No relativo a especies introducidas, nas mostras estudiadas desta subasociación somentes aparecen Pinus pinaster e Prunus laurocerasus, este último en maior número de inventarios.

Dentro desta unidade fitosociolóxica distínguense, como no caso da subasociación típica, una variante típica e outra mesotrofa, diferenciable da primeira pola presenza de taxóns máis esixentes en nutrientes, como Acer pseudoplatanus, Carex sylvatica, Fraxinus excelsior, Hypericum androsaemum, Lysimachia nemorum, Mercurialis perennis, Milium effusum, Polystichum setiferum, Potentilla sterilis, Primula acaulis, Prunus avium, Pulmonaria longifolia, Ranunculus tuberosus, Sanicula europaea ou Ulmus glabra. Como no caso anterior, esta variante medra nos enclaves de solos ácidos máis ricos en nutrientes dentro do ámbito dos carballais estudiados, sendo o tipo de bosque que se conforma nos lugares de contacto entre os carballais galaico-asturianos e os bosques mixtos de ladeiras abruptas e barrancos existentes nas áreas máis térmicas do territorio estudiado.

A presenza de Quercus pyrenaica en situacións soalleiras permite recoñecer, como no caso dos carballais galaico asturianos típicos, unha facies heliófila.

c) Carballais galaico-portugueses termófilos (Rusco aculeati-Quercetum roboris, $R-Q v, R-Q q$ )

As características ambientais e florísticas deste grupo de carballais amósanse nas figuras $6 a$ e $6 \mathrm{~b}$ e nas táboas 8 e
11. Un total de 14 inventarios, distribuidos por áreas próximas ao litoral entre as cuncas baixas dos ríos Mandeo e Ouro, considéranse incluídos na asociación Rusco aculeati-Quercetum roboris, pois carecen das especies higro-esciófilas que caracterizan á asociación BlechnoQuercetum roboris. Tres deles conteñen especies (Arbutus unedo, Daphne gnidium, Rubia peregrina) que se consideran diferenciais da subasociación de máis marcado carácter termófilo desta asociación (subas. quercetosum suberis) mentras que o resto pertencería á subasociación típica (subas. violetosum rivinianae).

En conxunto, son bosques de menor talla que os pertenecentes á asociación Blechno-Quercetum roboris (10-18 m, media de $12,4 \mathrm{~m}$ ), con cobertura no estrato superior que oscila entre o 70 e o $100 \%$ e entre o 50 e o $100 \%$ no inferior. Sitúanse maioritariamente en partes altas de vertentes fortemente insoladas (orientacións SE a SW) e de elevada inclinación $\left(10-40^{\circ}\right.$, promedio de $\left.27^{\circ}\right)$, sobre solos relativamente evolucionados (cambisoles) derivados principalmente de "alternancia de rochas silíceas metamorfizadas".

A diferenza dos bosques dominantes no territorio, Quercus robur adoita compartir o dosel con Quercus pyrenaica, Laurus nobilis e Castanea sativa, perdendo peso neste estrato superior Ilex aquifolium, Corylus avellana e Betula pubescens. Faltan por completo nestes bosques Acer pseudoplatanus, Fagus sylvatica, Fraxinus excelsior, Prunus avium, Quercus petraea, Quercus x rosacea, Sorbus aucuparia, Taxus baccata e Ulmus glabra, sendo escasos Castanea sativa, Betula pubescens e Corylus avellana. Por baixo das árbores dominantes mantéñense Pyrus cordata, Frangula alnus e Ulex europaeus, observándose unha notable reducción de Arbutus unedo e da uz blanca (Erica arborea). No estrato inferior predominan as herbas heliófilas (Pseudarrhenatherum longifolium, Pteridium aquilinum, Asphodelus sp., Digitalis purpurea) xunto a matas baixas (Daboecia cantabrica, Erica cinerea) e algunhas especies nemorais relativamente tolerantes á luz (Teucrium scorodonia, Physospermum cornubiense, Viola riviniana). Pinus pinaster é a única especie introducida que aparece nas mostras estudiadas deste tipo de bosque. 
Características e diferenciais (*) de Blechno spicant-Quercetum roboris

Quercus robur

Vaccinium myrtillus

Hedera hibernica

Blechnum spicant *

Ilex aquifolium

Holcus mollis

Teucrium scorodonia

Avenella flexuosa

Lonicera periclymenum

Oxalis acetosella *

Sorbus aucuparia *

Corylus avellana

Dryopteris dilatata *

Saxifraga spathularis *

Dryopteris affinis

Dryopteris aemula *

Polygonatum verticillatum *

Polypodium vulgare

Castanea sativa

Erica mackaiana *

Osmunda regalis *

Lastrea limbosperma *

Athyrium filix-femina *

Luzula henriquesii *

Quercus x rosacea

Quercus petraea

Dryopteris filix-mas

Características de

Caracteristicas de Quercetalia roboris

Melampyrum pratense

Hypericum pulchrum

Arenaria montana

$\begin{array}{llllllllllllllllllllllllllllllllllllllllll}4 & 5 & 5 & 5 & 5 & 5 & 4 & 4 & 4 & 5 & 5 & 4 & 4 & 5 & 5 & 5 & 4 & 5 & 5 & 4 & 4 & 4 & 5 & 4 & 5 & 2 & 5 & 5 & 5 & 5 & 5 & 5 & 5 & 5 & 5 & 4 & 5 & 5 & 5 & 5 & 4 & 5\end{array}$

$\begin{array}{lllllllllllllllllllllllllllllllllllllllllll}3 & 1 & 2 & 4 & 4 & 4 & 2 & 2 & 3 & 3 & 2 & 2 & 2 & 4 & 1 & 4 & 2 & 3 & 4 & 1 & 2 & \cdot & 1 & 3 & \cdot & 4 & 3 & 5 & 3 & 2 & 3 & 2 & 1 & 2 & 4 & 3 & 4 & 3 & 3 & 2 & 1 & 3\end{array}$

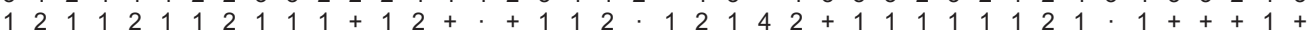

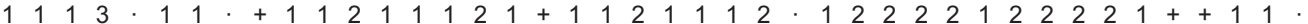

1. $221+111++1311 \mathrm{r} 1++.1231131+.1322223+2 .+$

$11 \cdot \cdot \cdot 21+22+2222+\cdot 222221+\cdot 22212212+31131$

$11 \cdot \cdot \cdot 11 \cdot \cdot \cdot 1++\cdot 1 \cdot 1 \cdot 2 \cdot+11+\cdot+22++22121+1 \mathrm{r} 1 \mathrm{r}+$

$\cdot 12++43 \cdot 1+111 \cdot 4242 \cdot 22 \cdot 32 \cdot \cdot 21113+4211$

$2 \cdot 12 \cdot \cdot 1+1 \cdot 111++1 \cdot+2 \cdot 21211 \cdot \cdot \cdot++++1211++42$.

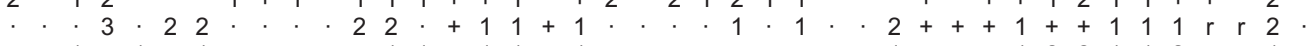

. $1 \cdot 1 \cdot 1 \cdot \cdot \cdot+11+11 \cdot 1 \cdot+\cdot++\cdot++1+\cdot \cdot 122112+\cdot 1$

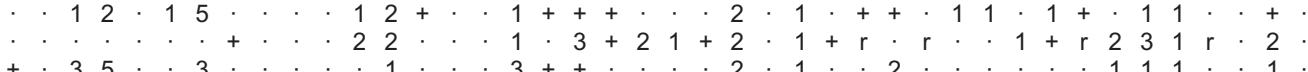
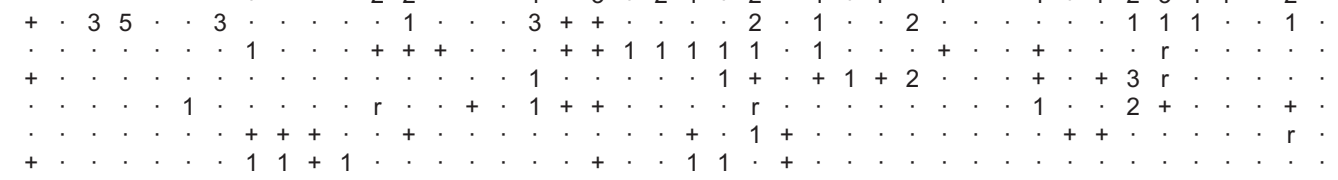

Características de Querco-Fagetea

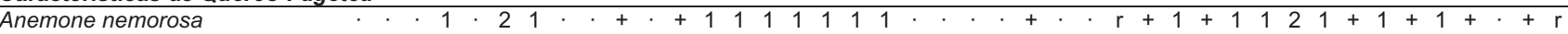

Stellaria holostea

Betula pubescens

Solidago virgaurea

Euphorbia dulcis

Hyacinthoides non-scripta

Compañeiras

Pteridum aquilinum

Erica arborea

Frangula alnus

Rubus sp.

Pyrus cordata

Asphodelus sp.

Daboecia cantabrica

Galium saxatile

Avenula sulcata

Agrostis capillaris

Potentilla erecta

Anthoxanthum amarum

Polygonatum odoratum

Festuca ovina

Rumex acetosa

Pseudoarrhenatherum longifolium

Agrostis curtisii

Omphalodes nitida

Digitalis purpurea

Carex pilulifera

Agrostis stolonifera

\begin{tabular}{|c|c|c|c|c|c|c|c|c|c|c|c|c|c|c|c|c|c|c|c|c|c|c|c|c|c|c|c|c|c|c|c|c|c|c|c|}
\hline & 1 & 2 & 21 & - & - & + & + & +1 & 1 & 1 & 1 & 1 & 1 & 1 & & & & & + & . & & $r+$ & 1 & + & 1 & 1 & 2 & 1 & + & 1 & + & 1 & + & + & \\
\hline & 2 & - & - 1 & 1 & . & . & . 1 & 11 & . & - & + & 1 & + & 1 & . & 2 & 1 & & 1 & . & . & · & + & + & + & + & 2 & 1 & 1 & + & + & & + & +1 & \\
\hline 1 & . 1 & . & 1 & 3 & 3 & 1 & + & +2 & ' & 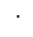 & . & 2 & . & + & 2 & 3 & 2 & 1 & 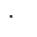 & 1 & 2 & · 1 & 1 & + & 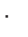 & . & . & . & 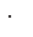 & 2 & 1 & . & . & 3 & \\
\hline$\cdot$ & . . & . & · 1 & 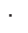 & $\cdot$ & $\cdot$ & . & . $\quad+$ & . & . & . & 1 & . & . & $\cdot$ & . & $\cdot$ & . & . & $\cdot$ & · & . & $\cdot$ & 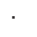 & . & . & . & . & & 1 & . & . & . & . & \\
\hline & . & . & . & . & . & . & . & $\cdot+$ & . & + & . & . & . & + & & " & . & $\cdot$ & - & . & & . & . & & . & & . & . & . & & . & . & & $r$ & \\
\hline
\end{tabular}

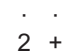

1
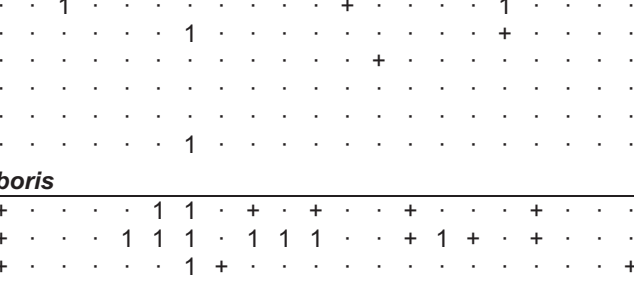


\begin{tabular}{|c|c|c|c|c|c|c|c|c|c|c|c|c|c|c|c|c|c|c|c|c|c|c|c|c|c|c|c|c|c|c|c|c|c|c|c|c|c|c|c|}
\hline \multicolumn{40}{|c|}{ Características e diferenciais (*) de Blechno spicant-Quercetum roboris } \\
\hline Hedera hibernica & + & 1 & + & 3 & 1 & + & 3 & 3 & 4 & 4 & 3 & 2 & 1 & 1 & 3 & & + & 1 & 2 & + & 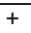 & + & T & 1 & + & + & 3 & 2 & 1 & 2 & 1 & 1 & 1 & 1 & 2 & 1 & 3 & & \\
\hline Quercus robur & 4 & 5 & 5 & 2 & 5 & 5 & 5 & 5 & 4 & 4 & 4 & 4 & 1 & 2 & 3 & 4 & 4 & 1 & 5 & 5 & 5 & 4 & 5 & 5 & 2 & 3 & 5 & 5 & 5 & 5 & 4 & & 4 & 1 & 4 & 1 & 4 & 3 & . \\
\hline Vaccinium myrtillus & 4 & 4 & 4 & 3 & + & 3 & + & 2 & + & 2 & 3 & 3 & 3 & 5 & 3 & 1 & 3 & 1 & 2 & 2 & 1 & 3 & 2 & 5 & 1 & 2 & 1 & 2 & 4 & 1 & + & 3 & 1 & 1 & 1 & 1 & 3 & + & . \\
\hline Holc & + & 1 & 1 & 2 & + & 2 & 3 & 1 & 1 & + & 1 & + & 1 & $\cdot$ & + & 1 & + & + & 1 & 1 & 1 & . & $\cdot$ & + & + & 1 & 3 & 1 & + & 1 & 2 & 2 & 1 & + & + & 1 & 1 & & 2 \\
\hline ant & + & & 2 & 3 & 3 & 2 & + & 4 & + & 1 & 4 & 1 & + & 1 & 3 & 1 & 1 & + & 2 & + & & $\cdot$ & + & + & 2 & + & 1 & 2 & . & + & $\cdot$ & $\cdot$ & . & $\cdot$ & + & + & 2 & 2 & + \\
\hline & . & 1 & 2 & 1 & 1 & 2 & 1 & 2 & + & 2 & & 1 & 1 & 2 & 3 & 3 & 1 & 1 & 2 & & + & + &. & . & + & 1 & 1 & 1 & 1 & 1 & 1 & . & 2 & . & 2 & + & 1 & 1 & 1 \\
\hline yme & 2 & . & . & 1 & . & + & 2 & 2 & 1 & 2 & 1 & + & 2 & + & 1 & + & 1 & 1 & 2 & & + & + & . & + & + & . & 1 & + & . & 1 & + & 1 & + & . & 1 & 1 & 2 & 1 & 4 \\
\hline sa & 2 & . & . & 1 & $r$ & 1 & + & 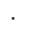 & . & 3 & 1 & 4 & 2 & 1 & 1 & 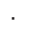 & 3 & 1 & 4 & 3 & 4 & 3 & . & 2 & 1 & . & . & 2 & + & + & $r$ & 2 & 3 & 1 & 1 & . & & + & + \\
\hline ria * & 1 & 1 & $r$ & (1) & . & + & & . & 1 & 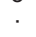 & + & 1 & 1 & 1 & + & + & + & 2 & . & 1 & 1 & 1 & + & 1 & & + & & 2 & $r$ & 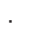 & . & 1 & 1 & 1 & . & 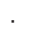 & . & & . \\
\hline Teu & . & + & 1 & + & 1 & 1 & + & . & $\cdot$ & $\cdot$ & + & $\cdot$ & $\cdot$ & . & 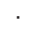 & . & $\cdot$ & $\cdot$ & . & 1 & 1 & . & $\cdot$ & + & $r$ & 1 & 2 & 1 & . & + & 1 & 1 & + & + & 1 & $\cdot$ & 1 & + & + \\
\hline ta & 3 & $\cdot$ & . & 1 & $\cdot$ & . & + & . & + & 3 & 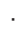 & 1 & 4 & 1 & 3 & 1 & + & + & 3 & 2 & & 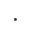 & $\cdot$ & . & + & + & + & + & . & & . & 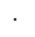 & + & . & . & $\cdot$ & 2 & + & · \\
\hline gare & + & $\cdot$ & . & . & $\cdot$ & $\cdot$ & 1 & + & + & 1 & 1 & . & 1 & 1 & . & + & + & + & + & . & + & . & . & . & . & + & + & . & . & . & . & $\cdot$ & 1 & + & . & + & 1 & 1 & \\
\hline is & + & $\cdot$ & . & + & $\cdot$ & + & 1 & . & + & $\cdot$ & . & + & $\cdot$ & $\cdot$ & . & 1 & + & $r$ & 1 & 1 & 1 & $\cdot$ & $\cdot$ & . & + & 1 & . & . & . & . & . & . & + & $\cdot$ & . & + & + & 1 & . \\
\hline Cas & $\cdot$ & $\cdot$ & . & . & . & $\cdot$ & 1 & 2 & 2 & 2 & $\cdot$ & . & 1 & $\cdot$ & $\cdot$ & 1 & 2 & 1 & . & $\cdot$ & $\cdot$ & $\cdot$ & 1 & . & 1 & $\cdot$ & 1 & . & . & . & . & . & . & $\cdot$ & 1 & 1 & 1 & 2 & 3 \\
\hline Cor & 2 & + & + & 2 & 2 & $\cdot$ & . & 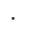 & $\cdot$ & 1 & + & . & . & $\cdot$ & 3 & & $r$ & . & 1 & 1 & . & $\cdot$ & $\cdot$ & 1 & 1 & 1 & . & + & . & . & . & . & . & . & $\cdot$ & $\cdot$ & . & 1 & . \\
\hline hular & 1 & $\cdot$ & . & + & . & $\cdot$ & . & . & $\cdot$ & . & + & 1 & 1 & + & + & & . & + & 1 & 1 & + & 1 & $\cdot$ & . & 1 & & . & 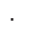 & . & . & . & . & . & . & . & . & . & 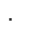 & . \\
\hline ea & . & . & . & 2 & . & . & 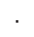 & . &. & 2 & 2 & 1 & 4 & 3 & 3 & 2 & . & 3 & . & 1 & & . & . & . & . & 3 & & & . & . & . & & . & . & . & . & . & & \\
\hline sii * & 1 & . & . & . & . & $\cdot$ & . & - & . & 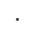 & 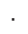 & 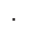 & 1 & . & 1 & & . & + & 1 & . & 1 & 1 & 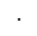 & . & + & + & & & . & 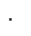 & & & . & . & . & . & 1 & & \\
\hline $1 / a$ * & . & $\cdot$ & . & + & $r$ & + & 1 & . & $\cdot$ & 2 & + & . & $\cdot$ & $\cdot$ & 1 & & $\cdot$ & $\cdot$ & 2 & $\cdot$ & &  & $\cdot$ & . & 1 & & & - & . & . & $\cdot$ & 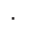 & . & . & . & $\cdot$ & & & \\
\hline Fag & $\cdot$ & $\cdot$ & . & . & . & $\cdot$ & . & . & 3 & . & . & . & $\cdot$ & $\cdot$ & 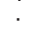 & 2 & 1 & 1 & 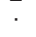 & $\cdot$ & . & . & $\cdot$ & . & 3 & 1 & . & - & . & . & . & . & . & . & 1 & . & . & 1 & \\
\hline vertici & . & 1 & $r$ & + & . & + & . & . & . & + & . & . & . & . & . & 2 & . & . & . & + & 1 & $\cdot$ & $\cdot$ & . & . & 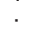 & & + & . & . & . & . & . & . & . & . & . & & \\
\hline ea & $\cdot$ & $\cdot$ & . & 3 & . & $\cdot$ & . & . & $\cdot$ & $\cdot$ & $\cdot$ & 1 & 1 & 4 & 2 & 1 & . & . & . & $\cdot$ & $\cdot$ & $\cdot$ & $\cdot$ & . & 2 & $\cdot$ & . & - & . & $\cdot$ & . & . & $\cdot$ & $\cdot$ & . & $\cdot$ & . & 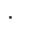 & . \\
\hline רula * & . & $\cdot$ & . & 1 & . & . & . & . & $\cdot$ & $\cdot$ & . & 1 & . & + & 1 & & . & . & . & . & . & . & . & - & 2 & $\cdot$ & . & & . & . & . & . & . & . & . & . & . & & \\
\hline רa * & . & $\cdot$ & + & . & . & $\cdot$ & . & . & $\cdot$ & $\cdot$ & + & . & . & + & . & . & . & . & $\cdot$ & $\cdot$ & . & . & 1 & $r$ & & . & . & & . & . & . & - & . & . & . & $\cdot$ & & & \\
\hline erm & . & . & . & 1 & . & + & 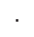 & . & $\cdot$ & $\cdot$ & . & . & . & $\cdot$ & 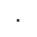 & . & . & . & 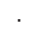 & . & & 1 & . & & 2 & $\cdot$ & . & & . & . & . & - & . & . & . & . & & & \\
\hline mina & . & . & . & . & . & . & . & - & . & . & + & & . & . & 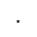 & + & . & . &  & . & & 1 & 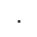 & . & 2 & . & . & . & . & . & . & . & - & . & . & . & & & \\
\hline galis * & + & . & . & + & $\cdot$ & . & 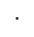 & . & $\cdot$ & $\cdot$ & . & + & . & · & $\cdot$ & $\cdot$ & . & . & $\cdot$ & . & $\cdot$ & $\cdot$ & $\cdot$ & 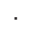 & 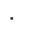 & $\cdot$ & . & $\cdot$ & . & $\cdot$ & $\cdot$ & $\cdot$ & $\cdot$ & $\cdot$ & $\cdot$ & $\cdot$ & . & & \\
\hline Dryopte & $\cdot$ & $\cdot$ & . & . & . & . & 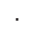 & . & + & 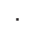 & . & 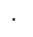 & . & $\cdot$ & 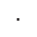 & ${ }^{\circ}$ & . & . & . & $\cdot$ & . & . & $\cdot$ & . & + & 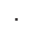 & & & . & . & . & . & . & . & . & . & . & . & \\
\hline Cytisus commutatus * & . & $\cdot$ & & & . & & & & & & & & . & & & & . & & & . & & . & & & & & & & & & & & & & & & & & \\
\hline
\end{tabular}

Diferenciais facies heliófila

Quercus pyrenaica

Quercus $x$ andegavensis

Características de Quercetalia roboris

Physospermum cornubiense

Arenaria montana

Melampyrum pratense

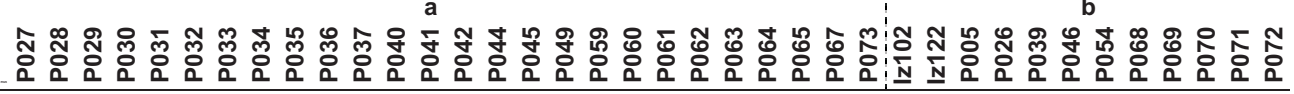

Características de Querco-Fagetea

Stellaria holostea

Anemone nemorosa

Betula pubescens

Viola riviniana

Euphorbia dulcis

Solidago virgaurea

Ajuga reptans

Hyacinthoides non-scripta

Compañeiras

Erica arborea

Rubus sp.

Pteridum aquilinum

Frangula alnus

Pyrus cordata

Daboecia cantabrica

Asphodelus sp.

Ulex gallii

Carex pilulifera

Pseudoarrhenatherum longifolium

Agrostis capillaris

Ulex europaeus

Potentilla erecta

Erica vagans

Avenula sulcata

Rumex acetosa

Brachypodium rupestre

Umbilicus rupestris

Agrostis curtisii

Galium saxatile

Carex cf. caryophyllea

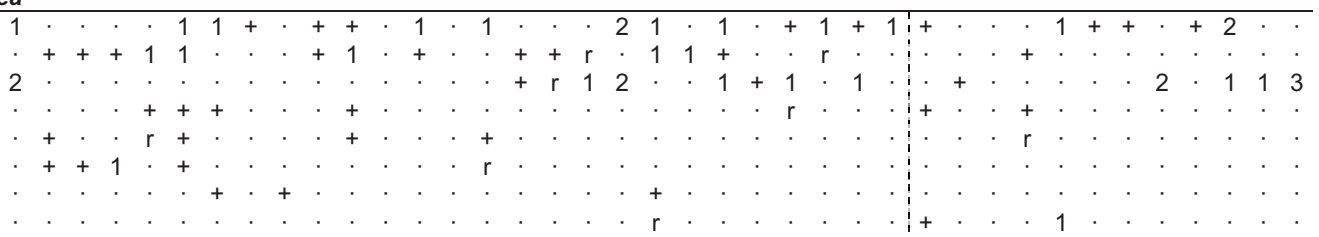

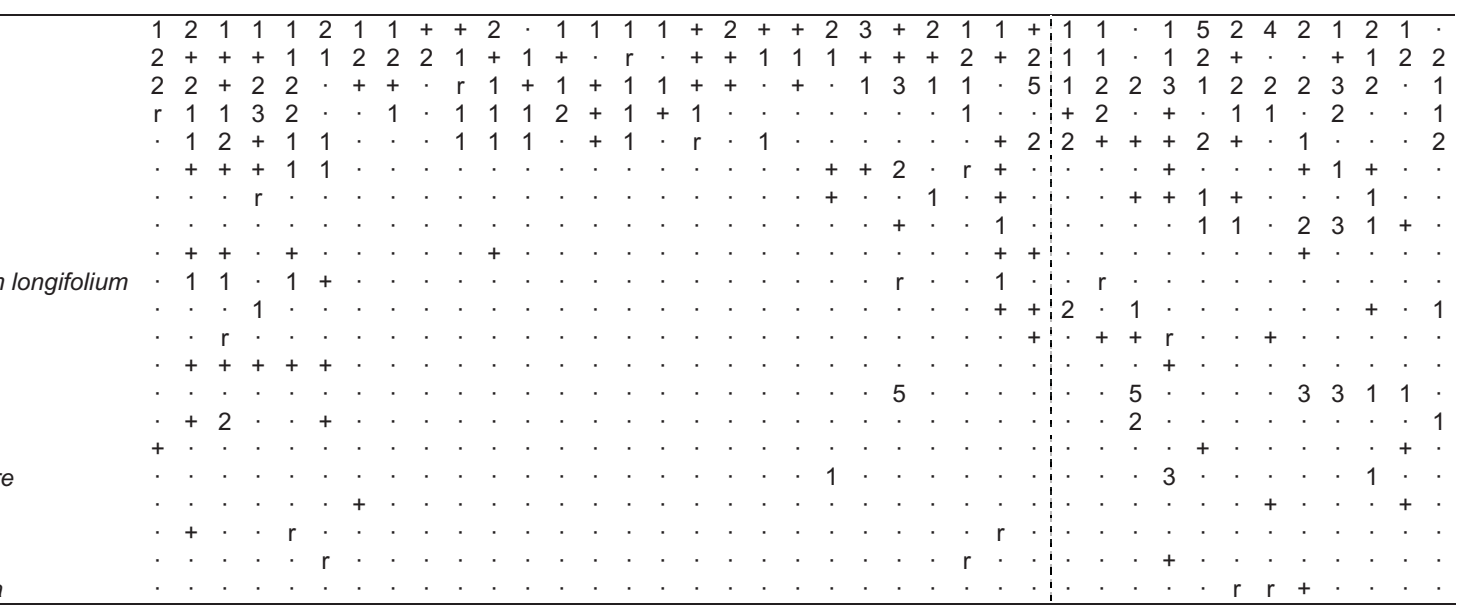

Táboa 9b.- Blechno spicant-Quercetum roboris subas. dryopteridetosum aemulae variante típica, a: facies típica, b: facies heliófila de Quercus pyrenaica 
a

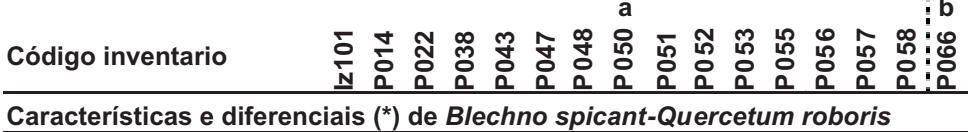

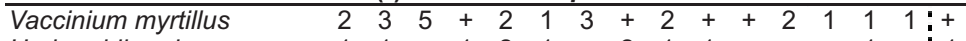

Hedera hibernica $\quad 11+121+211+++1.1$

$\begin{array}{llllllllllllllll:l}\text { Quercus robur } & 5 & 5 & 5 & 4 & 5 & 4 & 4 & 5 & 3 & 4 & . & . & 2 & 2 & 1 & 4\end{array}$

Lonicera periclymenum $++r+.11++11+\cdot 11+$

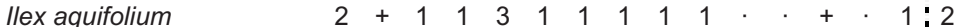

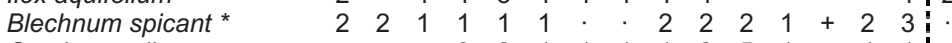

$\begin{array}{llllllllllllllll:l}\text { Corylus avellana } & \cdot & + & \cdot & 3 & 2 & 1 & 1 & 1 & 1 & 2 & 5 & 1 & \cdot & 4 & 1\end{array}$

Holcus mollis $\quad 1 \cdot 12+$. $12+1+1+1 \cdot 1+$

Saxifraga spathularis * $\quad 4.5+1+1+12+2++$.

Dryopteris affinis $\quad 1 \cdot{ }^{\circ} \cdot+11+11+231$

Avenella flexuosa $\quad 21++1 \cdot \cdot \cdot+1 \cdot 12+r$.

Dryopteris dilatata * $\quad+\quad+1 \mathrm{r} 2 \cdot . \quad \cdot 121+$.

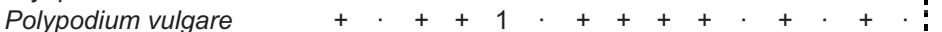

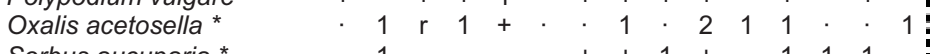

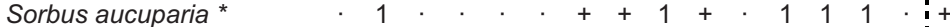

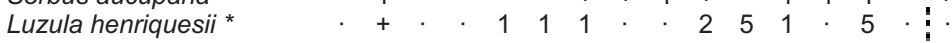

Teucrium scorodonia $\quad 1 \cdot++\cdot \cdot \cdot+1+1 \cdot+\cdot$

$131 \cdot \cdot \cdot 3 \cdot 3$

Castanea sativa $. \quad . \quad \cdot 3 \cdot+\cdot 3 \cdot 1+21$

Athyrium filix-femina *.$+ \quad$. . . . . $1 .+21 .+4$

Quercus x rosacea . . . . . . $132.4 \quad 34$

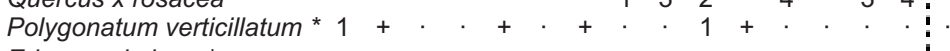

Erica mackaiana * . . . $r+.+r .4 .+.+$.



Dryopteris filix-mas

Dryopteris aemula *

Diferenciais de variante mesotrofa

Acer pseudoplatanus

Ranunculus tuberosus

Mercurialis perennis

Pulmonaria longifolia

Polystichum setiferum

Sanicula europaea

Primula acaulis

Scrophularia alpestris

Ulmus glabra

Fraxinus excelsior

Carex sylvatica

Prunus avium

Conopodium majus

Hypericum androsaemum

Diferencial facies heliófila

Quercus pyrenaica

Características de Querco-Fagetea

Stellaria holostea

Anemone nemorosa

Euphorbia dulcis

Betula pubescens

Hyacinthoides non-scripta

Ajuga reptans

Taxus baccata

Viola riviniana

Compañeiras

Rubus sp.

Erica arborea

Omphalodes nitida

Pteridum aquilinum

Frangula alnus

Asphodelus sp.

Pyrus cordata

Valeriana montana

Polygonatum odoratum

Brachypodium sylvaticum

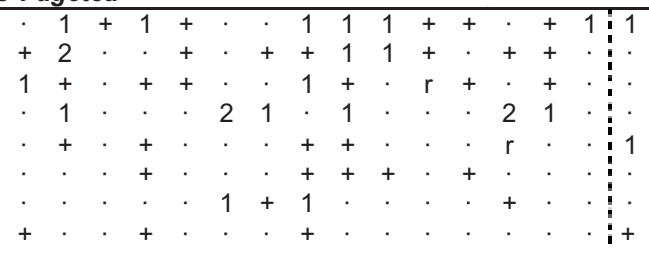

Táboa 9c.- Blechno spicant-Quercetum roboris subas. dryopteridetosum aemulae variante mesotrofa, a: facies típica, b: facies heliófila de Quercus pyrenaica 
A xulgar pola composición florística que presentan algúns dos inventarios desta categoría, e seguindo un razoamento análogo ao exposto para a asociación maioritaria de carballais do territorio, cabería diferenciar unha variante mesotrofa dentro de amba-las dúas subasociacións recoñecidas, evidenciable pola aparición de certas especies esixentes en nutrientes, como Lysimachia nemorum, Mercurialis perennis, Prunus avium ou Ranunculus tuberosus (táboa 11).

d) Reboleiras meso-termófilas con carballo (Lonicero periclymeni-Quercetum pyrenaicae, $L-Q$ ).

As características ambientais e florísticas deste grupo de carballais amósanse nas figuras $6 a$ e $6 \mathrm{~b}$ e nas táboas 8 e 11. Trátase de bosques pauciespecíficos no estrato superior, polo xeral dominados por Quercus pyrenaica e Castanea sativa, con presenza puntual doutras árbores, como Betula pubescens, Quercus robur ou Taxus baccata. Medran en áreas alonxadas da costa, relativamente continentalizadas e con menor influencia da nubosidade no verán. As mostras que se posúen desta asociación dentro da área de estudo amosan unha escasa presenza de acibo (Ilex aquifolium), abelaira (Corylus avellana), sanguiño (Frangula alnus) e espiñeiro (Crataegus monogyna) e carecen de especies higro-esciófilas e da práctica totalidade de termófitos que caracterizan aos anteriores tipos de bosques comentados, dos que se exceptúa Ruscus aculeatus. No nivel intermedio únicamente Pyrus cordata se mantén cunha constancia elevada.

Son bosques de talla variable $(10-20 \mathrm{~m})$, asentados sobre vertentes empinadas $\left(20-36^{\circ}\right)$ e solos pouco desenvolvidos (leptosoles) procedentes, principalmente, da alteración de lousas ou sedimentos cenozoicos. Aínda que a cobertura acadada polo nivel de copas é elevada (90-100\%), a foliación tardía do rebolo posibilita a pervivencia no seu sotobosque dun elevado número de especies típicas das matogueiras e formacións herbáceas do entorno, como Asphodelus sp., Brachypodium rupestre, Cirsium filipendulum, Cytisus scoparius, Daboecia cantabrica, Erica arborea, Lithodora prostrata, Omphalodes nitida, Potentilla erecta, Pseudarrhenatherum longifolium, Pteridum aquilinum, Rubus sp., Simethis planifolia ou Ulex europaeus. Xeralmente, estas especies acompañantes chegan a superar ao conxunto de especies de carácter nemoral, entre as que se poden sinalar Anemone nemorosa, Arenaria montana, Dryopteris affinis, Euphorbia dulcis, Hedera hibernica, Holcus mollis, Hypericum pulchrum, Melampyrum pratense, Physospermum cornubiense, Stellaria holostea, Teucrium scorodonia e Viola riviniana. A única especie de plantas vasculares alóctona que se ten observado neste tipo de bosque é Prunus lurocerasus.

e) Carballais pendentes de adscripción fitosociolóxica (SA).

Carballais situados no pedemonte meridional das serras que delimitan a cunca alta do Río Miño. As súas características ambientais e florísticas amósanse nas figuras $6 a$ e 6 b e nas táboas 8 e 11. Trátase de bosques de altura dominante comprendida entre os 16 e $25 \mathrm{~m}$, dominados polo carballo (Quercus robur), nos que adoitan estar presentes o castiñeiro, abidueiro e o acibo e, puntualmente, Corylus avellana ou Quercus pyrenaica. Carecen de especies termófilas e higro-esciófitos e son raros ou están ausentes moitos dos arbustos que caracterizan o sotobosque das comunidades comentadas nos apartados precedentes (táboa 11). Tamén se observa neles unha riqueza florística máis reducida (media de 16 taxóns) que contrasta cos elevados valores medios de cobertura que neles acadan os estratos medio e inferior (táboa 8). Entre as especies arbustivas presentes destacan Erica arborea, Daboecia cantabrica, Ulex europaeus e Genista florida. No nivel inferior predominan as silvas, o fulgueiro (Pteridium aquilinum) e diversas herbas de ampla distribución, algunhas das cales teñen un caracter máis ou menos edafo-higrófilo (Angelica major, Avenula sulcata, Deschampsia cespitosa subsp. subtriflora). Prunus laurocerasus é o único neófito rexistrado neste tipo de carballais.

As características xerais destes bosques os achegan aos descritos por Dalda (1972) na cercana cunca do Río Deo e poderían deberse as especiais condicións bioclimáticas e topo-edáficas que caracterizan á Terra Chá luguesa e as terras altas coruñesas que se extenden entre Curtis, Sobrado dos Monxes e Ordes, áreas cunha continentalidade máis acusada e unha menor termicidade que nos seus respectivos contornos (Rodríguez Guitián \& Ramil Rego 2007) e nas que os solos tenden a presentar rasgos de gleyzación. A súa caracterización fitosociolóxica definitiva necesita da realización de estudos específicos máis pormenorizados.

f) Consideracións acerca doutras formacións arboradas relacionadas cos bosques estudados.

Antes de rematar este traballo, queremos facer algúns comentarios sobre os inventarios florísticos existentes en referencias biliográficas que non foron tidos en conta neste traballo polas causas comentadas no apartado metodolóxico, así como sobre algunhas mostras propias de bosques con características intermedias entre os carballais e os faiais.

Con respecto aos primeiros, estimamos que dous dos inventarios tomados por Bellot (1968) dentro da área de estudio aquí considerada e publicados baixo o nome de Alianza Quercion robori-petraeae (cuadro 17: invs. 11 e 14), presentan unha composición florística que permitiría a súa inclusión na asociación Blechno spicant-Quercetum roboris. En situación semellante se encontran a maior parte dos inventarios de Díaz González (1975), Izco et al. (1990) e Mayor \& Fernández (2007) non incluídos neste estudo, pois neles obsérvase a presenza, máis ou menos abundante, das especies utilizadas como diferenciais dos bosques da Blechno-Quercetum, se ben en moitos casos o dominio fisionómico corresponde ao bidueiro (Betula pubescens) ou - castiñeiro (Castanea sativa), en lugar dos carballos. Amigo \& Romero (1998) e Rivas-Martínez et al. (2002) interpretan que os bidueirais existentes nas áreas mesotemperadas da parte centro-occidental do territorio estudiado son bosques de carácter secundario, formados tras procesos deforestadores antrópicos (talas severas, recuperación da vexetación arborada tras incendio ou abandono de áreas de cultivo), que pertencen á asociación 
Código inventario

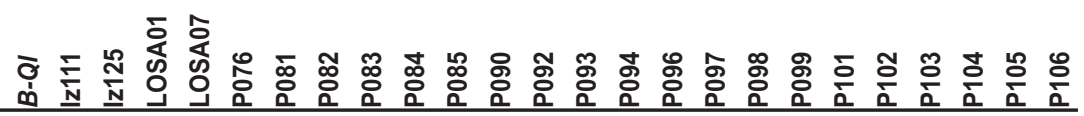

Características e diferenciais (*) de Blechno spicant-Quercetum roboris

Quercus robur

Hedera hibernica

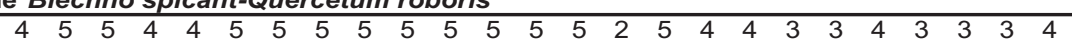

Holcus mollis

Lonicera periclymenum

Dryopteris affinis

Teucrium scorodonia

Ilex aquifolium

Castanea sativa

Blechnum spicant *

Dryopteris dilatata *

Vaccinium myrtillus

Corylus avellana

Polypodium vulgare

Saxifraga spathularis *

Oxalis acetosella *

Avenella flexuosa

Dryopteris aemula *

Luzula henriquesii *

Quercus x rosacea

Sorbus aucuparia *

Dryopteris filix-mas

Osmunda regalis *

Quercus petraea

Athyrium filix-femina *

Erica mackaiana *

Polygonatum verticillatum *

Cystopteris fagilis *

Woodwardia radicans

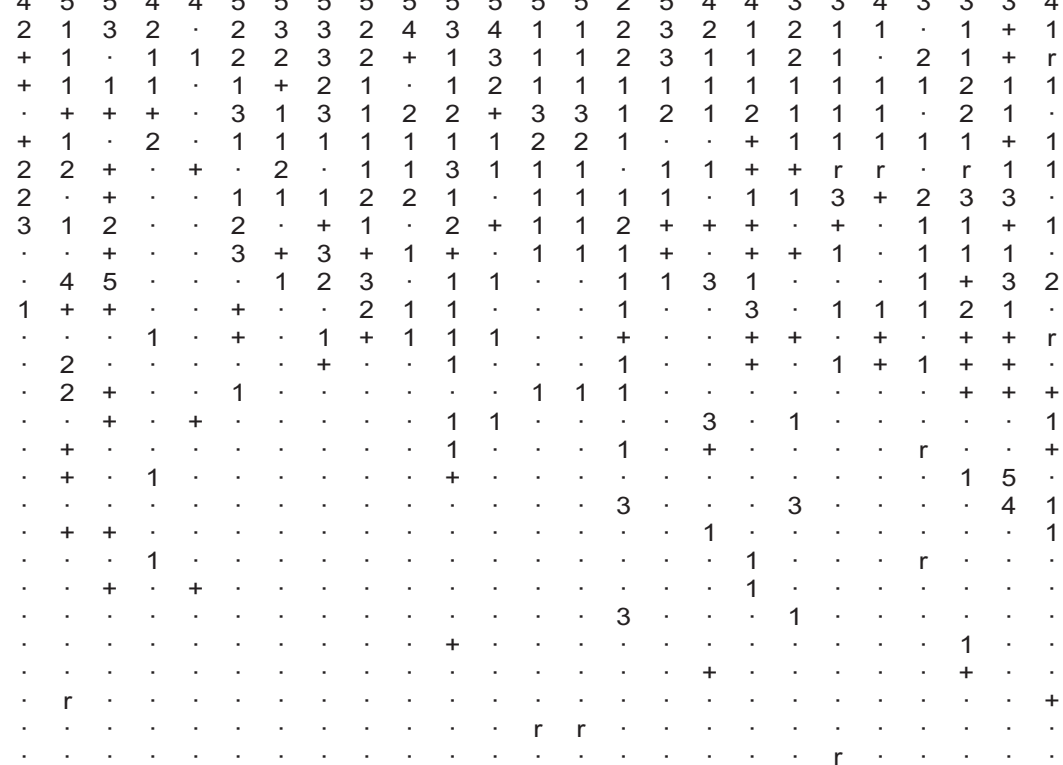

Diferenciais de subas. lauretosum nobilis

\begin{tabular}{|c|c|c|c|c|c|c|c|c|c|c|c|c|c|c|c|c|c|c|c|c|c|c|c|c|c|}
\hline Ruscus aculeatus & 1 & + & . & 1 & . & ?. & . & + & 1 & 1 & 1 & $\cdot$ & $\cdot$ & 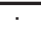 & $\cdot$ & . & + & + & + & 1 & 1 & $r$ & 1 & + & 1 \\
\hline Laurus nobilis & + & . & . & 1 & . & 1 & 2 & 2 & . & . & . & $r$ & 1 & 1 & 1 & 1 & $\cdot$ & $\cdot$ & + & . & + & . & . & . & . \\
\hline Arbutus unedo & 1 & . & 1 & . & . & . & . & . & 1 & . & . & . & $\cdot$ &  & . & . & 1 & . & . & 2 & 3 & . & . & 2 & 1 \\
\hline Rubia peregrina & 1 & . & . & 1 & . & . & . & . & . & . & . & . & . & . & . & . & . & . & . & . & . & . & . & + & . \\
\hline Asplenium onopteris & . & . & . & 1 & . & . & . & . & . & . & . & . & . & . & . & . & . & . & . & . & . & . & . & + & . \\
\hline Tamus communis & + & . & . & . & . & . & . & . & . & . & . & . & $\cdot$ & . & . & . & . & + & . & . & . & . & . & . & . \\
\hline Smilax aspera & . & $\cdot$ & . & $\cdot$ & 1 & . & $\cdot$ & . & $\cdot$ & . & . & . & $\cdot$ &. &. & . & . & . & . & . & . & . & . & . & . \\
\hline \multicolumn{26}{|c|}{ Características de Quercetalia roboris } \\
\hline Physospermum cornubiense & 1 & + & $\cdot$ & $\cdot$ & $\cdot$ & $r$ & $\cdot$ & $\cdot$ & $\cdot$ & ? & $\cdot$ & $\cdot$ & $\cdot$ & $\cdot$ & ${ }^{\circ}$ & $\cdot$ & $\cdot$ & + & $\cdot$ & 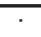 & $\cdot$ & 1 & $\cdot$ & + & $\cdot$ \\
\hline Hypericum pulchrum & + & . & . & . & . & . & . & . & . & . & . & . & 1 & 1 & . & . & . & 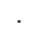 & . & 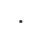 & . & . & $r$ & $r$ & + \\
\hline Melampyrum pratense & . & + & $r$ & $\cdot$ & . & . & $\cdot$ & . & . & . & . & . & $\cdot$ & 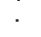 & . & . & . & . & . & . & . & . & . & . & $\cdot$ \\
\hline \multicolumn{26}{|l|}{ Características de Querco-Fagetea } \\
\hline Betula pubescens & $\cdot$ & $\cdot$ & + & $\cdot$ & $\cdot$ & 1 & $\cdot$ & 1 & $\cdot$ & $\cdot$ & 1 & + & 2 & 2 & 1 & 1 & 3 & $\cdot$ & 1 & 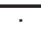 & $\cdot$ & 1 & 1 & $\cdot$ & + \\
\hline Stellari & . & 1 & $\cdot$ & 1 & . & . & . & 2 & . & 1 & . & . & 1 & 1 & . & . & . & . & . & . & . & $r$ & . & $r$ & + \\
\hline Viola riviniana & 1 & . & . & 2 & + & + & . & . & . & . & . & $r$ & 1 & 1 & . & . & . & + & . & . & . & . & + & . & . \\
\hline ne nemorosa & 1 & 1 & + & . & . & . & . & . & $\cdot$ & . & . & . & . & . & + & . & . & + & . & . & . & . & 1 & + & + \\
\hline Euphorbia dulcis & + & . & . & $\cdot$ & . & . & . & . & $\cdot$ & . & . & . & $\cdot$ & . & 1 & . & . & + & . & . & . & . & + & $r$ & $r$ \\
\hline Solidago virgaurea & . & $\cdot$ & . & $\cdot$ & . & . & $\cdot$ & . & $\cdot$ & $\cdot$ & . & . & $\cdot$ & . & 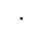 & . & . & . & . & . & . & 1 & + & $r$ & $r$ \\
\hline \multicolumn{26}{|l|}{ Compañeiras } \\
\hline Pteridum aquilinum & 1 & + & 1 & $\cdot$ & . & + & $\cdot$ & $\cdot$ & 2 & 1 & + & 2 & + & + & 1 & 2 & 3 & $\cdot$ & 1 & 2 & 2 & 1 & $\cdot$ & 1 & 3 \\
\hline Frangula alnus & $r$ & 1 & 2 & $\cdot$ & . & 1 & + & 1 & $\overline{1}$ & + & + & $\overline{1}$ & $\cdot$ & . & + & 1 & 2 & . & 1 & . & . & 1 & + & 1 & 1 \\
\hline Rubus sp. & + & . & . & + & 1 & + & $r$ & 1 & 1 & 1 & $\cdot$ & . & + & + & 1 & 1 & + & 1 & . & 2 & . & 1 & 1 & . & . \\
\hline Erica arborea & + & 1 & . & $\cdot$ & . & . & . & + & 2 & + & + & 1 & 2 & 2 & . & . & 1 & + & . & 2 & 2 & 1 & $\cdot$ & 1 & 2 \\
\hline Pyrus cordata & . & 1 & 1 & . & . & 1 & 2 & 1 & 2 & + & + & + & . & . & + & 1 & 1 & . & 2 & . & . & 1 & . & . & $\overline{1}$ \\
\hline Asphodelus sp. & . & $\cdot$ & . & 1 & 1 & 1 & 2 & 1 & . & 1 & . & . & $\cdot$ & . & 1 & · & + & $\cdot$ & + & $\cdot$ & . & 2 & + & $r$ & . \\
\hline Daboecia cantabrica & . & . & + & $\cdot$ & $\cdot$ & $\cdot$ & . & . & $\cdot$ & $\cdot$ & . & $r$ & 1 & 1 & $\cdot$ & 4 & 1 & $\cdot$ & 1 & 1 & 1 & . & $r$ & 1 & 2 \\
\hline Omphalo & + & + & . & . & . & + & . & . & . & 1 & . & . & + & + & + & . & . & 1 & $\cdot$ & . & + & . & $r$ & + & . \\
\hline Ulex & . & . & . & . & . & . & . & . & + & . & . & + & . & . & 1 & 1 & . & . & 1 & 1 & 1 & 2 & . & 1 & . \\
\hline Digitalis & . & $\cdot$ & . & 1 & $\cdot$ & + & $\cdot$ & . & $\cdot$ & . & . & . & $r$ & $r$ & . & . & . & $\cdot$ & $\cdot$ & $r$ & 1 & . & $\cdot$ & . & $r$ \\
\hline Lithodora prostrata & . & . & . & $\cdot$ & + & . & . & . & $\cdot$ & . & . & . & . & . & . & . & . & . & 1 & 1 & + & 2 & $\cdot$ & . & . \\
\hline Polygonatum odoratum & 1 & + & . & . & . & . & . & . & . & . & . & . & . & . & . & . & . & . & $\cdot$ & $\cdot$ & . & $\bar{r}$ & $\cdot$ & . & + \\
\hline Carex pilulifera & . & . & . & . & . & . & . & . & $\cdot$ & $\cdot$ & + & + & + & + & . & . & $\cdot$ & . & . & . & . & $\cdot$ & $\cdot$ & . & . \\
\hline Brachypodium rupestre & . & $\cdot$ & . & $\cdot$ & $\cdot$ & 1 & 1 & . & $\cdot$ & $\cdot$ & . & $\cdot$ & $\cdot$ & . & + & . & . & $\cdot$ & $\cdot$ & $\cdot$ & . & $\cdot$ & + & . & $\cdot$ \\
\hline Prunus laurocerasus & . & . & . & . & . & . & $\cdot$ & . & $\cdot$ & . & . & + & $r$ & r & . & 1 & . & $\cdot$ & $\cdot$ & $\cdot$ & . & $\cdot$ & $\cdot$ & . & . \\
\hline monogyna & . & . & . & . & . & . & . & . & . & 1 & . & . & . & . & . & . & . & + & . & . & . & . & + & . & . \\
\hline Brachypodium sylvaticum & . & . & . & 2 & . & . & . & . & . & . & . & . & . & . & . & . & . & . & + & . & . & 2 & . & . & . \\
\hline Pseudoarrhenatherum longifolium & . & . & . & . & . & 1 & . & . & . & . & . & . & . & . & . & . & . & . & 2 & . & . & $\bar{r}$ & . & . & . \\
\hline Umbilicus rupestris & . & . & . & . & . & 1 & $r$ & + & . & . & . & . & . & . & . & . & . & . & 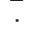 & . & . & . & . & . & . \\
\hline
\end{tabular}

Táboa 10a.- Blechno spicant-Quercetum roboris subas. lauretosum nobilis variante típica, facies típica 
Características e diferenciais (*) de Blechno spicant-Quercetum roboris

Quercus robur

Hedera hibernica

Dryopteris affinis

Lonicera periclymenum

Corylus avellana

Teucrium scorodonia

Holcus mollis

Blechnum spicant *

Ilex aquifolium

Polypodium vulgare

Castanea sativa

Oxalis acetosella *

Vaccinium myrtillus

Dryopteris dilatata *

Saxifraga spathularis *

Luzula henriquesii *

Avenella flexuosa

Quercus x rosacea

Athyrium filix-femina *

Quercus petraea

Polygonatum verticillatum *

Fagus sylvatica

Dryopteris filix-mas

Dryopteris aemula *

Sorbus aucuparia *

Erica mackaiana *

Lastrea limbosperma *

Woodwardia radicans *

Osmunda regalis *

Diferenciais de subas. lauretosum nobilis

Ruscus aculeatus

Laurus nobilis

Rubia peregrina

Asplenium onopteris

Tamus communis

Arbutus unedo

Davallia canariensis

Smilax aspera

Clematis vitalba

Diferenciais de variante mesotrofa

\section{Polystichum setiferum}

Ranunculus tuberosus

Acer pseudoplatanus

Brachypodium sylvaticum

Primula acaulis

Pulmonaria longifolia

Hypericum androsaemum

Mercurialis perennis

Sanicula europaea

Fraxinus excelsior

Carex sylvatica

Diferencial facies heliófila

Quercus pyrenaica

Características de Quercetalia roboris

Physospermum cornubiense

Hypericum pulchrum

Arenaria montana

Lathyrus linifolius

Melampyrum pratense

Hieracium umbellatum

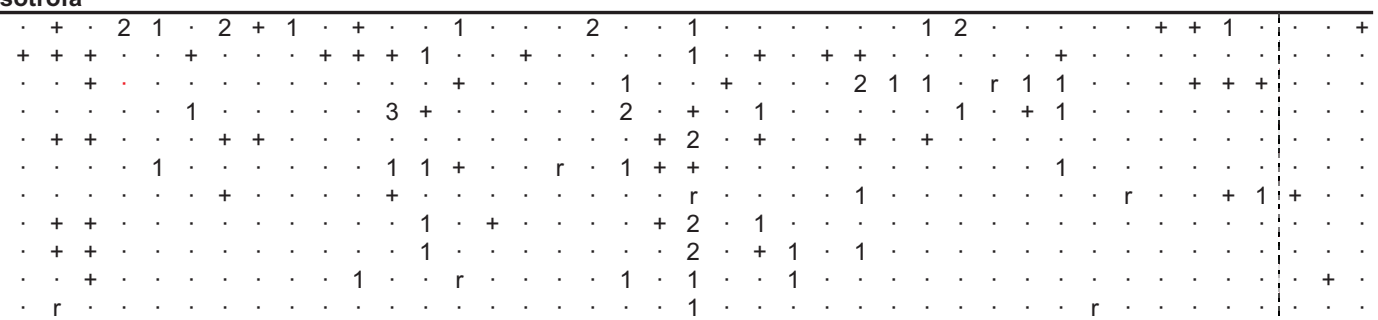

Características de Querco-Fagetea

Stellaria holostea

Viola riviniana

Anemone nemorosa

Euphorbia dulcis

Betula pubescens

Ajuga reptans

Taxus baccata

Euphorbia hyberna

Crepis lampsanoides

Hyacinthoides non-scripta

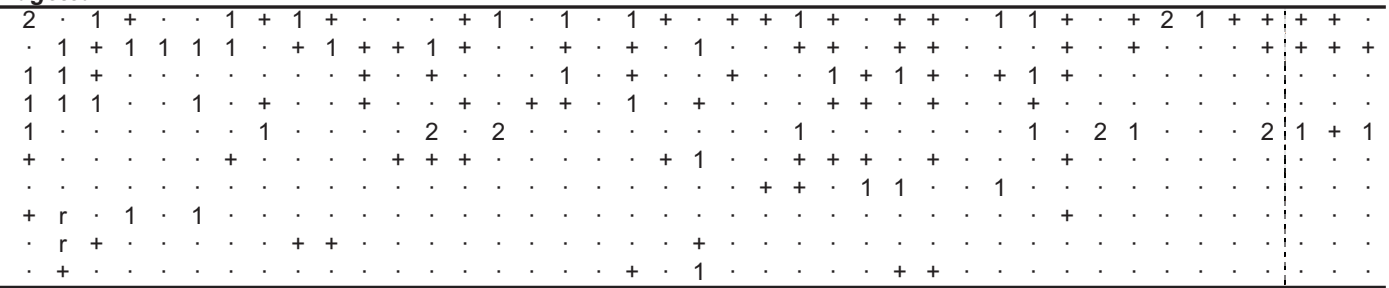

Táboa 10b.- Blechno spicant-Quercetum roboris subas. lauretosum nobilis variante mesotrofa: a: facies típica, b: facies heliófila de Quercus pyrenaica 


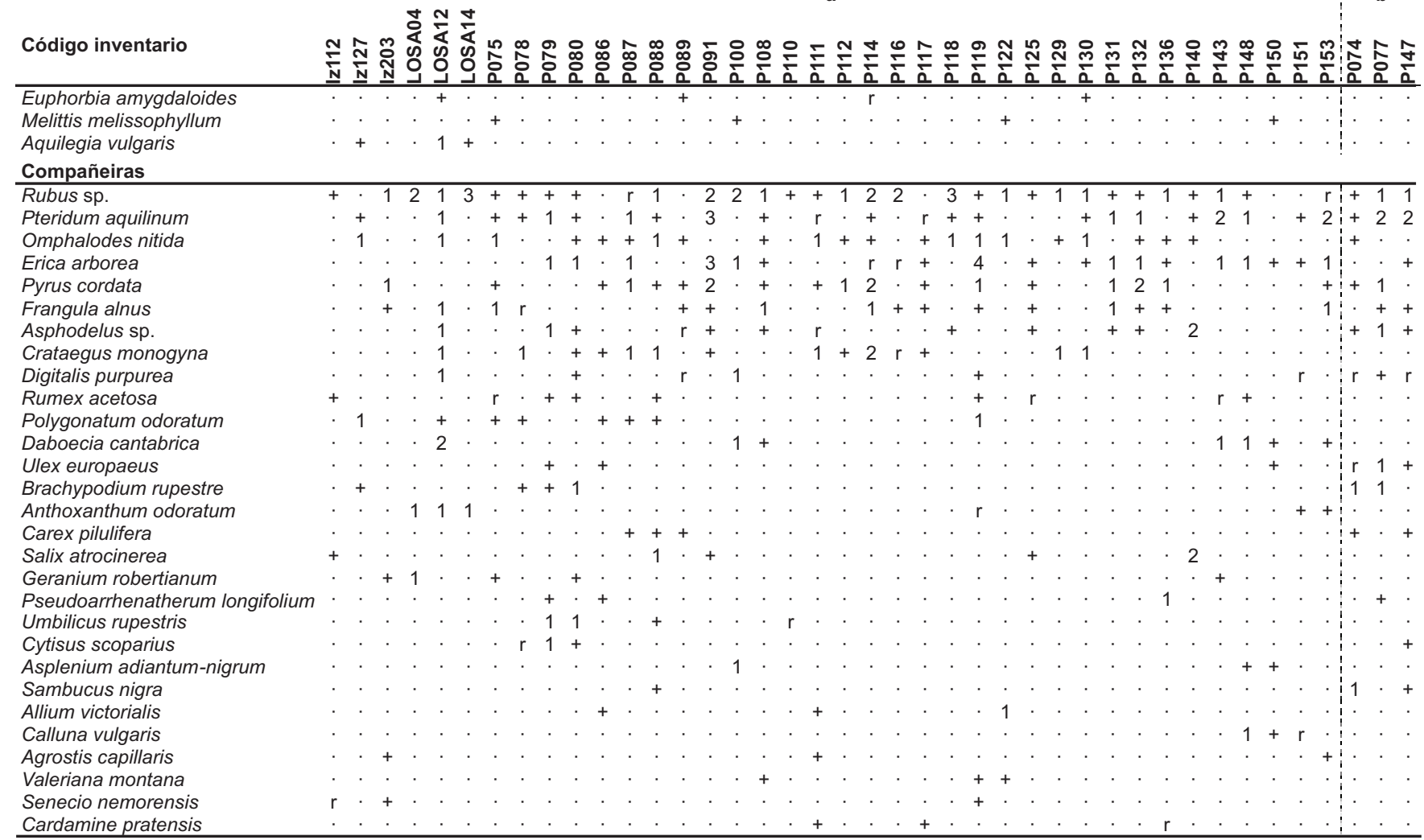

Táboa 10b cont.- Blechno spicant-Quercetum roboris subas. lauretosum nobilis variante mesotrofa: a: facies típica, b: facies heliófila de Quercus pyrenaica

Holco mollis-Betuletum celtibericae. Esta opinión non é compartida por autores como Díaz González (1996) e Díaz González \& Fernández Prieto (1994a, 1994b), para quenes serían unha facies de bidueiro dos bosques dominantes no territorio (Blechno-Quercetum roboris). Sexa como fose, a conexión dinámica entre os bidueirais e os carballais evidénciase pola progresiva aparición nos primeiros de carballos e outras especies típicas dos bosques estudados, como o acibo ou a abelaira, que reemplazan progresivamente a Betula pubescens conforme estas formacións se van facendo senescentes. Con frecuencia, a adscripción fitosociolóxica destes estadíos intermedios non é doada e pode variar en función dos criterios aplicados.

En situación parecida atopanse os casos dominados polo castiñeiro. Na súa maior parte, estas formacións arboradas proceden de antigos soutos ("castañares" ou "castañedos" en Asturias) situados en terreos con condicións favorables para o crecemento potencial dos carballais, nos que se ven realizando desde hai décadas un aproveitamento en monte baixo da especie dominante, Castanea sativa (Díaz González \& Fernández Prieto 1994a, Rodríguez Guitián 2004, 2005). Rodríguez Guitián et al. (2005) sosteñen que, a pesar da sustitución das árbores preexistentes, as condicións ecolóxicas nas que se desenvolven este tipo de masas arboradas e o seu aproveitamento en turnos relativamente longos (30-40 anos), permiten que o seu cortexo florístico siga mantendo un gran parecido co que caracteriza aos carballais. Desde o punto de vista fitosociolóxico, Izco et al. (1990) consideran que estas situacións nas que o castiñeiro se convirte, favorecido pola actividade humana, na especie dominante deben ser interpretados de xeito xenérico como "facies de Castanea sativa", sen ubicala en ningunha das subasociacións por eles consideradas. Polo momento, fundamentados no carácter marcadamente antrópico destas formacións, preferimos consideralos como "fases de Castanea sativa" que, eventualmente e en función da composición florística particular que presenten, poden subordinarse a algunha das facies aquí descritas dentro da asociación Blechno spicantQuercetum roboris. En esta situación incluiríanse a maior parte dos inventarios aportados por Díaz González (1975) así como os inventarios 2, 3 e 13 de Losa Quintana (1973)

Con relación aos inventarios tomados por Losa Quintana (1973) na cunca baixa do Río Eume que non foron incluídos neste traballo, dous deles (inv. 2 e 6, op. cit.) presentan unha composición florística que posibilita a súa inclusión na asociación galaico-portuguesa termófila Rusco aculeatiQuercetum roboris, ao carecer por completo de especies higro-esciófilas.

En último lugar, queremos comentar que nas áreas nas que se poñen en contacto os carballais estudiados cos faiais da asociación Saxifrago spathularidis-Fagetum sylvaticae confórmanse bosques con caracterísiticas intermedias entre ambos, nos que se produce un desplazamento progresivo 
dos carballos pola faia (táboa 12). Estes "carballais-faiais", que son relativamente frecuentes na mitade oriental da área de estudio (cuncas dos ríos Cabornel, Negro, Esva, Llanteiro e Uncín), podense atopar igualmente, aínda que de xeito moito máis puntual, nas cabeceiras do Río Eo e o Río da Serra, nos concellos lugueses de Pol, Baleira e A
Fonsagrada. Como xa indicamos, o feito de considerarmos á faia como unha especie integrante da composición florística que presentan estes bosques en gran parte da área de estudio, non recomenda un tratamento diferenciado desde o punto de vista fitosociolóxico para estes bosques de carácter ecotónico.

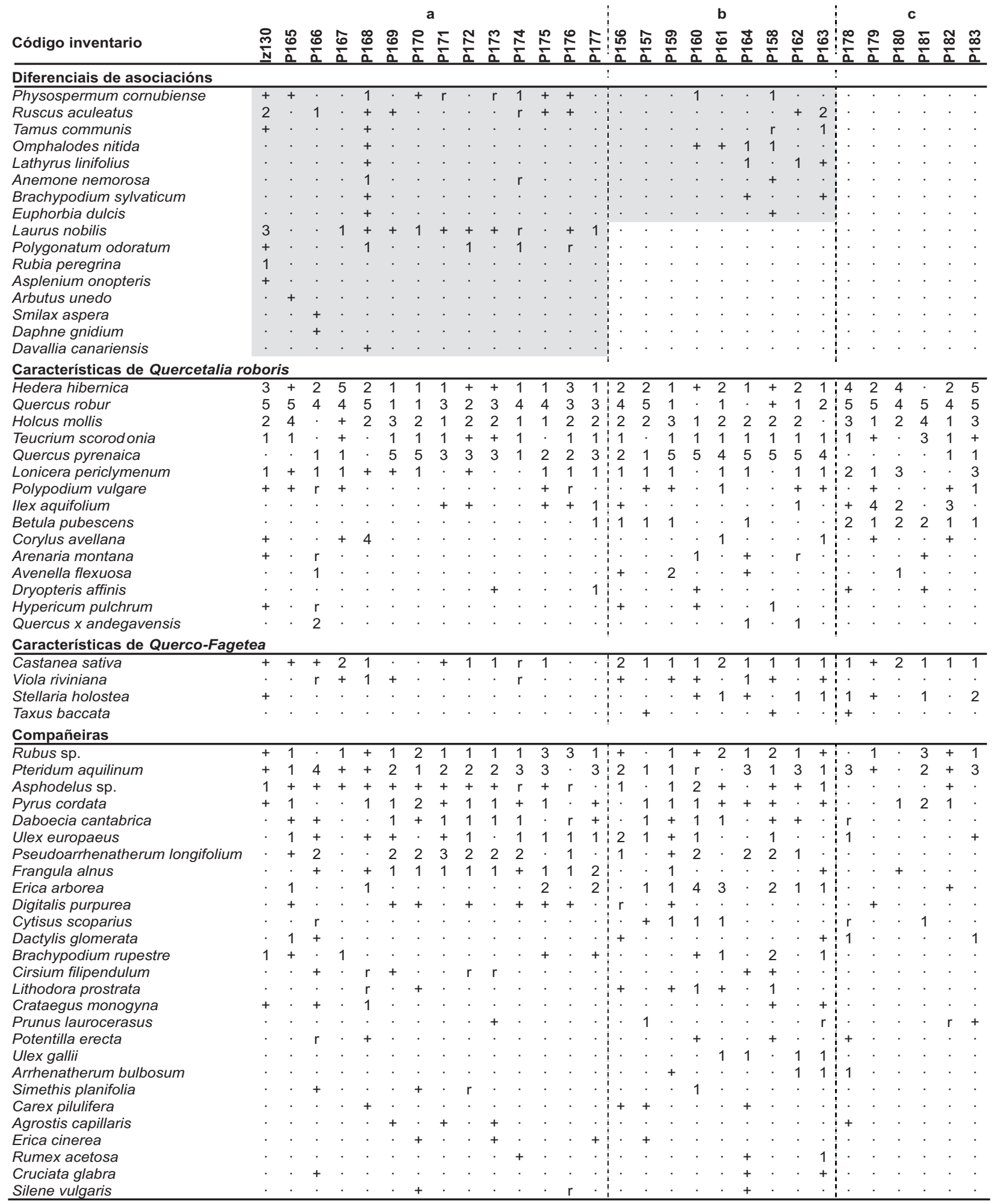

Táboa 11.- a: Rusco aculeati-Quercetum roboris; b: Lonicero periclymeni-Quercetum pyrenaicae; c: carballais sen adscripción fitosociolóxica 


\begin{tabular}{|c|c|c|c|c|c|c|c|c|c|c|c|c|}
\hline $\mathrm{N}^{\circ}$ inv. & 1 & 2 & 3 & 4 & 5 & 6 & 7 & 8 & 9 & 10 & 11 & 12 \\
\hline Altitude (m) & 225 & 305 & 420 & 200 & 300 & 320 & 820 & 205 & 370 & 730 & 630 & 470 \\
\hline Pendente ${ }^{\circ}$ & 38 & 35 & 8 & 40 & 26 & 34 & 30 & 34 & 32 & 31 & 20 & 41 \\
\hline Orientación & ESE & NNE & $\mathrm{E}$ & sw & NNW & NNW & $\mathrm{E}$ & $\mathrm{E}$ & NE & NNW & ENE & $\mathrm{N}$ \\
\hline Altura $E_{1}(m)$ & 25 & 15 & 16 & 26 & 24 & 16 & 20 & 16 & 20 & 18 & 26 & 22 \\
\hline Cobertura $E_{1}(>1,5 \mathrm{~m})(\%)$ & 100 & 80 & 90 & 100 & 100 & 95 & 100 & 95 & 100 & 100 & 100 & 95 \\
\hline Cobertura $\mathrm{E}_{2}(<1,5 \mathrm{~m})(\%)$ & 100 & 70 & 90 & 95 & 65 & 60 & 70 & 40 & 90 & 65 & 5 & 95 \\
\hline Área $\left(m^{2}\right)$ & 300 & 200 & 250 & 300 & 120 & 200 & 500 & 200 & 240 & 200 & 300 & 300 \\
\hline$N^{\circ}$ taxóns & 26 & 31 & 29 & 36 & 19 & 26 & 24 & 10 & 22 & 29 & 27 & 27 \\
\hline \multicolumn{13}{|c|}{ Características e diferenciais $\left(^{*}\right)$ de Blechno spicant-Quercetum roboris } \\
\hline Quercus robur & 2 & 2 & 2 & 4 & 2 & 3 & 4 & 2 & 4 & 3 & 2 & 5 \\
\hline Blechnum spicant * & + & 1 & 1 & + & 3 & + & 1 & + & 1 & 2 & 1 & 1 \\
\hline Hedera hibernica & 1 & 1 & 1 & 1 & 2 & 1 & + & . & 1 & 2 & + & 1 \\
\hline Fagus sylvatica & 3 & . & . & 4 & 4 & 3 & 4 & 4 & 4 & 3 & 4 & 4 \\
\hline Vaccinium myrtillus & + & 1 & . & + & 1 & 1 & 3 & . & 4 & 2 & + & 1 \\
\hline Holcus mollis & 3 & 2 & + & 3 & 2 & 1 & . & . & + & 1 & + & 1 \\
\hline Dryopteris dilatata * & + & $\mathrm{r}$ & . & 1 & + & + & + & . & 1 & 1 & + & 1 \\
\hline Corylus avellana & 1 & 3 & 2 & 1 & . & . & 1 & . & . & 1 & 2 & 1 \\
\hline Dryopteris affinis & 3 & 1 & . & + & . & 2 & 1 & . & . & 1 & + & 2 \\
\hline Lonicera periclymenum & . & 1 & 1 & 3 & . & 1 & . & . & 2 & 1 & + & + \\
\hline Teucrium scorodonia & 2 & 1 & $\mathrm{r}$ & 1 & . & . & + & . & . & + & + & . \\
\hline Avenella flexuosa & . & . & . & + & . & 1 & 1 & + & 1 & 1 & . & 1 \\
\hline Ilex aquifolium & . & . & 1 & 1 & 2 & . & . & . & 1 & 1 & 2 & . \\
\hline Oxalis acetosella * & + & . & + & . & + & . & . & . & + & + & . & 1 \\
\hline Polypodium vulgare & . & . & . & + & . & . & + & . & 1 & 1 & 1 & . \\
\hline Saxifraga spathularis * & . & $\mathrm{r}$ & . & . & . & . & 1 & . & + & 1 & . & . \\
\hline Athyrium filix-femina * & 1 & $r$ & . & + & . & . & . & . & . & . & . & + \\
\hline Luzula henriquesii & . & . & . & . & . & 3 & . & . & . & 1 & . & 5 \\
\hline Dryopteris filix-mas & . & . & 1 & . & . & . & . & . & 1 & . & 1 & . \\
\hline Osmunda regalis * & + & . & . & 1 & . & . & . & . & . & . & . & . \\
\hline Dryopteris aemula & . & . & . & . & . & . & . & . & . & . & . & 1 \\
\hline Sorbus aucuparia & . & . & . & . & . & . & . & . & . & + & . & . \\
\hline Polygonatum verticillatum & $\cdot$ & · & · & · & · & · & · & . & · & + & · & $\cdot$ \\
\hline \multicolumn{13}{|c|}{ Diferenciais de subas. lauretosum nobilis } \\
\hline$\overline{R u s c u s ~ a c u l e a t u s}$ & + & 1 & 3 & 1 & 1 & + & $\bar{r}$ & $\cdot$ & $\bar{r}$ & $\cdot$ & $\cdot$ & $\cdot$ \\
\hline Laurus nobilis & 2 & $r$ & . & . & 1 & . & . & . & . & . & . & . \\
\hline Arbutus unedo & . & 1 & . & . & 1 & . & . & . & . & . & . & . \\
\hline Tamus communis & . & $r$ & . & . & . & . & . & . & . & . & . & . \\
\hline \multicolumn{13}{|c|}{ Diferenciais de variante mesotrofa } \\
\hline Primula acaulis & $\cdot$ & $\cdot$ & + & $\cdot$ & $\cdot$ & + & $\cdot$ & $\cdot$ & $\cdot$ & $\cdot$ & $\cdot$ & + \\
\hline Polystichum setiferum & . & . & 1 & . & . & . & . & . & . & . & . & + \\
\hline Brachypodium sylvaticum & . & 2 & . & . & . & . & . & . & . & . & . & . \\
\hline Mercurialis perennis & . & . & 2 & . & . & . & . & . & . & . & . & . \\
\hline Helleborus occidentalis & . & . & 1 & . & . & . & . & . & . & . & . & . \\
\hline Pulmonaria longifolia & . & . & + & . & . & . & . & . & . & . & . & . \\
\hline Prunus avium & . & . & . & . & . & . & . & . & . & . & . & + \\
\hline Ranunculus tuberosus & . & $\mathrm{r}$ & . & . & . & . & . & . & . & . & . & . \\
\hline \multicolumn{13}{|c|}{ Diferencial de fase de Castanea sativa } \\
\hline Castanea sativa & 4 & 3 & 3 & 2 & 1 & + & $\cdot$ & 2 & 2 & 2 & 3 & $\cdot$ \\
\hline \multicolumn{13}{|c|}{ Características de Quercetalia roboris } \\
\hline Physospermum cornubiense & + & 1 & $\mathrm{r}$ & . & + & $\mathrm{r}$ & . & . & . & . & + & $\cdot$ \\
\hline Hieracium umbellatum & . & . & . & . & . & . & + & . & . & . & + & . \\
\hline \multicolumn{13}{|c|}{ Características de Querco-Fagetea } \\
\hline Stellaria holostea & $\bar{\cdot}$ & $\bar{\cdot}$ & + & 1 & $r$ & $\bar{c}$ & 1 & $\bar{c}$ & $\cdot$ & + & $\cdot$ & + \\
\hline Solidago virgaurea & + & . & . & 1 & . & . & + & + & + & . & . & + \\
\hline Betula pubescens & 1 & + & . & 1 & 1 & . & . & . & . & . & 1 & . \\
\hline Viola riviniana & + & 1 & . & + & . & + & . & . & . & . & . & . \\
\hline Euphorbia dulcis & . & . & . & + & . & . & + & . & . & . & . & + \\
\hline \multicolumn{13}{|l|}{ Compañeiras } \\
\hline Rubus sp. & 1 & 1 & 1 & + & + & $r$ & + & $\cdot$ & 1 & + & + & + \\
\hline Pteridum aquilinum & 1 & 1 & . & + & + & $r$ & 1 & 2 & 1 & . & . & 1 \\
\hline Frangula alnus & 1 & 1 & . & . & . & 1 & . & + & 1 & + & . & + \\
\hline Erica arborea & . & 1 & . & + & . & 1 & 3 & . & 1 & . & $\mathrm{r}$ & . \\
\hline Pyrus cordata & . & . & + & 1 & . & 1 & . & . & + & + & 1 & . \\
\hline Daboecia cantabrica & 1 & 1 & . & + & . & 1 & . & . & 2 & . & . & . \\
\hline Asphodelus sp. & . & . & . & 1 & 2 & . & 1 & . & . & . & . & . \\
\hline Omphalodes nitida & . & 1 & + & . & . & . & . & . & . & . & $\mathrm{r}$ & . \\
\hline Rumex acetosa & . & . & + & . & . & . & $r$ & . & . & $r$ & . & . \\
\hline
\end{tabular}

Táboa 12.- Fases de Castanea sativa e carballais-faiais acidófilos galaico-asturianos e ovetenses (Blechno spicant-Quercetum roboris)

1-3) fase de Castanea sativa, 4-12) carballais/faiais 


\section{Esquema sintaxonómico}

Para rematar, amosamos o esquema sintaxonómico das comunidades arboradas citadas neste traballo (táboa 13), encadrándoo dentro do proposto por Rivas-Martínez et al. (2001, 2002).

\section{Conclusións}

A revisión da información dispoñible sobre a composición florística e condicións ecolóxicas nas que crecen os bosques dominados por especies caducifolias e marcescentes do xénero Quercus no extremo occidental da Cornixa Cantábrica confirma que maioritarimente se corresponden coa asociación Blechno spicant-Quercetum roboris. Ditos bosques caracterízanse por albergar un número elevado de especies higro-esciófilas que non están presentes nos carballais de distribución máis meridional ou occidental cos que establecen contacto. Non obstante, contrariamente ao considerado ata o de agora, a información manexada neste traballo resta protagonismo ao carballo común (Quercus robur) nos aspectos fisionómicoestruturais desta comunidade en favor doutras quercíneas
(Quercus petraea, Q. x rosacea, Q. pyrenaica) que, localmente, poden chegar a desplazar ao primeiro no estrato superior destes bosques. Ademáis, recoñécese a existencia doutros tipos de bosques en situacións ecolóxicas particulares nas que se produce unha sustitución dos carballais maioritarios.

Como acontece con outros tipos de vexetación, factores bioclimáticos e topo-edáficos axudan a comprender a variabilidade florística que se pode atopar nos bosques estudiados. Desde un punto de vista fitosociolóxico, esto se plasma na diferenciación de dúas subasociacións con base termoclimática dentro do tipo de carballal dominante no territorio: unha típica mesófila e outra termófila; á súa vez, dentro de cada unha delas pódense diferenciar bosques sobre solos moi pobres en nutrientes (variante típica) doutros nos que o sustrato presenta un maior contido en bases por estar situados, principalmente, en valgadas ou partes baixas de ladeira (variante mesotrofa). Por último, algúns bosques situados en posicións de maior insolación poden incorporar o rebolo ( $Q$. pyrenaica) e $Q$. x andegavensis (híbrido deste con $Q$. robur) entre as súas especies arbóreas como diferenciais da facies heliófila.

\section{Querco-FAgeteA Br.-BI. \& Vlieger in Vlieger 1937}

Or. Quercetalia roboris Tüxen 1931

Al. Quercion pyrenaicae Rivas Goday ex Rivas-Martínez 1965

Subal. Quercenion robori-pyrenaicae (Br.-Bl., P. Silva \& Rozeira 1956) Rivas -Martínez 1975

As. Blechno spicant-Quercetum roboris Tüxen \& Oberdorfer 1958

subas. dryopteridetosum aemulae

variante típica

facies típica

facies heliófila de Quercus pyrenaica

variante mesotrofa

facies típica

facies heliófila de Quercus pyrenaica

subas. lauretosum nobilis

variante típica

facies típica

facies heliófila de Quercus pyrenaica

variante mesotrofa

facies típica

facies heliófila de Quercus pyrenaica

As. Rusco aculeati-Quercetum roboris Br.-BI., P. Silva \& Rozeira 1956

subas. violetosum rivinianae

subas. quercetosum suberis

As. Hyperico pulchri-Quercetum roboris Rivas-Martínez, Báscones, T.E. Díaz, Fernández-González \& Loidi 1991

As. Linario triornithophorae-Quercetum pyrenaicae Rivas-Martínez, T.E. Díaz, F. Prieto, Loidi \& Penas 1984

As. Melampyro pratensis-Quercetum pyrenaicae Rivas-Martínez ex Rivas -Martínez, T.E. Díaz, F. Prieto, Loidi \& Penas 1984

As. Lonicero periclymeni-Quercetum pyrenaicae Rivas-Martínez 2002

Al. Ilici-Fagion Br.-BI. 1967

Subal. Luzulo henriquesii-Quercenion petraeae Rivas-Martínez \& Izco 2002

As. Linario triornithophorae-Quercetum petraeae (Rivas-Martínez, Izco \& Costa ex F. Navarro 1974) F. Prieto \& Vázquez 1987

As. Luzulo henriquesii-Quercetum petraeae (F. Prieto \& Vázquez 1987) T.E. Díaz \& F. Prieto 1994

As. Saxifrago spathularidis-Fagetum sylvaticae Rodríguez Guitián, Amigo, C. Real \& R. Romero 2003 subas. fagetosum sylvaticae

subas. sorbetosum aucupariae

Táboa 13.- Esquema sintaxonómico dos bosques citados neste traballo 
Aínda que o esquema de reparto topográfico de comunidades de carballal establecido por Losa Quintana (1973) no treito inferior das Fragas do Eume (RuscoQuercetum en posicións de forte insolación versus BlechnoQuercetum en ladeiras avesías) non tivo maior trascendencia nos traballos posteriores que abordaron a caracterización da cuberta vexetal dentro da área de estudio, serve para explicar a presenza de retazos da asociación Rusco aculeati-Quercetum roboris en diversas localidades próximas ao litoral do extremo $\mathrm{N}$ das provincias de A Coruña e Lugo (comarcas de Ortegal e O Valadouro), principalmente sobre solos pedregosos de ladeiras soalleiras. Este feito suxire que o contacto entre estas dúas asociacións de bosques ten lugar a traveso dunha área xeográfica bastante máis ampla do que ata o de agora se viña admitindo, podéndose identificar retazos de carballais termófilos galaico-portugueses ata o $\mathrm{N}$ da provincia de Lugo. En senso inverso, o límite occidental dos bosques da Blechno-Quercetum roboris seguindo a faixa litoral semella situarse máis ao $\mathbf{S}$ da desembocadura do Río Eume, sendo recoñecible a súa presenza, principalmente en ladeiras avesías, ata, alo menos, o tramo medio do Río Mandeo.

Por outro lado, os bosques dominados polo rebolo (Quercus pyrenaica) existentes nas cuncas medias e cabeceiras dos ríos Eo, Navia e Narcea, áreas nas que se rexistra un descenso apreciable da nubosidade durante a época estival con respecto ás situadas máis ao $\mathrm{N}$ dentro do territorio estudiado, carecen de especies termófilas pouco tolerantes aos contrastes térmicos (Smilax aspera, Rubia peregrina, Laurus nobilis) e amosan un parecido florístico coas existentes ao longo da cunca media do Río Navia. Por elo, considerámolos incluibles na asociación Lonicero periclymeni-Quercetum pyrenaicae.

En último lugar, é necesario abordar o estudo dos carballais existentes na cabeceira dos ríos Mandeo, Mendo e Miño, nos que están ausentes tanto especies higro-esciófilas como termófilas, para clarificar a súa situación sintaxonómica. Mentres esto non ocurre, a confirmación da presencia dentro do territorio estudiado de tres asociacións vexetais de bosques dominados por quercíneas supón un considerable incremento da súa diversidade fitocenótica e realza aínda máis, se cabe, a importancia que para a conservación do patrimonio natural ibérico teñen as masas arboradas autóctonas do estremo setentrional galego e o noroeste asturiano.

Agradecementos $\mathrm{O}$ autor agradece a axuda prestada durante a realización dos traballos de campo a Ramiro Alvite Díaz, Miguel Balboa Murias, Adolfo Blanco de la Parte, José Manuel Blanco López, Ramón Alberto Díaz Varela, Montserrat Fernández Martínez, Javier Ferreiro da Costa, Jorge Filgueiras Silva, Manuel Fontao Alvarado, Pilar González Hernández, José Manuel López Dacal, Natalia López López, Blanca López Varela, Miguel Ángel Negral Fernández, José Luís Penín Franco, Pablo Ramil Rego, Manuel Rodríguez Romero, Mónica Rodríguez Freire, Mercedes Rois Díaz e Rosa Romero Franco, así como as suxestións realizadas por dous revisores anónimos que contribuíron apreciablemente á mellora do manuscrito orixinal.

\section{Bibliografía}

Allorge, V. \& Allorge, P. (1941): Les ravins à fougères de la corniche vasco-cantabrique. Bull. Soc. Bot. France 88: 91111.

Álvarez Rodríguez, A. (1976): Estudio de la flora y vegetación del Puerto de Leitariegos y cuenca alta del Naviego. Memoria de Licenciatura. Universidad de Oviedo.

Álvarez, M.A. \& Díaz-Fierros, F. (1995): Los Suelos. En: C. Aramburu \& F. Bastida (Eds.): Geología de Asturias: 173186. Ed. Trea. Gijón.

Amaral Franco, J. do (1990): 3. Quercus L. En: S. Castroviejo (Coord.): Flora Iberica, Vol. II: 15-36. Real Jardín Botánico. C.S.I.C. Madrid.

Amigo, J. \& Norman, G. (1993): La conservación de las Fragas del Río Eume: valoraciones botánicas. Congreso Forestal Español. Ponencias y Comunicaciones, Tomo IV: 15-20. S.E.C.F. Xunta de Galicia. Lourizán.

Amigo, J. \& Norman, G. (1995): Identification of site-types important for rare ferns in an area of deciduous woodland in northwest Spain. Vegetatio 116: 133-146.

Amigo, J. \& Romero, M.I. (1998): Abedulares de origen antrópico en Galicia: caracterización fitosociológica. Stvdia Botanica 17: 37-51. Ediciones Universidad. Salamanca.

Amigo, J., Guitián Rivera J. \& Fernández Prieto, J.A. (1987): Datos sobre los bosques ribereños de aliso (Alnus glutinosa) cántabro-atlánticos ibéricos. Publ. Univ. La Laguna. Ser. Informes 22: 159-176.

Amigo, J., Izco, J., Guitián, J. \& Romero, M.I. (1998): Reinterpretación del robledal termófilo galaico-portugués: Rusco aculeati-Quercetum roboris. Lazaroa 19: 85-98.

Aseginolaza Iparaguirre, C., Gómez García, D., Lizaur Sukia, X., Monserrat Martí, G., Morante Serrano, G., Salaverria Monfort, M. \& Uribe-Echevarria Díaz, P.M. (1996): Vegetación de la Comunidad Autónoma del País Vasco. Servicio Central de Publicaciones de Gobierno Vasco. Vitoria-Gasteiz. 361 pp.

Báscones, J.C. (1978): Relaciones suelo-vegetación de la Navarra húmeda del noroeste. Estudio florístico-ecológico. Tese de Doutoramento. Universidad de Navarra.

Bellot, F. (1968): La vegetación de Galicia. Anal. Inst. A. J. Cavanilles XXIV: 3-306.

Boudrie, M. (1998): Les ptéridophytes du Pays basque et du nord-ouest de l'Espagne: écologie, répartition, protection. Actes du IIIéme Colloque International de Botanique Pyrénéo-Cantabrique. Le Journal de Botanique, 5: 43-52.

Braun-Blanquet, J. (1967): Vegetationsskizzen aus dem Baskenland mit Ausblicken auf das weitere IberoAtlantikum, II. Vegetatio 14(1-4), 1-126.

Braun-Blanquet, J. (1979): Fitosociología. Bases para el estudio de las comunidades vegetales. 820 pp. Ed. Blume. Barcelona. 
Carballeira, A., Devesa, C., Retuerto, R., Santillán, E. \& Ucieda, F. (1983): Bioclimatología de Galicia. 391 pp. Fundación Barrié de la Maza. A Coruña.

Casaseca, B, (1959): La vegetación y flora del término municipal de Santiago de Compostela. Bol. Univ. Compostelana 67: 297-349.

Castroviejo Bolíbar, M.P.A. (1988): Fitoecología de los Montes del Buio y Sierra del Xistral (Lugo). 323 p. Consellería de Agricultura. Xunta de Galicia. Santiago de Compostela.

Castroviejo, S. (Coord.)(1986-2007): Flora Iberica, Vols. IVIII, X, XIV, XV, XVIII e XXI. Real Jardín Botánico. C.S.I.C. Madrid.

Catalán, P. (1987): Geobotánica de las cuencas BidasoaUrumea (NO de Navarra-NE de Guipúzcoa). Estudio ecológico de los suelos y de la vegetación de la cuenca de Artikutza (Navarra). Tese de Doutoramento. 686 pp. Facultad de Ciencias. Universidad del País Vasco.

Dalda, J. (1972): Vegetación de la cuenca del Río Deo (Cuenca alta del Mando). Estudio ecológico-fitosociológico y florístico. Mon. Univ. Santiago de Compostela 14. 158 pp. Secretariado de Publicaciones. Universidade de Santiago de Compostela. Santiago de Compostela.

Dantas Barreto, R.R. (1958): Os Carvalhais da Serra da Peneda. Estudio fitosociológico. Agronom. Lus. 20(2): 83153.

Díaz González, T.E. (1975): La vegetación del litoral occidental asturiano. Rev. Fac. Cien. Oviedo 15(2)-16: 369545.

Díaz González, T.E. (1996): IV-Vegetación. En: J. Ruiz de la Torre (Dir.): Mapa Forestal de España. E. 1:200.000. Hoja 31 (Avilés): 73-99. I.C.O.N.A. Ministerio de Agricultura, Pesca y Alimentación. Madrid

Díaz González, T.E. \& Fernández Prieto J.A. (1994a): La vegetación de Asturias. Itinera Geobot. 8: 243-528.

Díaz González, T.E. \& Fernández Prieto J.A. (1994b): El paisaje vegetal de Asturias. Itinera Geobot. 8: 5-242.

Dupont, P. (1974): Le chêne tauzin (Quercus pyrenaica Willd.) et la végétación associé dans la province de Santander (Nord de l'Espagne). Coll. Phytosoc. 3: 167-181.

Felicísimo Pérez, A.M. (1990): El clima de Asturias. Enciclopedia temática de Asturias, Tomo 10, 179-208. Gijón.

Fernández Prieto, J.A. \& Díaz González, T.E. (1998): IVVegetación. In: J. Ruiz de la Torre (Dir.): Mapa Forestal de España, Escala 1:200.000, Hoja 3-2 (Cangas de Narcea), 95-123, Ministerio de Medio Ambiente. Madrid.

Fernández Prieto, J.A. \& Vázquez, V.M. (1987): Datos sobre los bosques asturianos orocantábricos occidentales. Lazaroa 7: 363-382.

García de Longoria, L. (1798): La conservación de los montes de Asturias y Galicia. Monumenta Historica Asturiensia, XXVII. 88 pp. Edición preparada por R. Rodríguez Álvarez. Ed. Auseva S.A. Gijón.
Géhu, J.-M. (1998): Epistémologie de la typologie phytosociologique de la végétation. It. Geobot. 11: 65-83.

Guinea, E. (1949): Vizcaya y su paisaje vegetal (Geobotánica vizcaína). Junta de Cultura de Vizcaya. 432 pp. Bilbao.

Guinea, E. (1953): Geografía botánica de Santander. Diputación Provincial de Santander. 420 pp. Santander.

Guitián Rivera, L. (1995): Origen y evolución de la cubierta forestal de Galicia. Tese de Doutoramento inédita. 474 pp. Facultade de Xeografía e Historia. Universidade de Santiago de Compostela.

Guitián Rivera, L. (1996): Transformaciones recientes en las áreas de distribución del haya y la encina en el noroeste de la Península Ibérica. En: L. Guitián Rivera \& R. Lois González (Coord.): Actividad humana y cambios recientes en el paisaje: 95-105. Consellería de Cultura. Xunta de Galicia. Santiago de Compostela.

Herrera Gallástegui, M. (1995): Estudio de la vegetación vascular de la cuenca del Río Asón. Guineana 1. 435 pp.

IGME (1982): Mapa Geológico de España. Escala 1:200.000. Hoja 8 (2-2): Lugo. Servicio de Publicaciones. Ministerio de Industria y Energía. Madrid.

IGME (1984): Mapa Geológico de España. Escala 1:200.000. Hoja 1 (2-1): La Coruña. Serv. Pub. Ministerio de Industria y Energía. Madrid.

IGN (1991): Atlas Nacional de España. Sección II, Grupo 9. Climatología. 32 pp. Madrid.

ITGE (1991): Mapa Geológico de España. Escala 1:200.000. Hoja 2 (3-1): Avilés. Serv. Pub. Ministerio de Industria y Energía. Madrid.

Izco, J. (1987): Galicia. En: M. Peinado Lorca \& S. RivasMartínez (Eds.): La vegetación de España. Colección Aula Abierta 3: 385-418. Serv. Pub. Universidad de Alcalá de Henares.

Izco, J. (1994): O bosque atlántico. En: C. Vales (Ed.): Os bosques atlánticos europeos: 13-49. Ed. Bahía. A Coruña.

Izco, J. (2004): Taxonomía y nomenclatura. En: A. Rigueiro (Ed.): Proyecto Galicia. Vol. 41 (Botánica I): 205-233. Hércules Ediciones S.A. A Coruña).

Izco, J, Amigo, J \& Guitián, J. (1990): Los robledales galaico-septentrionales. Acta Bot. Malacit., 15: 267-276.

Izco, J., Rodríguez-Dacal, C. \& Sánchez, J.M. (1994): Análisis geobotánico de las Caldas de Lugo. Estudios sobre el Balneario de Lugo. Memoria de la Real Academia de Farmacia, $n^{\circ}$ 20: 75-103. Madrid.

Lastra Menéndez, J.L. (1989): Estudio de la flora y vegetación vascular del concejo de Grado (Asturias) y sus contornos. Tese de Doutoramento inédita. 365 pp. Dep. Biología de Organismos y Sistemas. Universidad de Oviedo.

Loidi Arregui, J. (1983): Estudio de la flora y vegetación de la cuenca de los ríos Deva y Urola en la provincia de Guipúzcoa. 298 pp. Publ. Univ. Complutense de Madrid, Ser. Tesis Doctorales, Madrid. 
Loidi Arregui J., Biurrun Galarraga, I. \& Herrera Gallástegui, M. (1997): La vegetación del centro-norte de España. Itinera Geobot., 9, 161-618.

Losa Quintana, J.M. (1973): Estudio de las comunidades arbóreas naturales de la cuenca del Río Eume (La Coruña). Trab. Comp. Biol. 3: 1-62.

Macías Vázquez, F. \& Calvo de Anta, R. (1992): Suelos de la provincia de La Coruña. 85 pp. Diputación Provincial de A Coruña.

Macías Vázquez, F. \& Calvo de Anta, R. (2001): Los Suelos. Atlas de Galicia. Tomo 1: Medio Natural: 173-217. Sociedade para o Desenvolvemento Comarcal de Galicia. Consellería da Presidencia. Xunta de Galicia. Santiago.

Martínez Cortizas, A. \& Castillo Rodríguez, F. (1996): Estacionalidad pluviométrica en Galicia: comportamiento, representatividad espacial y mecanismos asociados. Geographicalia 33: 137-145.

Martínez García, G., Mayor López, M., Navarro Andrés, F. \& Díaz González, T.E. (1974): Estudio fitosociológico y fitotopográfico de las vertientes septentrional y meridional del Puerto de Ventana. Rev. Fac. Cien. Oviedo 15(1): 55109.

Mayor, M. \& Fernández, M. (2007): Flora y vegetación de Asturias. Aspectos ecológicos, geográficos y fitosociológicos. Cuadernos de campo de la Zona Occidental. Colección Universidad en Español. Editorial CEP S.L. Madrid.

Navarro, F. (1974): La vegetación de la Sierra del Aramo y sus estribaciones (Asturias). Rev. Fac. Cienc. XV-1: 111243.

Onaindía Olalde, M. (1986): Ecología vegetal de las Encartaciones y Macizo del Gorbea (Vizcaya). 271 pp. Servicio Editorial. Universidad del País Vasco.

Pinto da Silva, A.R., Rozeira, A. \& Fontes, F. (1950): Os carvalhais da Serra do Gerês. Esboço fitosiológico. Agronom. Lus. 12(3): 433-448.

Pulgar Sañudo, I. (1999): La vegetación de la Baixa Limia y sierras del entorno. Tese de Doutoramento inédita. 275 pp. Facultade de Bioloxía. Universidade de santiago de Compostela.

Quintanilla, L.G. \& Amigo, J. (1999a): Catálogo de las pteridofloras de los espacios naturales protegidos de Galicia. Bot. Comp. 23: 11-110.

Quintanilla, L.G. \& Amigo, J. (1999b): Distribución del género Cystopteris Berh. (Athyriaceae, Pteridophyta) en Galicia (NO de la Península Ibérica. Nova Acta Cien. Comp. (Biol.) 9: 117-124.

Quintanilla, L.G., Amigo, J. Pangua, E. \& Pajarón, S. (2002): Análisis biogeográfico de la pteridoflora de la Sierra de la Capelada (La Coruña, España). Lazaroa 23: 17-24.

Ramil-Rego, P., \& Aira Rodríguez, J. (1992): Contribución al conocimiento de la vegetación Tardiglaciar y Holocena en el extremo norte de la Terra Chá (Galicia, España). Nova Acta Cient. Comp. (Biol.) 3: 49-58.
Ramil-Rego, P., \& Aira Rodríguez, J. (1998): Caracterización de la vegetación de las Sierras Septentrionales de Galicia desde el final del Tardiglaciar. Bot. Macaronesica, 23: 255269.

Ramil-Rego, P., Rodríguez-Guitián, M.A., Muñoz Sobrino, C. \& Gómez-Orellana, L. (2000): Some considerations about the postglacial history and recent distribution of Fagus sylvatica in the NW Iberian Peninsula. Folia Geobot., 35, 241-271.

Rigueiro Rodríguez, A. (1991): IV-Vegetación. En: J. Ruiz de la Torre (Dir.): Mapa Forestal de España. E. 1:200.000, folla 2-1 (A Coruña): 45-62. I.C.O.N.A. Ministerio de Agricultura, Pesca y Alimentación. Madrid.

Rigueiro Rodríguez, A. \& Silva-Pando, F. J. (1984): Aportaciones a la flora de Galicia, I. An. Jardín Bot. Madrid 40 (2): 385-395.

Rivas-Goday, S. (1950): Apreciación sintética de los grados de vegetación de la Sierra de Gerês. Agron. Lus. 12(3): 449480.

Rivas-Martínez, S. (1987): Memoria del Mapa de Series de Vegetación de España. Serie Técnica, 1: 9-208, I.C.O.N.A. Madrid.

Rivas-Martínez, S. (2007): Mapa de series, geoseries y geopermaseries de vegetación de España (Memoria del Mapa de Vegetación Potencial de España. Parte 1). Itinera Geobot. (Nueva Serie) 17. 436 pp.

Rivas-Martínez, S., Díaz, T.E., Fernández Prieto, J.A., Loidi, J. \& Penas, A. (1984a): La vegetación de la alta montaña cantábrica. Los Picos de Europa. Ed. Leonesas. León. 300 pp.

Rivas-Martínez, S., Loidi, J., Cantó, P., Sancho. L.G. \& Sánchez-Mata, D. (1984b): Datos sobre la vegetación del valle del río Bidasoa (España). Lazaroa 6: 127-150.

Rivas-Martínez, S., Báscones, J.C., Díaz, T.E., FernándezGonzález, F. \& Loidi, J. (1991): Vegetación del Pirineo occidental y Navarra. Itinera Geobot., 5: 5-456.

Rivas-Martínez, S., Fernández-González, F., Loidi, J., Lousâ, M. \& Penas, A. -2001- Syntaxonomical checklist of vascular plant communities of Spain and Portugal to association level. — Itinera Geobot. 14, 5-341.

Rivas-Martínez, S., Díaz, T.E., Fernández-González, F., Izco, J., Loidi, J., Lousâ, M. \& Penas, A. (2002): Addenda to the syntaxonomical checklist of 2001. Itinera Geobot., 15, 2 vol.

Rodríguez Guitián, M.A. (2004): Aplicación de criterios botánicos para a proposta de modelos de xestión sustentable das masas arborizadas autóctonas do Subsector Galaico-Asturiano Septentrional. Tese de Doutoramento inédita. Escola Politécnica Superior de Lugo. Universidade de Santiago de Compostela. 620 pp.

Rodríguez Guitián, M.A. (2005): Avaliación da diversidade sílvica do subsector galaicoasturiano septentrional: tipos de bosques, valor para a conservación e principais ameazas. Recursos Rurais, Serie Cursos 2: 23-44. 
Rodríguez Guitián, M.A. (2006): Acerca de la identidad fitosociológica de los hayedos silicícolas sublitorales del centro de la cornisa cantábrica. Lazaroa 27: 59-78.

Rodríguez Guitián, M.A. \& Ramil Rego. P. (2007): Revisión de las clasificaciones climáticas aplicadas al territorio gallego desde una perspectiva biogeográfica. Recursos Rurais 1(3): 31-53.

Rodríguez Guitián, M.A. \& Ramil-Rego, P. (2008): Fitogeografía de Galicia (NW Ibérico): análisis histórico y nueva propuesta corológica. Recursos Rurais 1(4): 19-50.

Rodríguez Guitián, M.A., Amigo Vázquez, J. \& Romero Franco, R. (2000): Aportaciones sobre la interpretación, ecología y distribución de los bosques supratemplados naviano-ancarenses. Lazaroa 21: 51-71.

Rodríguez-Guitián, M.A, Ferreiro da Costa, J., Negral Fernández, M.A. \& Merino García, A. (2001): Distribución y ecología del haya (Fagus sylvatica L.) en el Subsector Galaico-Asturiano Septentrional (NW Ibérico). Actas del III Congreso Forestal Español. Mesas 1 y 2: 201-201. Granada.

Rodríguez-Guitián, M.A., Real, C., Amigo, J. \& Romero, R. (2003): The Galician-Asturian beechwoods (Saxifrago spathularidis-Fagetum sylvaticae): description, ecology and differentiation from other Cantabrian woodland types. Acta Bot. Gallica 150(3): 285-305.

Rodríguez Guitián, M.A., Rigueiro Rodríguez, A., Real, C., Blanco López, J.M. \& Ferreiro da Costa, J. (2005): El hábitat "9260 Bosques de Castanea sativa" en el extremo noroccidental ibérico: primeros datos sobre la variabilidad florística de los "soutos". Bull. Soc. Hist. Nat. Toulouse 1412: 75-82.

Sahuquillo, E., Cajade, D. \& Fraga, M. (2001): Taxonomic revision of Hedera L. species from the NW Iberian Peninsula. Bol. Soc. Brot. 70: 89-100.

Silva-Pando, F.J. (1990): La flora y vegetación de la Sierra de Ancares: base para la planificación y ordenación forestal. Tese de Doutoramento inédita. 532 pp. Departamento de Biología Vegetal-I. Universidad Complutense de Madrid.

Silva-Pando, F.J. (1991a): IV-Vegetación. En: J. Ruiz de la Torre (Dir.): Mapa Forestal de España. Escala 1:200.000. Hoja 2-2. Lugo: 39-77. I.C.O.N.A. Ministerio de Agricultura, Pesca y Alimentación. Madrid.
Silva-Pando, F.J. (1991b): IV-Vegetación. En: J. Ruiz de la Torre (Dir.): Mapa Forestal de España. Escala 1:200.000. Hoja 2-3. Orense: 59-102. I.C.O.N.A. Ministerio de Agricultura, Pesca y Alimentación. Madrid.

Silva-Pando, F.J. (1991c): IV-Vegetación. En: J. Ruiz de la Torre (Dir.): Mapa Forestal de España. Escala 1:200.000. Hoja 2-4. Verín: 39-66. I.C.O.N.A. Ministerio de Agricultura, Pesca y Alimentación. Madrid.

Taboada Castro, T., Ramil-Rego, P. \& Díaz-Fierros, F. (1996): Dinámica vegetacional y procesos de estabilidad/inestabilidad en suelos de la Serra do Bustelo (Portugal) durante el Subatlántico. Nova Acta Cient. Comp. (Biol.) 6: 21-34.

Tutin, T.G., Heywood, V.H., Burges, N.A., Moore, D.M., Valentine, D.H., Walters, S.M. \& Webb, D.A. (Eds.) (19641980): Flora Europaea, Vols. 1-5, Cambrigde Univertity Press. Cambrigde.

Tüxen, R. \& Oberdorfer, E. (1958): Die Pflanzenwelt Spaniens. II Teil. Eurosirische PhanerogamenGesellschaften Spaniens. Veröff. Geobot. Inst. Rübel, 32: 1328.

Vázquez, A. \& Díaz González, T.E. (2005): Parque Nacional de los Picos de Europa. Naturaleza y biodiversidad en tierra de lobos. Ed. Nobel. Oviedo. 174 pp.

Viane, R., Mayor López, M. \& Jermy, C. (1987): The systemathics and ecology of the Pteridophytes of Northern Spain. Excursion Guide. XIV International Botanical Congress. 54 pp. Berlin.

Vila, P. \& Díaz-Maroto, I.J. (2002): Las masas actuales de Quercus petraea en Galicia. Invest. Agr.: Sist. Recur. For. 11(1): 5-28.

Weber, H.E., Moravec, J. \& Theurillat, J.-P. (2000): International Code of Phytosociological Nomenclature. $3^{\text {th }}$ edición. Journal of Vegetation Science 11: 739-768. Versión en castelán traducida por J. Izco \& M. Del Arco (2003): Código internacional de nomenclatura fitosociológica. Materiales Didácticos Universitarios. Serie Botánica, $n^{\circ} 2$. 155 pp. Universidade de Santiago de Compostela. Universidad de La Laguna. 
Anexo I

Localización xeográfica, características ambientais, cobertura por estratos, superficie de inventario, unidade litolóxica, tipo de solo,posición fisiográfica e riqueza de plantas vasculares das mostras de bosques estudiadas.

\begin{tabular}{|c|c|c|c|c|c|c|c|c|c|c|c|c|c|c|c|c|c|c|}
\hline Código & Com. & Localidade & UTM X & UTM Y & Ic & Itc & lo & Alt. P. & Or. & $\mathrm{AE}_{1}$ & $\mathrm{CE}_{1}$ & $\mathrm{CE}_{2}$ & $\mathrm{CE}_{3}$ & Area & Lit. & Solo & Pos. Fis. & $\mathrm{N}$ \\
\hline B-Qd tipo & $B-Q d$ & Lu: entre Ribadeo e Lugo (Serra de Meira). & 642 & 4792 & 10,86 & 249 & 9,91 & 44010 & $\mathrm{NE}$ & $\overline{---}$ & 100 & $\overline{---}$ & 90 & 100 & LOU & REG & $\mathrm{LA}$ & 21 \\
\hline B-Ql tipo & $B-Q \mid$ & C: Cerdido, devesa del Mera. & 588 & 4826 & 10,13 & 296 & 7,95 & 13020 & $E$ & --- & 100 & --- & 80 & 150 & ARM & REG & LA & 25 \\
\hline $\mathrm{C080}$ & $B-Q d$ & Lu: Vilalba, Carballotorto. & 612 & 4808 & 9,10 & 1961 & 12,46 & 6008 & -- & --- & -- & --- & -- & 100 & ARM & CAM & LA & 11 \\
\hline C090 & $B-Q d$ & Lu: Muras, Fraga de Riobó. & 611 & 4811 & 8,86 & 1731 & 13,51 & 171031 & -- & --- & -- & --- & -- & 100 & CUA & REG & LA & 12 \\
\hline C100 & $B-Q d$ & Lu: Viveiro, Fraga de Saimas. & 618 & 4827 & 9,32 & 2181 & 11,50 & 50029 & -- & -- & -- & -- & -- & 100 & GA & REG & LA & 20 \\
\hline C101 & $B-Q d$ & Lu: Ourol, Fraga de Besteburiz. & 616 & 4822 & 9,43 & 2281 & 11,02 & 4507 & -- & --- & -- & --- & -- & 100 & GA & REG & LA & 15 \\
\hline C110 & $B-Q d$ & Lu: Mondoñedo, Fragavella. & 622 & 4811 & 9,06 & 1921 & 15,74 & 461920 & --- & --- & -- & --- & -- & 100 & GCA & REG & LA & 22 \\
\hline C111 & $B-Q d$ & Lu: O Valadouro, Fraga das Lerias. & 620 & 4820 & 9,44 & 2291 & 12,57 & 744529 & -- & --- & -- & --- & -- & 100 & GCA & CAM & LA & 28 \\
\hline Iz101 & $B-Q d$ & C: Monfero, montes da Serra da Loba entre Irixoa e o límite provincial. & 586 & 4797 & 11,92 & 2361 & 12,21 & 147020 & W & --- & -- & --- & --- & 160 & OLL & CAM & LA & 22 \\
\hline Iz102 & $B-Q d$ & C: Monfero, montes da Serra da Loba entre Irixoa e o límite provincial. & 587 & 4798 & 9,43 & 2411 & 11,93 & 3505 & $\mathrm{~N}$ & --- & 60 & --- & 70 & 150 & LOU & REG & LA & 25 \\
\hline Iz103 & $B-Q d$ & Lu: Muras, entre Xermade e Muras. & 604 & 4812 & 9,77 & 2161 & 12,07 & $7550--$ & NE & --- & --- & --- & --- & 200 & ARM & CAM & LB & 24 \\
\hline Iz104 & $B-Q d$ & Lu: Muras, entre Muras e O Viveiró. & 603 & 4815 & 9,10 & 1961 & 12,46 & 600 --- & -- & --- & -- & --- & --- & 250 & LOU & REG & LA & 22 \\
\hline Iz106 & $B-Q d$ & C: A Capela, Presa in ferior do Río Eume, ladeir & 580 & 4807 & 10,45 & 2411 & 11,63 & 45015 & $\mathrm{~N}$ & --- & 95 & -- & 80 & 180 & GCA & REG & LA & 20 \\
\hline Iz107 & $B-Q d$ & C: Monfero, Xestoso, Fraga de Pontedapena. & 589 & 4803 & 10,45 & 2411 & 11,63 & 35020 & -- & -- & -- & --- & -- & 120 & OLL & REG & LA & 15 \\
\hline Iz111 & $B-Q /$ & Lu: O Valadouro, Vilacampa. & 622 & 4824 & 9,54 & 2391 & 11,74 & 400 & -- & --- & -- & --- & --- & 150 & CUA & REG & LA & 27 \\
\hline Iz112 & $B-Q \mid$ & Lu: Trabada, Vilapena. & 643 & 4807 & 10,03 & 2431 & 11,16 & 51015 & NW & --- & 90 & --- & 95 & 120 & GA & REG & LA & 29 \\
\hline Iz113 & $B-Q d$ & otorto, Aug & 642 & 4807 & 10,17 & 2281 & 12,08 & 360020 & W & --- & 85 & -- & 95 & 150 & ARM & REG & $\mathrm{LA}$ & 27 \\
\hline Iz114 & $B-Q d$ & Lu: Trabada, Fraga tem Serrra da Cadeira. & 643 & 4809 & 10,05 & 2411 & 11,26 & 52020 & $\mathrm{~N}$ & --- & 95 & -- & 95 & 200 & ARM & REG & LA & 29 \\
\hline Iz116 & $B-Q d$ & Lu: Ribeira de Piquín, entre O Couso e Vilar de Curota. & 643 & 4786 & 10,56 & 2201 & 11,41 & 65020 & SE & --- & 90 & --- & 90 & 200 & ARM & REG & LA & 22 \\
\hline Iz117 & $B-Q d$ & Lu: Mondoñedo, Estelo. & 623 & 4810 & 9,14 & 2011 & 15,03 & 358035 & $\mathrm{~N}$ & -- & 95 & -- & 70 & 120 & GCA & REG & LB & 25 \\
\hline Iz118 & $B-Q d$ & Lu: Muras, Aborbó, entre A Bals & 610 & 4814 & 8,97 & 1841 & 13,03 & 366020 & $\mathrm{~N}$ & --- & 85 & --- & 95 & 200 & ARM & CAM & LA & 20 \\
\hline Iz119 & $B-Q d$ & Lu: Muras, entre Viveiró e Muras & 610 & 4814 & 8,82 & 1691 & 13,70 & 73030 & $\mathrm{~N}$ & -- & 80 & -- & 100 & 180 & ARM & CAM & $\mathrm{LA}$ & 29 \\
\hline Iz120 & $B-Q d$ & doñedo, Fragavella. & 629 & 4812 & 8,93 & 1791 & 16,86 & 68030 & $S$ & --- & 90 & -- & 80 & 250 & GCA & REG & LA & 29 \\
\hline Iz121 & $B-Q d$ & Monte $\mathrm{O} \mathrm{Te}$ & 653 & 4794 & 10,45 & 1971 & 13,91 & 178020 & $\mathrm{~N}$ & -- & 95 & -- & 95 & 200 & LOU & REG & LA & 25 \\
\hline Iz122 & $B-Q d$ & Lu: & 611 & 4822 & 9,71 & 256 & 9,77 & 3200 & -- & --- & 100 & --- & 85 & 120 & $\mathrm{GA}$ & REG & LB & 18 \\
\hline Iz125 & $B-Q I$ & Lu: & 646 & 4810 & 9,79 & 270 & 9,53 & 35020 & NW & -- & 95 & -- & 10 & 200 & ARM & CAM & LB & 22 \\
\hline Iz127 & $B-Q I$ & , Deves & 588 & 4826 & 10,15 & 298 & 7,86 & 12025 & $E$ & --- & 95 & --- & 80 & 300 & BAS & REG & LA & 37 \\
\hline Iz130 & $R-Q q$ & C: A Capela, Fraga de Caaveirc & 576 & 4806 & 8,37 & 330 & 8,31 & 10025 & NE & --- & 100 & --- & 90 & 250 & LOU & REG & LB & 25 \\
\hline Iz203 & $B-Q I$ & Lu: Mondoñedo, Devesa do Porto de Campo do Oso. & 636 & 4805 & 9,54 & 2391 & 11,74 & 40030 & $\mathrm{~N}$ & --- & 100 & --- & 75 & 120 & LOU & CAM & VAL & 38 \\
\hline LOSA01 & $B-Q \mid$ & C: Cabanas, Fragas do Eume. & 572 & 4808 & 8,07 & 343 & 7,76 & 50 & SW & --- & --- & --- & -- & 100 & OLL & REG & LB & 22 \\
\hline LOSA04 & $B-Q I$ & o Eume. & 577 & 4806 & 8,13 & 340 & 7,93 & 60 & S & --- & -- & -- & -- & 100 & OLL & REG & LB & 27 \\
\hline LOSA07 & $B-Q I$ & o Eume. & 575 & 4807 & 8,43 & 328 & 8,41 & 110 --- & SW & --- & -- & --- & -- & 100 & OLL & REG & LA & 15 \\
\hline LOSA12 & $B-Q I$ & Eume. & 575 & 4807 & 8,37 & 330 & 8,31 & 100 --- & $\mathrm{N}$ & --- & -- & --- & -- & 100 & CUA & REG & LA & 35 \\
\hline LOSA14 & $B-Q I$ & C: M & 575 & 4807 & 8,37 & 330 & 8,31 & 100 --- & $\mathrm{N}$ & --- & -- & --- & -- & 100 & CUA & REG & LA & 26 \\
\hline MF31 & $B-Q d$ & ón, Busmente. & 687 & 4810 & 9,94 & 2531 & 10,55 & 545014 & W & --- & 100 & --- & -- & 100 & -- & -- & -- & 16 \\
\hline MF36 & $B-Q d$ & As: Villayón, Le & 686 & 4814 & 9,91 & 2571 & 10,35 & 543014 & $\mathrm{~N}$ & --- & 100 & --- & -- & 100 & -- & -- & -- & 14 \\
\hline P001 & $B-Q d$ & C: Irixoa, entre O Carboeiro e & 577 & 4795 & 10,82 & 2741 & 10,15 & 532028 & $\mathrm{~N}$ & 16 & 90 & 40 & 95 & 300 & LOU & REG & LB & 21 \\
\hline P002 & $B-Q d$ & C: Aranga, Vilares. & 585 & 4787 & 12,84 & 2051 & 13,92 & 59524 & NNE & 12 & 100 & -- & 90 & 200 & LOU & REG & LA & 21 \\
\hline P003 & $B-Q d$ & C: As & 597 & 4813 & 10,98 & 2181 & 12,48 & 54028 & $\mathrm{~N}$ & 20 & 95 & -- & 95 & 120 & LOU & REG & LB & 28 \\
\hline P004 & $B-Q d$ & nachaíña. & 600 & 4807 & 11,41 & 235 & 9,53 & 4758 & NW & 20 & 100 & --- & 80 & 300 & SC & CAM & LB & 16 \\
\hline P005 & $B-Q d$ & Lu: & 601 & 4807 & 11,73 & 239 & 9,02 & 4600 & --- & 22 & 100 & 5 & 90 & 300 & SC & CAM & $\mathrm{CHA}$ & 18 \\
\hline P006 & $B-Q d$ & Lu: I & 602 & 4819 & 9,43 & 2281 & 11,02 & 45030 & NW & 16 & 95 & -- & 95 & 200 & LOU & REG & LA & 23 \\
\hline P007 & $B-Q d$ & Lu: & 605 & 4811 & 8,96 & 1831 & 13,08 & 66523 & NE & 14 & 100 & --- & 90 & 200 & CUA & REG & LA & 18 \\
\hline P008 & $B-Q d$ & jeira. & 606 & 4808 & 6,51 & 1781 & 17,15 & 70020 & NNW & 10 & 100 & --- & 80 & 200 & CUA & REG & LA & 18 \\
\hline P009 & $B-Q d$ & velle. & 608 & 4809 & 8,72 & 1591 & 14,13 & 37522 & NNW & 12 & 100 & --- & 90 & 300 & CUA & REG & LA & 27 \\
\hline P010 & $B-Q d$ & Lu: & 608 & 4810 & 8,74 & 1611 & 14,04 & 76520 & NNE & 15 & 100 & -- & 80 & 200 & CUA & REG & LA & 29 \\
\hline P011 & $B-Q d$ & Lu: Vilalba, Frag & 609 & 4807 & 5,96 & 1711 & 17,99 & 72518 & SSE & 16 & 100 & -- & 95 & 300 & GCA & REG & LA & 23 \\
\hline P012 & $B-Q d$ & Lu: Vilalba, Fra & 609 & 4807 & 5,74 & 1691 & 18,33 & 73518 & SE & 16 & 95 & --- & 90 & 300 & GCA & REG & LA & 25 \\
\hline P013 & $B-Q d$ & Lu: & 609 & 4809 & 8,70 & 1571 & 14,23 & 78524 & NW & 15 & 100 & --- & 90 & 200 & CUA & REG & LA & 22 \\
\hline P014 & $B-Q d$ & Lu: & 609 & 4809 & 8,68 & 1561 & 14 & 79024 & NNW & 14 & 100 & --- & 95 & 300 & CUA & REG & LA & 30 \\
\hline P015 & $B-Q d$ & Lu: & 609 & 4813 & 8,88 & 1751 & 13 & 70030 & WNW & 17 & 100 & -- & 90 & 200 & CUA & REG & LA & 21 \\
\hline P016 & $B-Q d$ & Lu: I & 609 & 4813 & 8,79 & 1671 & 13 & 028 & WNW & 17 & 100 & -- & 70 & 250 & CUA & REG & LA & 28 \\
\hline P017 & $B-Q d$ & O Coto Grande. & 609 & 4815 & 8,79 & 1671 & 13,80 & 023 & NNW & 17 & 100 & --- & 90 & 200 & CUA & REG & LA & 26 \\
\hline P018 & $B-Q d$ & de Riobó. & 610 & 4811 & 8,91 & 1781 & 13,27 & 68522 & $\mathrm{~N}$ & 17 & 100 & -- & 90 & 300 & CUA & REG & LA & 25 \\
\hline P019 & $B-Q d$ & s, Fraga de Riobó. & 612 & 4811 & 8,61 & 1491 & 14,61 & 82522 & NNW & 14 & 100 & --- & 80 & 200 & CUA & REG & LA & 21 \\
\hline P020 & $B-Q d$ & Lu: & 613 & 4816 & 8,90 & 1771 & 13,32 & 6908 & W & 13 & 85 & -- & 60 & 200 & CUA & REG & LA & 20 \\
\hline P021 & $B-Q d$ & Lu: & 613 & 4817 & 8,91 & 1781 & 13,27 & 68519 & WNW & 16 & 95 & -- & 80 & 200 & CUA & REG & LB & 23 \\
\hline P022 & $B-Q d$ & 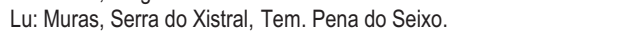 & 615 & 4817 & 8,79 & 1671 & 13,80 & 74018 & NW & 14 & 100 & --- & 90 & 200 & CUA & REG & LA & 20 \\
\hline P023 & $B-Q d$ & ouriz. & 617 & 4821 & 9,11 & 1971 & 12,41 & 59524 & NNE & 13 & 90 & -- & 90 & 200 & CUA & REG & LA & 27 \\
\hline P024 & $B-Q d$ & Lu: & 17 & 4822 & 9,03 & 1901 & 12 & 63024 & SSW & 11 & 95 & --- & 90 & 200 & GCA & CAM & LA & 21 \\
\hline P025 & $B-Q d$ & las Lerias. & 619 & 4820 & 9,10 & 1961 & 15,40 & 60026 & NNE & 12 & 95 & -- & 100 & 200 & BAS & REG & LA & 22 \\
\hline P026 & $B-Q d$ & Lu: O Valadou & 620 & 4819 & 9,31 & 2171 & 13,66 & 50534 & SSW & 12 & 95 & --- & 90 & 200 & GCA & CAM & LA & 31 \\
\hline P027 & $B-Q d$ & Lu: Mondoñedo, Fragavella. & 621 & 4811 & 9,02 & 1891 & 16,04 & 63519 & $S$ & 11 & 100 & -- & 80 & 200 & GCA & CAM & LB & 28 \\
\hline P028 & $B-Q d$ & Lu: Mondoñedo, Fragavella. & 621 & 4811 & 8,96 & 1831 & 16,58 & 66526 & S & 18 & 100 & --- & 80 & 200 & GCA & CAM & LB & 27 \\
\hline P029 & $B-Q d$ & , Fraga Mc & 621 & 4813 & 9,42 & 2271 & 12,75 & 45522 & NW & 18 & 100 & -- & 80 & 300 & GCA & CAM & LB & 33 \\
\hline P030 & $B-Q d$ & a Muradoira. & 621 & 4813 & 9,21 & 2071 & 14,48 & 55024 & $E$ & 16 & 100 & --- & 60 & 200 & BAS & CAM & LA & 29 \\
\hline P031 & $B-Q d$ & Lu: & 623 & 4812 & 9,05 & 1911 & 15,85 & 62530 & $E$ & 17 & 95 & -- & 70 & 200 & GCA & CAM & LA & 32 \\
\hline P032 & $B-Q d$ & Lu: P & 629 & 4774 & 10,32 & 2061 & 11,22 & 52526 & $\mathrm{~N}$ & 24 & 90 & 20 & 90 & 300 & LOU & REG & LB & 23 \\
\hline P033 & $B-Q d$ & Lu: Meira, O Chao. & 639 & 4785 & 10,64 & 2111 & 10,71 & 51016 & NNE & 24 & 90 & -- & 90 & 300 & LOU & CAM & LB & 15 \\
\hline P034 & $B-Q d$ & Lu: Baleira, San Román. & 640 & 4772 & 11,80 & 220 & 9,98 & 65522 & $\mathrm{~N}$ & 22 & 100 & -- & 85 & 200 & LOU & CAM & LA & 18 \\
\hline P035 & $B-Q d$ & Lu: Riotorto, Augaxosa. & 641 & 4806 & 9,88 & 2601 & 10,14 & 41012 & NW & 16 & 100 & --- & 95 & 300 & LOU & REG & LA & 22 \\
\hline P036 & $B-Q d$ & Lu: Meira, Seixosmil, Carballal & 642 & 4785 & 10,54 & 2191 & 11,48 & 66020 & SSE & 18 & 100 & -- & 95 & 150 & ARM & CAM & LB & 28 \\
\hline P037 & $B-Q d$ & arballal das Carrieiras. & 642 & 4786 & 10,56 & 2201 & 11,41 & 65028 & NE & 14 & 100 & -- & 80 & 225 & ARM & CAM & TES & 20 \\
\hline P038 & $B-Q d$ & Lu: Baleira, O Real de Sampaio, Mte. O Freixido. & 643 & 4771 & 12,53 & 1911 & 11,18 & 86032 & WNW & 12 & 100 & -- & 80 & 100 & CUA & REG & $\mathrm{LA}$ & 31 \\
\hline
\end{tabular}




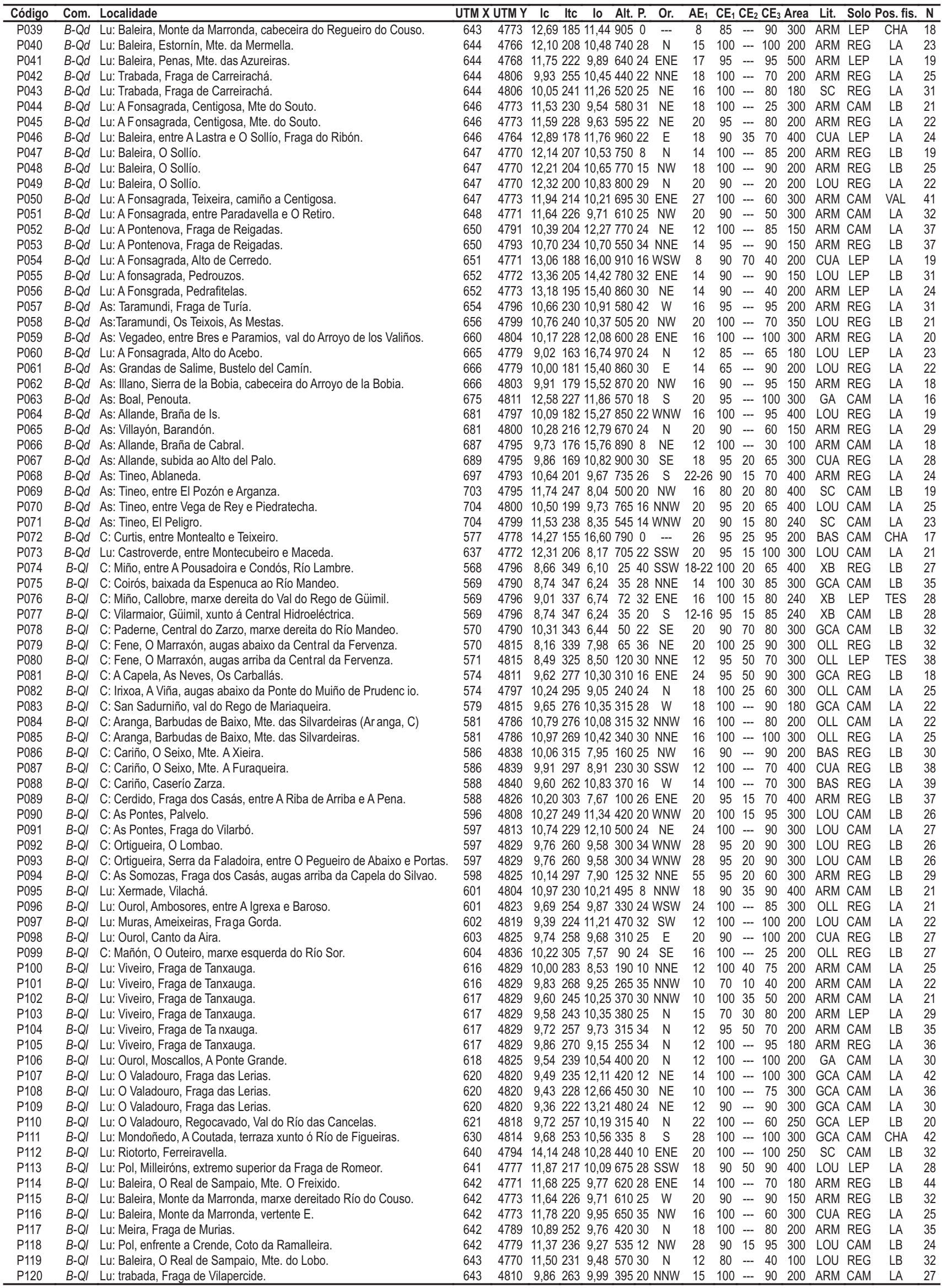




\begin{tabular}{|c|c|c|c|c|c|c|c|c|c|c|c|c|c|c|c|c|c|c|}
\hline Código & Com. & Localidade & UTM X & $\overline{\text { UTM Y }}$ & Ic & Itc & 10 & Alt. P. & Or. & $\mathrm{AE}_{1}$ & $\mathrm{CE}_{1}$ & $\mathrm{CE}_{2}$ & $\mathrm{CE}_{3}$ & Area & Lit. & Solo & Pos. fis. & $\mathrm{N}$ \\
\hline P121 & $B-Q I$ & Lu: Baleira, entre Crende e Boel, Fraga do Rego de San Bernabel. & 643 & 4779 & 11,09 & 247 & 8,81 & 45530 & WNW & 14 & 95 & 20 & 85 & 400 & LOU & REG & LB & 28 \\
\hline P122 & $B-Q I$ & Lu: Baleira, Estornín, Mte. da Mermella. & 644 & 4766 & 12,00 & 212 & 10,30 & 071032 & NNE & 24 & 100 & -- & 80 & 200 & ARM & CAM & $\mathrm{LA}$ & 34 \\
\hline P123 & $B-Q I$ & Lu: Baleira, Estornín, Mte. da Mermella. & 644 & 4766 & 12,03 & 3211 & 10,36 & 672020 & SSE & 25 & 100 & -- & 70 & 250 & ARM & CAM & $\mathrm{LA}$ & 18 \\
\hline P124 & $B-Q I$ & Lu: Trabada, Fraga de Vilapena, Mte. Escourido. & 644 & 4807 & 9,60 & 291 & 8,31 & 23034 & $\mathrm{~N}$ & 14 & 100 & --- & 100 & 140 & ARM & REG & LB & 17 \\
\hline P125 & $B-Q I$ & Lu: Trabada, Fraga de Vilapena. & 644 & 4807 & 9,80 & 269 & 9,63 & 36035 & ENE & 15 & 100 & -- & 50 & 200 & CUA & REG & LB & 35 \\
\hline P126 & $B-Q I$ & Lu: Baleira, Estornín, Mte. da Mermella. & 645 & 4765 & 11,87 & 217 & 10,09 & 967532 & WSW & 18 & 100 & -- & 40 & 200 & ARM & REG & LB & 21 \\
\hline P127 & $B-Q \mid$ & Lu: Baleira, Estornín, Mte. da Mermella. & 645 & 4765 & 12,18 & 3205 & 10,59 & 976030 & NNE & 20 & 100 & -- & 90 & 200 & ARM & LEP & LA & 33 \\
\hline P128 & $B-Q I$ & Lu: Baleira, Estornín, Mte. da Mermella. & 645 & 4766 & 11,94 & 214 & 10,21 & 169530 & WNW & 18 & 100 & -- & 75 & 200 & ARM & REG & $\mathrm{LA}$ & 26 \\
\hline P129 & $B-Q /$ & Lu: Baleira, Penas, Mte. Suagranda. & 645 & 4767 & 11,57 & 229 & 9,60 & 59028 & $\mathrm{~N}$ & 20 & 95 & -- & 90 & 150 & ARM & LEP & TES & 29 \\
\hline $\mathrm{P} 130$ & $B-Q I$ & Lu: A Pontenova, Vilargondurfe, Mte. As Furocas. & 645 & 4796 & 11,31 & 293 & 7,65 & 12530 & SSE & 12 & 100 & -- & 85 & 100 & LOU & REG & LB & 23 \\
\hline $\mathrm{P} 131$ & $B-Q I$ & Lu: A Fonsagrada, Teixeira, camiño a Centigosa. & 646 & 4772 & 11,80 & 220 & 9,98 & 65521 & W & 19 & 95 & -- & 90 & 300 & ARM & CAM & LB & 28 \\
\hline P132 & $B-Q I$ & Lu: A Pontenova, entre Fontangordo e Vilaeimil . & 648 & 4794 & 10,79 & 242 & 10,27 & 749035 & $E$ & 18 & 100 & -- & 95 & 300 & ARM & LEP & LB & 33 \\
\hline $\mathrm{P} 133$ & $B-Q I$ & Lu: Baleira, Fraga de Fontela. & 649 & 4763 & 13,54 & 215 & 13,45 & 570028 & $\mathrm{E}$ & 20 & 100 & -- & 100 & 300 & ARM & REG & LA & 27 \\
\hline P134 & $B-Q I$ & Lu: A Fonsagrada, Fra ga de Ferreirola. & 649 & 4774 & 11,91 & 216 & 10,15 & 568525 & $\mathrm{~N}$ & 18 & 100 & -- & 75 & 300 & ARM & CAM & LA & 27 \\
\hline P135 & $B-Q I$ & Lu: A Fonsagrada, Fraga de Ferreirola. & 650 & 4774 & 12,14 & 4207 & 10,53 & 375035 & $\mathrm{~N}$ & 14 & 100 & -- & 70 & 250 & CUA & REG & $\mathrm{LA}$ & 31 \\
\hline P136 & $B-Q I$ & Lu: A Pontenova, Fraga de Reigadas. & 650 & 4792 & 10,69 & 9233 & 10,77 & 756032 & $\mathrm{E}$ & 14 & 80 & -- & 80 & 200 & ARM & REG & $\mathrm{LA}$ & 37 \\
\hline P137 & $B-Q I$ & Lu: A pontenova, Fraga de Reigadas. & 650 & 4793 & 10,84 & 4248 & 9,98 & 45035 & ESE & 12 & 90 & -- & 70 & 150 & ARM & REG & LA & 23 \\
\hline P138 & $B-Q I$ & Lu: A Pontenova, Fraga de Reigadas. & 650 & 4794 & 10,80 & 244 & 10,19 & 948034 & $E$ & 16 & 95 & -- & 90 & 150 & ARM & REG & LA & 31 \\
\hline P139 & $B-Q I$ & Lu: Vilaousende, A Fraga. & 656 & 4817 & 9,68 & 302 & 6,49 & 6020 & NNW & 14 & 95 & -- & 90 & 300 & ARM & CAM & LA & 23 \\
\hline P140 & $B-Q I$ & Lu: Ribadeo, Vilaousende, A Fraga. & 656 & 4817 & 9,75 & 299 & 6,61 & 8030 & $\mathrm{NE}$ & 14 & 100 & -- & 90 & 150 & ARM & CAM & LB & 25 \\
\hline P141 & $B-Q I$ & As: Castropol, Val do Arroyo de Grilo. & 663 & 4818 & 9,44 & 309 & 7,24 & 12523 & SSW & 16 & 100 & -- & 40 & 240 & ARM & CAM & LB & 25 \\
\hline P142 & $B-Q I$ & As: El Franco, Matafoyada. & 671 & 4820 & 9,31 & 323 & 6,38 & 4016 & ESE & 16 & 100 & -- & 100 & 300 & CUA & CAM & LA & 23 \\
\hline P143 & $B-Q I$ & As: Coaña, entre Lebredo e Las Mestas. & 677 & 4816 & 9,65 & 286 & 8,62 & 26040 & ENE & 20 & 100 & -- & 100 & 300 & LOU & LEP & LA & 33 \\
\hline P144 & $B-Q I$ & As: Allande, subida ao Alto del Palo, La Roza. & 691 & 4795 & 10,73 & 3205 & 9,53 & 71530 & SSW & 14 & 90 & 25 & 40 & 300 & CUA & REG & LA & 21 \\
\hline P145 & $B-Q \mid$ & As: Allande, subida ao Alto del Palo, entre Penaseita e La F & 691 & 4795 & 10,73 & 3205 & 9,53 & 71536 & SSW & 20 & 85 & 30 & 50 & 400 & CUA & REG & $\mathrm{LA}$ & 28 \\
\hline P146 & $B-Q I$ & As: Valdés, Cercenadas. & 692 & 4816 & 9,83 & 286 & 9,38 & 26038 & $\mathrm{~N}$ & 18 & 100 & -- & 90 & 300 & LOU & REG & $\mathrm{LA}$ & 25 \\
\hline P147 & $B-Q I$ & As: Tineo, entre Olleros e Bárcena del Monasterio. & 701 & 4805 & 12,57 & 7275 & 8,19 & 32532 & SSE & 20 & 95 & 15 & 80 & 300 & LOU & REG & LA & 30 \\
\hline P148 & $B-Q I$ & As: Valdés, Ferrera de Paredes, Mte. Cuesta Ferrera. & 705 & 4817 & 10,77 & 7311 & 7,86 & 11038 & $\mathrm{NE}$ & 17 & 95 & -- & 70 & 200 & LOU & REG & LB & 29 \\
\hline P149 & $B-Q I$ & As: valdés, Ferrera de Paredes, Mte. Cuesta Ferrera. & 705 & 4817 & 10,74 & 4311 & 7,91 & 11538 & NE & 19 & 100 & -- & 70 & 250 & LOU & REG & LA & 26 \\
\hline P150 & $B-Q I$ & As: Valdés, Brieves, confluencia dos ríos Ferrera e Esba. & 706 & 4817 & 11,09 & 320 & 7,35 & 6038 & NW & 14 & 100 & -- & 70 & 200 & LOU & REG & LA & 32 \\
\hline P151 & $B-Q I$ & As: Valdés, Brieves, confluencia dos ríos Ferrera e Esba. & 706 & 4817 & 10,96 & 6317 & 7,55 & 8038 & WNW & 20 & 100 & -- & 40 & 400 & LOU & REG & LA & 27 \\
\hline P152 & $B-Q /$ & As: Tineo, Trabazo, Mte. Los Fornones. & 707 & 4810 & 8,70 & 255 & 11,22 & 244026 & ENE & 14 & 100 & -- & 70 & 200 & LOU & REG & LA & 20 \\
\hline P153 & $B-Q I$ & As: Valdés, enfrent & 708 & 4815 & 10,71 & 1310 & 7,96 & 12032 & $\mathrm{NE}$ & 14 & 100 & -- & 85 & 180 & LOU & REG & VAL & 31 \\
\hline P154 & $B-Q l$ & As: Valdés, El Pontig & 709 & 4815 & 9,89 & 287 & 9,28 & 25032 & WNW & 14 & 100 & -- & 25 & 300 & LOU & REG & LA & 17 \\
\hline P155 & $B-Q I$ & As: Valdés, entre Foyedo e La Mafalla. & 717 & 4823 & 10,02 & 2291 & 7,72 & 23034 & NE & 14 & 100 & -- & 95 & 150 & ARM & REG & $\mathrm{LA}$ & 25 \\
\hline P156 & $L-Q p$ & Lu: Pol, entre Lúa e Boel. & 643 & 4780 & 11,11 & 247 & 8,84 & 46020 & SW & 18 & 95 & 5 & 60 & 400 & LOU & REG & LA & 21 \\
\hline P157 & $L-Q p$ & Lu: A Fonsagrada, Gulpilleiras. & 647 & 4775 & 11,70 & 224 & 9,80 & 62524 & S & 14 & 90 & 20 & 65 & 300 & LOU & REG & LA & 20 \\
\hline P158 & $L-Q p$ & Lu: A Fonsagrada, Vilardiaz, Val do Rego Fargaoso. & 655 & 4787 & 11,53 & 3230 & 9,54 & 58028 & $\mathrm{E}$ & 14 & 90 & -- & 85 & 250 & LOU & LEP & LA & 27 \\
\hline P159 & $L-Q p$ & Lu: A Fonsagrada, entre Mazaeda e Ríotorto. & 655 & 4781 & 11,87 & 7217 & 10,09 & 967528 & SE & 14 & 90 & 15 & 80 & 400 & LOU & CAM & LB & 26 \\
\hline P160 & $L-Q p$ & Lu: A Fonsagrada, entre Vilaframil e Castañeira. & 657 & 4785 & 11,36 & 237 & 9,25 & 53036 & WNW & 10 & 100 & -- & 90 & 200 & ARM & LEP & LA & 26 \\
\hline P161 & $L-Q p$ & As: Alland & 695 & 4793 & 11,11 & 221 & 8,98 & 63530 & WSW & 18 & 90 & 40 & 50 & 300 & ARM & REG & LA & 20 \\
\hline P162 & $L-Q p$ & As: Allande, entre & 697 & 4790 & 11,44 & 234 & 8,49 & 56522 & SW & 14 & 95 & 15 & 60 & 300 & SC & REG & $\mathrm{LA}$ & 22 \\
\hline P163 & $L-Q p$ & As: Tineo, entre Gera & 703 & 4796 & 12,19 & 9265 & 7,38 & 40528 & SE & $18-22$ & 95 & 20 & 90 & 400 & SC & CAM & LA & 45 \\
\hline P164 & $L-Q p$ & As: Tineo, entre La Llama e Arganza. & 703 & 4794 & 11,81 & 1250 & 7,93 & 48522 & SSE & 18 & 90 & 30 & 85 & 300 & SC & REG & $\mathrm{LA}$ & 28 \\
\hline P165 & $R-Q q$ & Lu: Viveiro, Fraga de Tanxauga. & 617 & 4829 & 9,76 & 260 & 9,58 & 30020 & SSW & 15 & 70 & 10 & 85 & 200 & ARM & LEP & LA & 20 \\
\hline P166 & $R-Q q$ & Lu: Alfoz, A Carballeira. & 629 & 4820 & 10,28 & 8311 & 5,54 & 600 & -- & 18 & 95 & -- & 100 & 300 & GCA & CAM & $\mathrm{CHA}$ & 35 \\
\hline P167 & $R-Q v$ & C: Mugardos, ente O Seixo e O Monte & 563 & 4811 & 7,90 & 351 & 7,55 & 2014 & ESE & 24 & 100 & 25 & 80 & 400 & $\mathrm{XB}$ & CAM & LB & 23 \\
\hline P168 & $R-Q v$ & C: Cariño, Pena Marela, vertente E. & 587 & 4837 & 9,74 & 277 & 10,01 & 131026 & SSE & 14 & 100 & -- & 50 & 300 & BAS & CAM & LA & 36 \\
\hline P169 & $R-Q v$ & Lu: Viveiro, Frag & 617 & 4830 & 9,93 & 277 & 8,82 & 22025 & SSW & 10 & 80 & 10 & 75 & 200 & ARM & CAM & LA & 20 \\
\hline P170 & $R-Q v$ & Lu: Viveiro, Fraga de Loureiros. & 617 & 4830 & 9,92 & 276 & 8,86 & 22535 & SSW & 12 & 80 & 25 & 70 & 200 & ARM & CAM & TES & 20 \\
\hline P171 & $R-Q v$ & Lu: Viveiro, Fraga de Loureiros. & 617 & 4830 & 9,86 & 270 & 9,15 & 25520 & SSE & 12 & 80 & 50 & 70 & 200 & ARM & CAM & LA & 18 \\
\hline P172 & $R-Q v$ & Lu: Viveiro, Fraga de Loureiros. & 617 & 4830 & 9,78 & 262 & 9,49 & 29020 & SE & 10 & 70 & 15 & 70 & 200 & ARM & CAM & $\mathrm{LA}$ & 21 \\
\hline P173 & $R-Q v$ & Lu: Viveiro, Fraga de Loureiros. & 617 & 4830 & 9,88 & 272 & 9,05 & 24540 & SE & 12 & 90 & 20 & 70 & 200 & ARM & CAM & LA & 22 \\
\hline P174 & $R-Q v$ & Lu: Viveiro, Fraga de Loureiros. & 617 & 4830 & 9,74 & 258 & 9,68 & 31040 & SW & 10 & 70 & 5 & 70 & 200 & ARM & CAM & VAL & 23 \\
\hline P175 & $R-Q v$ & Lu: Viveiro, Fraga de Loureiros. & 617 & 4830 & 9,78 & 262 & 9,49 & 29035 & SW & 12 & 90 & 40 & 80 & 200 & ARM & CAM & LA & 19 \\
\hline P176 & $R-Q v$ & Lu: Viveiro, Fraga de Loureiros. & 617 & 4830 & 9,88 & 272 & 9,05 & 24523 & SSW & 12 & 70 & 10 & 100 & 200 & ARM & CAM & LA & 21 \\
\hline P177 & $R-Q v$ & Lu: Viveiro, Fraga de Loureiros. & 617 & 4830 & 9,92 & 276 & 8,86 & 22510 & SW & 12 & 90 & 60 & 70 & 200 & ARM & CAM & TES & 19 \\
\hline P178 & SA & Lu: Vilalba, Tardao. & 601 & 4796 & 11,95 & 5241 & 8,68 & 4502 & $\mathrm{NE}$ & 20 & 95 & -- & 100 & 300 & ARM & CAM & LA & 21 \\
\hline P179 & SA & Lu: Xermade, O Castiñeiro. & 594 & 4804 & 11,08 & 8231 & 10,04 & 44906 & ESE & 25 & 95 & 70 & 100 & 400 & LOU & CAM & LB & 16 \\
\hline P180 & SA & Lu: Xermade, A Carba. & 604 & 4807 & 8,25 & 198 & 14,44 & 462010 & WSW & 16 & 80 & -- & 80 & 200 & CUA & CAM & $\mathrm{LA}$ & 19 \\
\hline P181 & SA & Lu: Vilalba, A Barreira. & 610 & 4802 & 11,08 & 8217 & 10,04 & 44900 & -- & 20 & 100 & -- & 90 & 400 & GCA & CAM & $\mathrm{CHA}$ & 10 \\
\hline P182 & SA & Lu, Vilalba, Doulfe. & 613 & 4806 & 7,70 & 169 & 15,28 & 864522 & SSW & 17 & 95 & -- & 90 & 120 & ARM & CAM & LB & 14 \\
\hline P183 & SA & Lu: Pol, O Mazo. & 629 & 4774 & 10,10 & 0203 & 11,56 & 65358 & SSW & 20 & 90 & 10 & 100 & 400 & SC & CAM & LA & 15 \\
\hline
\end{tabular}


Anexo II.

Outras especies presentes nas táboas de inventarios.

Táboa 9a.

Características de Quercetalia roboris: en Iz120: Ceratocapnos claviculata: +; Lathyrus linifolius: +; Características de QuercoFagetea: en B-Qd: Euphorbia hyberna: +; en C090: Euphorbia amygdaloides: 1; en C111: Euphorbia hyberna: 1; Stachys officinalis: 1; en Iz119: Conopodium pyrenaeum: +; en P009: Ajuga reptans: r; Euphorbia amygdaloides: +; en P011: Ajuga reptans: r; en P012: Viola riviniana: 1; Compañeiras: en C080: Festuca rubra: 3; en C100: Euphorbia helioscopia: 1; en C101: Erica cinerea: 1; en C110: Festuca rubra: 1; Helychrysum foetidum: 1; en Iz103: Prunus laurocerasus: +; en Iz104: Dactylorhiza incarnata: r; Ulex europaeus: +; en Iz114: Salix atrocinerea: +; en Iz117: Simethis planifolia: 1; en Iz120: Brachypodium rupestre: +; Cruciata laevipes: +; en P001: Ulex minor: +; en P004: Danthonia decumbens: +; en P009: Crataegus monogyna: +; Narcissus triandrus: +; en P010: Calluna vulgaris: 1; Molinia caerulea: +; Serratula tinctoria var. seoanei: +; en P011: Cruciata glabra: r; Brachypodium sylvaticum: 2; en P012: Brachypodium sylvaticum: 1; en P016: Narcissus asturiensis: r; Narcissus triandrus: r; en P021: Ulex europaeus: r.

Táboa 9b.

Características de Quercetalia roboris: en P030: Hypericum pulchrum: 1; Lathyrus linifolius: r; en P026: Lathyrus linifolius: +; en P031: Hypericum pulchrum: +; Características de Querco-Fagetea: en P027: Polygonatum odoratum: 1; en P031: Polygonatum odoratum: r; en P032: Crepis lampsanoides: +; en P033: Euphorbia amygdaloides: +; en P040: Taxus baccata: 1; en P064: Crepis lampsanoides: r; Compañeiras: en P005: Festuca sp.: +; en P026: Agrostis stolonifera: +; Cirsium filipendulum: 1; Calluna vulgaris: r; Lithodora prostrata: 1; Serratula tinctoria var. seoanei: +; en P027: Allium victorialis: +; en P028: Agrostis stolonifera: 2; en P030: Brachypodium sylvaticum: +; Cirsium filipendulum: r; Omphalodes nitida: r; en P031: Anthoxanthum odoratum: r; Digitalis purpurea: +; en P032: Geranium robertianum: +; en P034: Sambucus nigra: +; en P036: Omphalodes nitida: +; en P039: Erythronium dens-canis: r; en P046: Narcissus asturiensis: r; en P054: Narcissus asturiensis: r; en P060: Digitalis purpurea: r; en P061: Cytisus scoparius: r; en P063: Simethis planifolia: +; P067: Dactylis glomerata: +; en P068: Anthoxanthum odoratum: +; Lithodora prostrata: +; en P073: Anthoxanthum amarum: +; Cytisus striatus: $+$

Táboa 9c.

Características de Quercetalia roboris: en Iz101: Physospermum cornubiense: +; en P050: Ceratocapnos claviculata: r; en P056: Melampyrum pratense: +; Características de Querco-Fagetea: en P038: Euphorbia hyberna: +; en P050: Crepis lampsanoides: +; Melittis melissophyllum: +; en P052: Euphorbia hyberna: 1; Lilium martagon: r; en P055: Crepis lampsanoides: 1; en P057: Melittis melissophyllum: +; Compañeiras: en P014: Agrostis capillaris: 1; Doronicum plantagineum: +; en P022: Daboecia cantabrica: r; en P038: Crataegus monogyna: 1; Dactylis glomerata: +; Lapsana communis: +; Narcissus asturiensis: 1; en P043: Rumex acetosa: +; en P050: Arrhenatherum elatius subsp. bulbosum: +; Cardamine pratensis: +; Crataegus monogyna: 1; Geranium robertianum: 1; Prunus laurocerasus: $r$; Silene dioica: +; Umbilicus rupestris: r; en P051: Ulex europaeus: r; en P052: Allium victorialis: 3; Cardamine pratensis: +; en P053: Geranium robertianum: +; Silene dioica: +; en P057: Arrhenatherum elatius subsp. bulbosum: 1; en P058: Prunus laurocerasus: r.

Táboa 10a.-

Características de Quercetalia roboris: en LOSA07: Hieracium umbellatum: +; Características de Querco-Fagetea: en LOSA07: Ajuga reptans: +; Euphorbia amygdaloides: +; en P076: Euphorbia amygdaloides: +; en P084: Crepis lampsanoides: r; Melittis melissophyllum: r; en P104: Crepis lampsanoides: r; Taxus baccata: 2; Compañeiras: en LOSA01: Anthoxanthum odoratum: 1; Cytisus scoparius: 2; Cardamine flexuosa: +; en LOSA07: Linaria triornithophora: +; Ulex gallii: 2; en P076: Lamium maculatum: +; en P081: Narcissus asturiensis: +; en P082: Anthoxanthum amarum: 1; Avenula sulcata: +; Ulex minor: 1; en P083: Pinus pinaster. $r$; en P090: Avenula sulcata: +; Cytisus scoparius: r; Erica cinerea: r; Galium saxatile: +; en P092: Ajuga pyramidalis: +; en P093: Ajuga pyramidalis: +; en P096: Danthonia decumbens: 1; Erica cinerea: +; en P098: Sambucus nigra: +; en P099: Agrostis capillaris: 1; Rumex acetosa: +; en P102: Asplenium adiantum-nigrum: +; en P103: Cirsium filipendulum: r; en P104: Salix atrocinerea: 1; en P105: Picris hieracioides: r; Rumex acetosa: + .

Táboa 10b.

Diferenciais de variante mesotrofa: en Iz203: Circaea lutetiana: 1; Lysimachia nemorum: +; Milium effusum: 1; Ulmus glabra: +; en P087: Potentilla sterilis: +; en P088: Lysimachia nemorum: +; en P114: Prunus avium: +; en P117: Potentilla sterilis: r; en P130: Iris foetidissima: +; Prunus avium: +; Características de Quercetalia roboris: en LOSA14: Veronica officinalis: 1; Características de Querco-Fagetea: en P111: Stachys officinalis: 1; en P114: Helleborus foetidus: 1; en P143: Solidago virgaurea: 1; Compañeiras: en LOSA04: Ulex gallii: 2; en LOSA12: Cardamine flexuosa: +; Ulex gallii: 2; en LOSA14: Cardamine flexuosa: +; Lithodora prostrata: 1; en P075: Fraxinus angustifolia: +; Lamium maculatum: +; en P077: Lithodora prostrata: +; en P078: Fraxinus angustifolia: r; Fraxinus oxycarpa: +; Polypodium cambricum: +; en P080: Nepeta cataria: +; en P087: Centaurea nigra: r; Cirsium filipendulum: +; Clinopodium vulgare: r; Erica vagans: +; Picris hieracioides: +; en P091: Anthoxanthum amarum: 1; Prunus spinosa: +; en P100: Linaria triornithophora: +; en P108: Anthoxanthum amarum: 1; Cirsium filipendulum: r; en P111: Angelica major: +; Cruciata glabra: +; Dactylis glomerata: 1; Prunella vulgaris: +; Serratula tinctoria var. seoanei: +; en P112: Prunus laurocerasus: r; en P114: Fragaria vesca: 1; Vicia sepium: 1; en P118: Carex cf. caryophyllea: r; en P125: Narcissus asturiensis: 1; en P129: Silene dioica: +; en P130: Prunus spinosa: 1; en P143: Angelica sylvestris: +; en P147: Dactylis glomerata: +; en P148: Erica cinerea: +; Galium saxatile: +.

Táboa 11.

Características de Quercetalia roboris: en P157: Luzula forsteri: +; en P160: Melampyrum pratense: 1; en P163: Luzula forsteri: +; en P166: Melampyrum pratense: r; en P174: Hieracium murorum: +; en P176: Ceratocapnos claviculata: r; en P182: Vaccinium myrtillus: 2; Características de Querco-Fagetea: en P163: Euphorbia amygdaloides: +; Potentilla sterilis: 2; Ranunculus tuberosus: 1; en P166: Potentilla sterilis: r; Prunus avium: r; en P167: Euphorbia amygdaloides: +; Mercurialis perennis: 2; Polystichum setiferum: 1; Primula acaulis: +; en P168: Hyacinthoides non-scripta: +; Lysimachia nemorum:+; Melittis melissophyllum: +; Mercurialis perennis: +; Ranunculus tuberosus: +; en P173: Solidago virgaurea: +; en P181: Hyacinthoides non-scripta: r; en P182: Conopodium majus: r; Compañeiras: en Iz130: Peucedanum lancifolium: +; en P157: Calluna vulgaris: +; en P159: Cytisus striatus: +; Erica australis: +; en P162: Silene nutans: 
+; en P163: Carex cf. caryophyllea: 2; Rosa sp. (pl.): +; en P164: Agrostis curtisii: +; Carex cf. caryophyllea: 1; Centaurea nigra: +; Rosa sp. (pl.): +; en P166: Erica vagans: +; Peucedanum lancifolium: 1; Picris hieracioides: +; Pinus pinaster: 1; Serratula tinctoria var. seoanei: 2; en P167: Arum italicum: 3; Geranium robertianum: +; Ranunculus ficaria: 1; Sambucus nigra: 1; en P168: Cruciata laevipes: +; Silene uniflora: +; en P173: Calluna vulgaris: +; en P178: Angelica major: r; Anthoxanthum amarum: 1; Crocus nudiflorus: r; en P179: Genista florida: r; Umbilicus rupestris: +; en P180: Deschampsia cespitosa subsp. subtriflora: +; en P181: Avenula sulcata: 2; en P182: Salix atrocinerea: $r$.

\section{Táboa 12.}

Características de alianza e orde: en 4: Arenaria montana: +; en 6: Hypericum pulchrum: r; en 7: Hypericum pulchrum: r; en 11: Lathyrus linifolius: r; Melampyrum pratense: +. Características de clase: en 2: Melittis melissophyllum: 1; Taxus baccata: 1; en 3: Ajuga reptans: +; Hyacinthoides non-scripta: 1; en 4: Anemone nemorosa: +; en 6: Polygonatum odoratum: +; Stachys officinalis: +; en 7: Crepis lampsanoides: +; en 11: Crepis lampsanoides: +; Euphorbia amygdaloides: r; Euphorbia hyberna: 1; en 12: Anemone nemorosa: 1; Polygonatum odoratum: r. Compañeiras: en 1: Digitalis purpurea: r; Lithodora prostrata: +; en 2: Lithodora prostrata: 1; en 3: Chrysosplenium oppositifolium: 1; Prunus laurocerasus: 1; Silene dioica: 1; Umbilicus rupestris: +; en 4: Angelica sylvestris: +; Prunus laurocerasus: 1; Pseudarrhenatherum longifolium: +; Senecio nemorensis: 1; Ulex europaeus: r; en 6: Agrostis capillaris: +; en 7: Silene vulgaris: r; en 8: Carex pilulifera: +; Pseudarrhenatherum longifolium: 1; en 10: Allium victorialis: 1; Digitalis purpurea: +; Senecio nemorensis: r; Valeriana montana: +; en 12: Doronicum plantagineum: 1.

Localidades (salvo indicación contraria, todas no fuso 29T): 1: As: Coaña, Las Traviesas (678/4816); 2: Lu: Viveiro, Fraga de Tanxauga (617/4829); 3: Lu: Riotorto, Ferreiravella (639/4794); 4: As: Valdés, entre Foyedo e La Mafalla (718/4823): 5: As: Tineo, Naraval, subida ao Alto de Toural (700/4810); 6: As: Cangas de Onís, por debaixo de Busto Vela (fuso 30T, 336/4805); 7: As: Allande, La Porquera (684/4798); 8: As: Belmonte, Albariza (724/4798); 9: As: Valdés, entre Siñeriz e Los Piñeros (691/4815); 10: Lu: Baleira, Monte da Marronda, vertente N (641/4774); 11: Lu: Pol, Cubeiro, Mte. A Faia (638/4774); 12: As: Piloña, entre La Presanca y la Mallada Degoes, monte El Muñizón (fuso 30T 311/4793). 